Portland State University

PDXScholar

Summer 7-16-2018

\title{
Politics in the Social Media Era: the Relationship Between Social Media Use and Political Participation During the 2016 United States Presidential Election
}

Kevin Everett Curry

Portland State University

Follow this and additional works at: https://pdxscholar.library.pdx.edu/open_access_etds

Part of the Mass Communication Commons, Political Science Commons, and the Social Media Commons

Let us know how access to this document benefits you.

\section{Recommended Citation}

Curry, Kevin Everett, "Politics in the Social Media Era: the Relationship Between Social Media Use and Political Participation During the 2016 United States Presidential Election" (2018). Dissertations and Theses. Paper 4506.

https://doi.org/10.15760/etd. 6390

This Dissertation is brought to you for free and open access. It has been accepted for inclusion in Dissertations and Theses by an authorized administrator of PDXScholar. Please contact us if we can make this document more accessible: pdxscholar@pdx.edu. 
Politics in the Social Media Era: The Relationship Between

Social Media Use and Political Participation During the 2016 United States Presidential Election

\author{
by \\ Kevin Everett Curry
}

A dissertation submitted in partial fulfillment of the requirements for the degree of

\author{
Doctor of Philosophy \\ in \\ Public Affairs and Policy
}
Dissertation Committee: Christopher Shortell, Chair Lindsay J. Benstead Richard A. Clucas
Lee Shaker

Portland State University

2018 
(C) 2018 Kevin Everett Curry 


\begin{abstract}
The growth of social media use raises significant questions related to political information and its effect on political knowledge and participation. One issue is whether social media delivers news and political information in a similar manner as traditional news media sources, like newspapers, TV, and radio, by contributing to political knowledge, which is linked to voter turnout. This dissertation examines the relationship between an individual's social media use, their use of traditional news media sources, and whether they turn out to vote. It utilizes American National Election Survey data from the 2016 U.S. Presidential election to complete three studies. First, the dissertation compares people who prefer social media and those who prefer traditional news media sources across as series of political habits and attitudes. Second, it looks at the expansion of the media environment and examines whether a person's social media use and preference for news or entertainment is related to political knowledge and voter participation. Finally, this dissertation examines whether social media use increases the odds an individual will turn out to vote, thus acting in a similar manner as traditional news media.
\end{abstract}

The results identify differences between people who prefer social media and people who prefer traditional news media sources. In particular, people who prefer social media tend to be younger, have less political knowledge, and have a lower voter turnout rate. However, unlike traditional news media use, the use of social media did not increase the odds an individual turned out to vote in 2016. Further, the use of social media and an individual's content preference of 
entertainment versus news was not related to political knowledge nor voter turnout. While social media does not appear to have a positive relationship with turnout, it does not appear to discourage a person from voting either. The results suggest that more work needs to be done, including examining the relationship between age, social media use and turnout, as well as how content length may be related to political participation. Finally, further examination is needed of the possible indirect ways social media may be related to voter attitudes and participation. 


\section{Dedication}

To my wife, Katie, for the encouragement and support as I chased the dream of completing my Ph.D.. Also, to my daughters, Hannah and Grace, I hope you are inspired to chase your dreams as well. 


\section{Acknowledgements}

This dissertation could not have been finished without the support and encouragement of many, many people. First, special thanks to my advisor and committee chair, Christopher Shortell, for guiding both this dissertation project and my academic career at the Hatfield School of Government. A journal article assigned in his course four years ago started me on the journey that led to this dissertation, and his advice on navigating the Pubilc Affairs and Policy Ph.D. program was invaluable. Next, thank you to my dissertation committee, Lindsay Benstead, Richard Clucas, and Lee Shaker, for feedback on the direction of the project and thoughtful input on the final version.

To Ashlie Denton, my fellow survivor from the 2013 cohort, your hard work was an inspiration, and your counsel and feedback on so many things helped me make it through. I am excited we finished at the same time!

I appreciate the ongoing motivation from my colleagues at Linfield College. In particular, the counsel of Brenda Devore Marshall, who helped me navigate the decision to return to school, and was a constant source of encouragment and advice along the way. Next, a big thank you to my bosses who allowed me the flexibility to be a full-time employee while also attending school. At the Oregon Legislature, thank you to State Rep. Mike McLane, and his chief of staff, Shawn Cleave, and at Linfield College, thank you to Dave Ostrander and Scott Nelson. 
To my mother and father for their many, many years of support in my academic pursuits. The childhood memory of my mother typing my father's dissertation on an IBM Selectric at the kitchen table inspired me as I sat down to grind out pages of this dissertation. To my sisters, Kimberly and Joan, for their love and support as well.

Finally, and most importantly, to my wife, Katie, and my daughters, Hannah and Grace. I would have never achieved this goal without Katie's love, encouragement, and patience. She took on extra parenting duties and served in a support role for three students over these years! She was a sounding board, a dissertation editor, and my chief problem-solver for so many items related to school and this dissertation. Hannah and Grace, thank you for your love, I am excited to see where life takes you as you chase your own dreams! 


\section{Table of Contents}

Abstract

Dedication

Acknowledgements

i

List of Tables

iv

vii

Chapter 1

Introduction and Overview

1

Chapter 2

Review of Literature

Chapter 3

The Social Media User and Traditional News User Compared

68

Chapter 4

Content Preference and Social Media Use

Chapter 5

Social Media, Traditional News Media, and the Odds of Turning Out to Vote

Chapter 6

Conclusions, Limitations and Discussion of Future Research

References

Appendix A: Political Knowledge Questions

Appendix B: Civic Engagement Questions

Appendix C: Questions for Additional Regression Variables 


\section{List of Tables}

Table 1.1: Social Media Platform Timeline of Launch Year 8

Table 1.2: U.S. Adults (\%) on Each Social Media Platform 9

Table 1.3: Where Americans Get News Online 11

Table 3.1: Preferred Media Groups $\quad 71$

Table 3.2: Days Per Week Using Social Media by Days Per Week Using Traditional Media 73

Table 3.3: Preferred Media Group by Age Group (\%) 75

Table 3.4: Preferred Media Group by Education Level: No College Degree (\%)

Table 3.5: Preferred Media Group by Education Level: Associates Degree of Higher (\%) 78

Table 3.6: Preferred Media Group by Gender (\%) 79

Table 3.7: Preferred Media Group by Party Affiliation (\%) 81

Table 3.8: Political Knowledge Score by Preferred Media Group (\%) 84

Table 3.9: Trust in Government by Preferred Media Group (\%) 86

Table 3.10: Civic Engagement Score by Preferred Media Group (\%) 87

Table 3.11: Partisanship by Preferred Media Group (\%) 89

Table 3.12: Vote Intention by Preferred Media Group (\%) 90

Table 3.13: Voter Turnout by Preferred Media Group (\%) 91

Table 3.14: General Tendencies by Preferred Media Group (\%) 
Table 4.1: Top Ten Entertainment TV Shows from the American National Election Study

Table 4.2: Top Ten News TV Shows from the American National Election Study

Table 4.3: Descriptive Statistics Internet Access, Social Media Use, Voter Turnout

Table 4.4: Descriptive Statistics Relative Entertainment Preference

Table 4.5: Descriptive Statistics Gender

108

Table 4.6: Descriptive Statistics Political Knowledge Scale

108

Table 4.7: Descriptive Statistics Age Group 109

Table 4.8: Descriptive Statistics Education Level

109

Table 4.9: Linear Regression Estimating Change in Political Knowledge

Table 4.10: Logistic Regression Estimating Odds of Turning Out to Vote

Table 5.1: Descriptive Statistics Weekly Media and Traditional News Media Use

Table 5.2: Descriptive Statistics Gender

Table 5.3: Descriptive Statistics Voter Turnout 125

Table 5.4: Descriptive Statistics Age Group 125

Table 5.5: Descriptive Statistics Education Level 126

Table 5.6: Logistic Regression Estimating Odds of Turning Out to Vote After Media Use 


\section{Chapter 1: Introduction and Overview}

The 2016 U.S. presidential election featured several ways in which the delivery of information via social media may or may not have influenced the outcome of the election. From Donald Trump's very active use of Twitter to concerns over 'fake news' in social media timelines and the use of Facebook ads by Russian interests, more than ever the potential impact of social media on elections needs a better understanding. Due to the salacious nature of these types of stories in the news media, one may be tempted to immediately believe they made a difference in the election. The temptation is to believe that changes in information consumption created by social media are affecting elections. This, however, may not necessarily be the case. As early as 2008 , social media was being heralded as a great new political information source and tool for campaigns. Many praised the 2008 Obama campaign for the role social media played in his victory at the polls. Subsequent research, however, suggested it wasn't an important influencer (Kushin and Yamamoto 2010).

Information is a key component of the decision-making process. In political decision-making, news and information has been found to increase the likelihood of voting. Specifically, consuming news from traditional sources, like newspapers, television, radio and the Internet, is positively related to turning out to vote (Delli Carpini and Keeter 1996; Gainous and Wagner 2014; Gentzkow 2006; Gil de Zúñiga, Jung, and Valenzuela 2012; Popkin 1994; Prior 2005, 2007; Smets and van Ham 2013). This behavior, and the decision to engage in it, is important because voting is a key component of democracy. It is the way 
individuals select representatives, indicate opinions on key issues, and in some places actually make law via the initiative process. With the growth of the Internet, and recently social media like Twitter and Facebook, individuals have greater opportunity to receive news and political information in another manner. In fact, this method is becoming preferred for those under 50 , especially Millennials and to a slightly lesser extent Gen Xers (Gottfried et al. 2016; Shearer and Gottfried 2017). The Pew Research Center (2016) defines Millennials as those born between 1981 and 1998, Generation X as those born from 1965 to 1980, Baby Boomers as being born between 1946 and 1964, and the Silent Generation as those born between 1928 and 1945. This is a fundamental change in how news is consumed. It remains unclear, however, whether receiving information and news via social media acts in a similar manner as news from traditional sources.

Changes in media technology affect the way individuals receive news and information. This, in turn, can affect their involvement in government and politics. By expanding the media environment and providing more choices, individuals have a greater opportunity to self-select entertainment over news (Gentzkow 2006; Prior 2007). This, in turn, reduces the opportunities for incidental exposure to news as well, which Downs (1957) argues is an important way individuals get political information. This result of content preference was found to be true with the growth of television and cable, but needs to be reexamined in the social media era.

After approximately ten years of development and increasing growth in 
social media use, it is important to understand the potential effects it is having within the political realm. Already, significant issues and questions have surfaced related to potential ways social media is affecting the political process in the United States. While this dissertation does not directly examine issues like fake news, Twitter bots or Facebook ad buys by Russian interests, the answers to the broader questions it does address provide important context to these specific topics. It seeks to clarify the relationship between social media, news and political information. This includes who prefers social media over traditional news sources and their political habits and attitudes. It also examines how the expansion in the size of the media environment is related to political knowledge and voter participation. Finally, it looks at whether social media increase the odds an individual will turn out to vote, thus acting in a similar manner as traditional news media. Overall, this dissertation asks what is the relationship between social media, news and political information, and whether an individual turns out to vote?

\section{What is Social Media?}

Generally speaking, 'social media' refers to a "broad and growing portion of the Internet that is designed as a platform which allows users, and groups of users, to create and exchange content, often in an interactive or collaborative fashion" (Gainous and Wagner 2014, 2). This content creation and sharing can take many forms, from the sharing of news articles and comments on platforms like Facebook and Twitter, to the sharing of photos or graphics on popular sites 
like Instagram, Snapchat or Pinterest, to video on sites like YouTube and Vimeo. While new sites are launched (and die) and the popularity and use of a site might fluctuate, Gainous and Wagner (2014) argue that the general concept of social media will likely continue to expand. "Even if a particular social media protocol wanes in popularity, we anticipate that this user-dominated system will continue to expand and more people will flock to it" (Gainous and Wagner 2014, 2).

When considering a definition of social media, it is helpful to look at the key characteristics of these kinds of sites. These include the opportunity for individuals to create their own profile, connect with others on the site, and to create, share and access content and information (Carr and Hayes 2015; Donath and Danah 2004; Goff 2013; Murthy 2013). From there, social media theorists drill down into more specific aspects of these characteristics. For example, Goff (2013) and Jue, Marr, and Kassotakis (2009) emphasize the presence of tools to collaborate as an important aspect of social media. Carr and Hayes (2015) include the ability "to opportunistically interact and selectively self-present" (50) as part of their definition. Some definitions include the value an individual gains from the site. This includes the ability to collaborate on the creation of content and the ability to interact with others (Carr and Hayes 2015; Jue, Marr, and Kassotakis 2009).

One important distinction is between 'social network' sites and 'social media' sites. For some theorists, the connections made on a 'social network' site are more personal, for example just with people one knows. The user community is generally limited to their existing network of friends and colleagues. For 
example, Facebook is a social network by its nature where your friends or followers are primarily people you know, at least tangentially. This was the intent from the start and founder Mark Zuckerberg put significant importance on the ability of the site to make these connections and the value they add to the individual. He considered it one way to make sure individuals were registering for the site as themselves and not hiding behind an online persona, which was happening on MySpace (Kirkpatrick 2011).

With social media sites, on the other hand, individuals connect and publish content to broader audiences beyond their existing social network. The growing popularity of social media sites and their reach beyond an individual's own social network provides the opportunity for someone to communicate with a broad audience. With regard to Facebook, Marichal (2012) calls this "the blurring of mass and personal communication..." (Marichal 2012, 5). Some theorists believe the ability to make these broad connections is an important part of social media (Carr and Hayes 2015). Twitter, which features followers that you may have no real connection with outside the social media platform, including journalists, celebrities, athletes and organizations, is a good example of a social media site.

In terms of a definition of social media for the purposes of this dissertation, the main characteristics described at the beginning of this section serve us well: The ability to create a personal profile, make connections with other users on the site, and to create, share and access content and information. This encompasses both social network and social media sites. 


\section{Brief History of Social Media}

As a communication method, social media is a relatively young tool. In an attempt to capture what it encompasses, Goff (2013) examines several older online tools that have been around for decades to find similar characteristics. The more recent tools most people identify with social media raised the usefulness and popularity of these platforms. Among the more obvious tools are wikis and blogs. Focusing on social networking sites, the earliest example of a website with social networking characteristics is sixdegrees.com, which was launched in 1997. This site reached 3.5 million users by 1999 , sold for $\$ 125$ million, and then succumbed in 2000 to the burst of the Internet bubble (Kirkpatrick 2011). In 2002, Friendster was launched as a site where individuals could create profiles that their friends, as well as their friends of friends, could peruse in order to make connections (Rivlin 2006). By 2003, several other social networking sites were launched, including Linkedln and short-lived sites like Tribe and Spoke. That fall, a total of $\$ 36$ million was invested into those four social sites, demonstrating the potential investors saw in these platforms (Kirkpatrick 2011).

2004 saw the addition of two new sites in the social media space. MySpace joined the social media universe in January with a site that allowed users far more freedom to create their own profiles than the more-restrictive Friendster. Then, in February, from a residence hall at Harvard University, Mark Zuckerberg released the first version of 'Thefacebook' and slowly began expanding it to select colleges throughout that year. Political affiliation was included from the start as one of the few identifiers a person could choose for a 
profile (Kirkpatrick 2011). Widespread adoption of the site, renamed simply Facebook, started in September of 2006 when it became open to anyone over the age of 13 years old who had an email address. Just a few months prior to this, a new upstart social media tool - Twitter - was launched in March of 2006, which some call a "microblogging service" (Goff 2013, 21). The growth and access to social media tools was accelerated in mid-2007 with the release of the first iPhone (Vogelstein 2008). This allowed individuals easy access to the sites via mobile applications and put social media just a few clicks away at any time and in any place.

New social media sites have launched in the ten years since widespread growth of Facebook and Twitter. One particular area of growth has been in photo sharing sites. Top among these is Instagram, launched in October 2010. It didn't take long for Facebook to recognize both the popularity and value of Instagram and in May 2012 it purchased the company for $\$ 1$ billion (Williams-Hawkins 2013). Snapchat was started in 2011 as an application for shooting and sending disappearing photos (Snap Inc. 2017). The company went public in March of 2017, renamed Snap Inc., and now also sells hardware, in this case a pair of Snapchat sunglasses with a built-in camera allowing the wearer to shoot photos and video which can be uploaded to the app (Snap Inc. 2017). An overview of the launch year for major social media platforms in outlined in Table 1.1. 


\begin{tabular}{|c|c|}
\hline \multicolumn{2}{|c|}{$\begin{array}{c}\text { Table 1.1: Social Media Platform Timeline } \\
\text { of Launch Year }\end{array}$} \\
\hline Platform & Year Launched \\
\hline Friendster & 2002 \\
\hline Linkedln, Tribe, Spoke & 2003 \\
\hline MySpace, Facebook & 2004 \\
\hline YouTube & 2005 \\
\hline Twitter & 2006 \\
\hline WhatsApp & 2009 \\
\hline Instagram, Pinterest & 2010 \\
\hline Snapchat & 2011 \\
\hline
\end{tabular}

\section{The Growth of Social Media Use}

Social media use has grown significantly during the past 10 years. For example, as of December 2017, Facebook has 1.4 billion daily active users worldwide, and 2.13 billion monthly active users (Facebook Reports Second Quarter 2017 Results 2017). Instagram has 800 million monthly active users as of September 2017, an increase of 200 million since December 2016 (Number of monthly active Instagram users from January 2013 to September 2017 (in million) 2017). Although it is nearly as old as Facebook, Twitter has fewer active users and hasn't seen the meteoric growth that Facebook and Instagram have demonstrated. At the end of 2017, Twitter had 330 million monthly active users worldwide, 68 million of them in the United States. While it is growing more slowly, it is still growing, with its user base representing a 12 percent growth in daily active users over the same period in 2016 (Q4 and Fiscal Year 2017 Leter to Shareholders 2018). Finally, Snapchat, the youngest of the platforms that are 
most popular in the United States, had 187 million daily active users worldwide at of the end of 2017, which is an increase of 18 percent from the same time in 2016 (Snap Inc. Reports Fourth Quarter and Full Year 2017 Results 2018). A review of the percentage of U.S. adults on each major social media platform is outlined below in Table 1.2.

\begin{tabular}{|lc|}
\hline \multicolumn{2}{|c|}{$\begin{array}{c}\text { Table 1.2: U.S. Adults (\%) on Each } \\
\text { Social Media Platform }\end{array}$} \\
\hline \multicolumn{1}{|c|}{ Platform } & Percentage of Users \\
\hline YouTube & 73 \\
Facebook & 68 \\
Instagram & 35 \\
Pinterest & 29 \\
Snapchat & 27 \\
Linkedln & 25 \\
Twitter & 24 \\
WhatsApp & 22 \\
\hline Source: "Social Media Fact Sheet", Pew Research \\
Center; February 5, 2018 \\
\hline
\end{tabular}

\section{News Consumption and the Shift to Online Sources}

The use of social media specifically as a news source has grown dramatically over the past decade (Gottfried et al. 2016; Purcell and Rainie 2014; Shearer and Gottfried 2017). This is one reason for the increased interest in any effects social media may have on political participation. It is also a reason for concerns over the possible negative effects of social media sites on democracy and elections. The consumption of news online is increasing and Americans generally feel better informed because of online news opportunities (Gottfried et al. 2016; Purcell and Rainie 2014). Overall, in August 2017, 67 percent of 
Americans reported getting at least some news from social media, with 20 percent reporting that they 'often' get news this way and 27 percent reporting they 'sometimes' do (Shearer and Gottfried 2017). In just a few short years, social media has rocketed past traditional news sources like cable television, local television and national broadcast and print outlets, to become a top source of political information for Millennials and Gen Xers. Overall, social media has been quickly catching up to television as a news source, with social media increasing from 38 percent to 43 percent of people who often get news from that source. At the same time, television has declined from 57 percent to 50 percent (Shearer and Gottfried 2017).

The Pew Research Center conducted a survey in January of 2016 that showed the growing role social media is playing in elections, especially for those under the age of 50 (Gottfried et al. 2016). The study found that social media was the top source of information related to the 2016 Presidential election for those age 18 to 29 . Thirty-five percent of respondents in that age group said it was the most helpful source of information. Although not the top source, social media ranked third on the list for those age 30-49, with 15 percent saying it was the most helpful source of information (Gottfried et al. 2016). Overall, 78 percent of those under the age of 50 report getting news via social media, according to a September 2017 Pew study (Shearer and Gottfried 2017). Those over the age of 50 , however, are closing the gap with 55 percent of respondents getting news from social media sources. This is a 10 percent increase over the previous year and the first time a majority $50+$ years old report using social media for news. 
The 2017 Pew survey also found an increase in usage by non-white respondents (64 percent to 74 percent) and those with some college education or less (60 percent to 69 percent) (Shearer and Gottfried 2017).

For those that consume news online, social media has joined news websites/apps as the most common way to find news. Of these individuals, 35 percent utilize social media as the pathway to news, while 36 percent go directly to news websites or use news apps. (See Table 1.3) Individuals have also formed habits around these preferred pathways. Nearly two-thirds (65 percent) utilized the same path more than half of the times they accessed news. Of those, social media was the most common (26 percent) and news websites/apps were second (23 percent) (Mitchell et al. 2017). Finally, 55 percent encounter news online while doing other things, while 44 percent are 'seekers' who go online to find news (Mitchell et al. 2016).

\begin{tabular}{|lc|}
\hline \multicolumn{2}{|c|}{ Table 1.3: Where Americans Get News Online } \\
\hline \multicolumn{1}{|c|}{ Source } & Percentage Who Access \\
\hline News org. website/app & 36 \\
Social media & 35 \\
Search engine & 20 \\
News org. email or alert & 15 \\
Family / friend email & \\
or text & 7 \\
Other & 9 \\
\hline Source: Mitchell, Gottfried and Weisel 2017 \\
\hline
\end{tabular}




\section{Social Media and The Media Environment}

Social media and traditional news sources are different, however, and may serve different roles in the news ecosystem. While both the Internet and social media serve to deliver news and political information, there may be something different about how, as well as which, individuals consume and act upon that information. One reason may be that by its nature social media is different from traditional mass media due to the opportunity to interact with others and self-select audiences and sources. It is more personal and allows users to avoid traditional media gatekeepers when looking for information (Carr and Hayes 2015; Gainous and Wagner 2014; Marichal 2012). For some types of social media, the typical user may be different. For example, users of Twitter have greater political interest, are more engaged and are less trusting of the mainstream media (Bode and Dalrymple 2014).

As discussed above, another difference between social media users and traditional news consumers is age. Younger age groups have adopted social media as their top news source more quickly than older generations, but their elders are catching up (Shearer and Gottfried 2017). An additional age-related difference is source recollection. In terms of interaction with news posts, 26 percent 'often' and 54 percent 'sometimes' click story links in social media, which means 80 percent actively click links (Mitchell et al. 2016). Although there is no difference related to age and the likelihood of following a news link online, younger consumers are less likely to recall the source of the news story (Mitchell et al. 2017). 
There may also be a difference in how people consume information from social media due to the nature of social media itself. Twitter, for example, restricts the number of characters in a tweet to 280 , which means by its nature the messages are short. Users have found ways around this restriction, linking to a longer piece, tweet threads (a series of numbered consecutive tweets) or attaching images of longer text written in another program. Generally speaking, however, the messages are short and consumed quickly as someone scrolls through their feed. Fast consumption while scrolling through a feed is also a feature of other social media platforms like Facebook, while Instagram and Snapchat rely on sending messages via photos. The quick nature of this processing stands in contrast to a longer written news story in a newspaper or online, and even a one-to-two minute radio or television story.

This difference in consumption may be important to any effect the information has on the individual. Research from political science, psychology and communication suggests that the speed with which an individual processes a message matters to how it affects information gathering, attitudes and behavior. The Elaboration Likelihood Model (ELM) from Petty and Cacioppo (1986), the concept of 'fast' and 'slow' thinking and heuristics from Kahneman and Tversky (Kahneman 2011; Tversky and Kahneman 1975, 1981), as well as work done on political heuristics (Bartels 1996) can help understand the potential difference between consuming information from social media and from traditional media. The work of these academics relates to the way individuals evaluate messages either quickly or more deliberately, making their work relevant to consumption of 
information from social media. For example, Petty and Cacioppo (1986) argue that attitude change is more likely when information is processed via the "central route' which requires deeper thinking. If social media is processed more quickly, by the 'peripheral route' in the ELM, perhaps attitude change and behavior are not as likely to be affected.

One concern related to the growth of content options via the Internet and social media is a greater opportunity for people to self-select content. Previous research, related to expansion of television and cable, suggests that the increase in choice in the media environment leads to individuals being able to self-select entertainment over news to a greater degree. By doing so, those who choose entertainment see less news and receive less political information (Gentzkow 2006; Prior 2005, 2007). They also reduce the likelihood of any incidental or accidental exposure to news and political information. Prior $(2005 ; 2007)$ argues that this leads to lower voter participation among these individuals. Further, those who choose news tend to be more partisan, which means elections become more polarized. Prior $(2005,2007)$ concludes that a person's content preference between entertainment and news is the best predictor of whether they will turn out to vote.

Since the rapid and significant growth of social media use in general represents an expansion of the media environment, the increased use for news in particular makes examining the effect this may have on political participation important. Prior's research is based on data from 1996, 1998 and 2000, which was still early in the history of the Internet and well before the growth in social 
media. While social media represents an expansion in the media environment, it may not necessarily create the same opportunities for individuals to self-select out of news entirely. In fact, it may create additional opportunities for incidental exposure to such information. It may also simply act as a supplement to a person's main media diet and therefore not have the same effect on consumption choice that the advent and growth of television and cable had on entertainment and news.

An additional reason social media use may not affect political participation is how social media fits within this expanding media environment in relation to long-standing media sources. Chadwick (2013) proposes what he terms the hybrid media system. He argues that anytime a new form of media is introduced there is a period of time where we have a hybrid system. In this system, the new media source takes on characteristics of existing media. For example, when television was first introduced, the shows being produced were essentially popular radio programs transferred to the screen. In fact, initial proponents of television, like NBC's David Sarnoff, were powerful radio people who viewed television as an entertainment outlet. They hoped to build it in a similar manner to AM radio with a focus on entertainment and advertising (Chadwick 2013). After a period of time, television began to find unique ways it could tell stories and eventually present news and information. This is when it became an important source of political information.

The same can be seen with social media today. Much of its content is similar to traditional media sources. Video on social media, for example, is similar 
to stories on television. As social media ages and matures, people discover unique ways it can present information. As time passes, producers also better understand how audiences consume and use information presented on social media and begin to create content that tailors to these uses. People have a shorter attention span on social media, so video length becomes truncated, for example. Quick, digestible content becomes the norm. Posts with images or video get more 'Likes' or shares, so the growth in those types of posts increases. The content and format of social media is always changing and adapting, as are its audiences. Similar to the early days of television, which focused on entertainment over news, the focus of social media today is likely to change and not be the same as what we see in the future. Thus, at this point, we should not expect it to affect political participation based on our understanding of traditional news media sources.

\section{Social Media and Political Participation}

Existing studies into any relationship between social media and political participation have presented a mix of results. There is no clear view about whether there is a relationship, and if there is what that relationship is. Past research has found that online news consumers do not act much differently than those who get news from traditional sources like newspapers, radio and television (Mitchelstein and Boczkowski 2010; Vargo et al. 2014). Bode (2016) argues that there is "potential for users to learn political information from social media" but that this learning "is not always realized within the general population" 
(Bode 2016, 24). Additional research has linked social media positively to political or civic participation like contacting a politician, attending a rally or signing a petition (Bode et al. 2014; Broockman and Green 2014; Gainous and Wagner 2014; Gil de Zúñiga, Molyneux, and Zheng 2014; Holt et al. 2013; Pasek, more, and Romer 2009; Vitak et al. 2011; Xenos, Vromen, and Loader 2014; Zhang, Seltzer, and Bichard 2013). These studies, however, did not include voting in their analysis.

Studies that do examine voting have found some positive relationships between online or social media news consumption and voter turnout (Bimber et al. 2014; Bimber and Copeland 2013; Bode 2012; Bond et al. 2012; Gainous and Wagner 2014). Others find little to no link between social media consumption and political participation, but these also did not include voting (Broockman and Green 2014; Dimitrova and Bystrom 2013; Green and Gerber 2015; Kushin and Yamamoto 2010). The relatively new nature of social media as a tool could account for some of the differences. As it ages, more and more people are adopting it as a source of information, in particular younger generations. For example, the five studies on social media which included voting and found a positive relationship were all published from 2012 on and looked at elections since 2010.

An additional way that social media and traditional media are different is the greater ability of consumers to self-select from whom they receive information. This ability started with the growth of cable news and the Internet (Gainous and Wagner 2014; Prior 2007). Again, similar to studies into social 
media and political participation, the results have been mixed. Some research has examined the potential social media allows for people to create information echo chambers as opposed to being exposed to new and opposing information. Some believe it does create an echo chamber and limit exposure to new and opposing information (Gainous and Wagner 2014; Marichal 2012; Messing and Westwood 2012; Sunstein 2009). Others argue that social networks are not ideologically driven, increase the opportunity to be exposed to novel or new information, and are more likely to spread information (Bakshy et al. 2012; Gentzkow and Shapiro 2011; Kim 2011). One explanation for the differences in opinion between these academics is that those who are concerned about echo chambers are basing their views on how individual's act in non-social media communication situations. Because people tend to consume information from ideologically similar sources offline and in some situations on the Internet, it will likely be true for social media as well. At the very least, the potential exists.

Those who have specifically examined the issue, however, have not found this to be the case or have found it to be limited because of the opportunity for incidental exposure to opposing views.

\section{Social Media and the 2016 Presidential Election}

The 2016 U.S. Presidential election introduced new issues related to social media and elections. In addition, with increased use of a variety of platforms there was greater focus on social media and political participation. The 2016 election featured the aggressive use of Twitter by Donald Trump, concerns 
over 'fake news' being distributed and shared on social media like Facebook and Twitter, and the use of social media by groups outside the United States to attempt to influence the outcome of the election. First, and most noticeable during the election itself, was the extensive use of Twitter by Donald Trump. The tactic allowed Trump to bypass any gatekeeping from the media and directly address the general population. His messages, however, reached even further than Twitter, as the media would invariably pick up his tweets and repost, write about or broadcast them along with commentary or analysis. This extended the reach of these messages to Americans who were not on Twitter or did not follow Trump on Twitter if they were users of the service. Because his comments on Twitter pushed the boundaries of typical statements by presidential candidates, the media actively covered them and increased their reach. Recall from the data presented above that only 24 percent of U.S. adults are on Twitter, which places it near the bottom on the list of major platforms. This is what set his use of Twitter apart from the use by his opponents in the Primary Election and by Hillary Clinton in the General Election. All of these candidates and their campaigns utilized Twitter as well. It was Trump's provocative content, the additional coverage by the traditional media, and responses from others that amplified his messages even more.

Second, the 2016 election raised concerns about the ability of social media sites like Facebook and Twitter to spread false and misleading information. Early research on social media and the 2016 election questions the conventional view that social media had a big effect on the campaign. For 
example, Allcott and Gentzkow (2017) examined web referral data combined with a post-election survey via SurveyMonkey's Audience Panel. The results present an interesting first look at the potential effect of 'fake news' on political decisions. First, they found "a meaningful rate of false recall" for placebo articles. In fact, recall for these was the same as for the fake news headlines (Allcott and Gentzkow 2017, 12). They argue that this suggests that respondents overstate their true recall of fake news which was likely lower. Second, they determined that social media was not the top source of election news. Third, the most circulated fake news stories were still only seen by "a small fraction of Americans" (Allcott and Gentzkow 2017, 22). Finally, for these stories to have had an effect on the election outcome it would have required 0.7 percent of Clinton voters and non-voters to shift to Trump. This, they argue, is "a persuasion rate equivalent to seeing 36 television campaign ads" (Allcott and Gentzkow 2017, 22).

Additional research since the election has quantified how much 'fake news' people may have seen and has examined the characteristics of those viewers. Guess, Nyhan and Reifler (2018) utilized browser history data from 2,525 Americans which was collected anonymously by YouGov with their permission. Their analysis estimates that one-in-four Americans viewed a fake news story but that overall it was a very small part of their news diet. Among Clinton supporters, for example, it amounted to only one percent, while for Trump supporters it was six percent. Two results of particular interest relate to the political knowledge of these news consumers as well as the amount of hard news 
they contribute. The research team determined that there was no evidence to support the contention that fake news was consumed only by those with less political knowledge. Fake news consumers were also heavy consumers of hard news, making the fake news just a small part of their overall news diet. "These results suggest that fake news doesn't crowd out hard news consumption" (Guess, Nyhan and Reifler 2018, S24).

Finally, revelations in fall 2017 that Russian interests created fake accounts and purchased ads on Facebook, Instagram and Google in an attempt to sway the election in favor of Donald Trump led to congressional hearings and fact finding. Twitter announced that more than 2,700 accounts were controlled by Russians along with more than 36,000 bots posting automatically. In total, these accounts posted more than 1.4 million times during the presidential election. Facebook revealed that up to 126 million users may have been exposed to this information as well as other content produced by Russian operatives (Timberg and Dwoskin 2017). The number is staggering, yet the question remains whether or not seeing that information had an influence on the voting decision made by those who viewed it. For example, Patrick Ruffini, co-founder of the Republicanleaning Echelon Insights digital ad firm and a long-time campaign expert, called the advertising "a laughably botched and failed attempt" to impact the election outcome (Ruffini 2017). He noted that even if the Russian-sponsored advertising reached 126 million Americans, the content reflected a very small share of the 33 trillion posts that Americans were exposed to on their Facebook timelines between 2015 and 2017. Further, the amount spent on the ads, approximately 
$\$ 100,000.00$, was less than is typically spent on competitive congressional races (Ruffini 2017).

The explanations of reach and potential effect described above are not meant to excuse the improper meddling of a foreign power in U.S. elections or the inappropriate use of technology to influence an election. Rather, they further demonstrate the need to better understand how U.S. citizens are accessing news and political information via social media and whether that information effects the vote decision. While this dissertation does not address these issues directly, it does examine more fundamental questions about whether social media has an effect on political knowledge and voter turnout. In doing so, it provides important context to the more specific questions around the potential effect of fake news, bots that promote specific stories, and even advertising campaigns on social media. These attempts during the 2016 election are salacious, and rightfully so. It is wise for us to take a step back and better understand the most fundamental questions about the relationship between the consumption of information from social media and political decision-making because that relationship at this point is still not clear.

During the past 10 years, we have seen a significant change in the way people access and consume news and information. The rapid growth in social media doesn't appear to be slowing down. Social media has changed how news and information is received as well as who is receiving information from different sources. In addition, its use for news and political information is spreading from younger generations to older ones. Since information is a key component to 
decision-making, it is important to understand what effect this change may have on democracy and the political process. With these changes, we are seeing social media being used to attempt to influence our elections in new ways, from spreading intentionally false stories, to politicians using it to bypass the traditional gatekeeping roles of the press.

At the same time, our understanding of the most basic questions about social media's effect on political decision-making is not clear. The link between news and information via traditional media and increased odds an individual will vote is established in the academic research. Whether social media acts in a similar role in a positive manner is still not. The natural tendency is to assume it does, which leads to assumptions about the effect of social media in general. It also focuses attention on exciting and potentially controversial uses and abuses like we saw in the 2016 election. The base question about the effect of social media on political participation and knowledge, however, is still unclear. Is this new expansion of the media environment giving people greater opportunity to self-select content and avoid news, and is this affecting political knowledge and voter turnout? Does social media act like traditional news media sources, like newspapers, radio, television and the Internet by delivering news and political information and increasing the odds people turnout to vote? These fundamental questions are important to understand because they will help inform more specific questions about the attempted use of social media for persuasion or even more nefarious uses like propaganda. This dissertation examines the 
fundamental relationship between social media, news and political information, and if social media have an impact on the odds an individual will turn out to vote.

\section{Structure of dissertation}

Thus far, this introductory chapter has presented the current landscape with regard to the development and use of social media. With this background in place, the next step is an overview of the chapters to come and how these will help examine the role social media may play in the political process.

In Chapter 2, the existing literature around social media, news and political participation is examined. This helps understand the research which has been done to date, how that research builds a base for the examinations in the rest of the dissertation, and what questions remain unanswered related to social media and political habits, such as voting. As noted above, results have been mixed with some research finding a relationship between social media use, political participation and voting while other research has found little to no link. Over the period of time covered by this research, however, social media use as a news and information source has grown dramatically as more and more people adopt it (Mitchell et al. 2016; Purcell and Rainie 2014; Shearer and Gottfried 2017).

Research into the similarities between traditional news consumers and individuals that rely on social media for information is also examined to see how these people are similar and different. Finally, Chapter 2 also looks at the literature around decision-making in general, and political decision-making in 
specific, to provide context for why consumption of news and information from social media may be different than from traditional news sources.

In Chapter 3, descriptive statistics are used to examine the differences between social media users and traditional news users with regard to demographics, and their habits and attitudes related to government and politics. This lays additional groundwork for understanding the effect this new information source may have on the decision to turnout to vote. Chapter 3 investigates these differences by comparing three groups. The groups are those that prefer social media, those that prefer traditional news sources, and those preferring both equally. Using data from the 2016 American National Election Studies (ANES) survey, respondents are divided into three groups. Two questions from this survey allow the creation of these groups. First, respondents were asked "During a typical week, how many days do you use social media such as Twitter and Facebook?" Second, they were asked "During a typical week, how many days do you watch, read, or listen to news on TV, radio, printed newspapers, or the Internet, not including sports?" It is important to note the difference in emphasis of these two questions. The social media question asks about social media use in general, while the traditional news media question asks about news specifically. Using responses from these two questions, respondents are sorted into three groups:

- Prefers Social Media: These respondents spend more days per week with social media than with traditional news media. 
- Prefers Traditional Media: This group is made up of respondents who engage more with traditional news media during the week than with social media.

- Prefers Both Equally: This group contains respondents who said they accessed social media the same number of days they accessed traditional news media.

The groups are compared first across a series of demographics, including age, sex, education level, and party affiliation. Next, they are compared across a series of questions related to attitudes about government and politics, including political knowledge, trust in government and level of partisanship. Finally, the groups are compared on political habits, including level of civic participation and voter turnout.

Based on the results of the literature reviewed in Chapter 2 and the investigation in Chapter 3, hypotheses are developed to examine two related issues. The first is whether the increase in media choice created by social media further allows individuals to self-select out of news by consuming primarily entertainment, and if this is related to political knowledge and voter turnout. The second is the relationship between the use of social media and the likelihood an individual will turn out to vote.

In Chapter 4, the first research study repeats part of Prior's $(2005,2007)$ research on the increase in media choice and its effect on political knowledge and the likelihood of voting. A key contention Prior examines in both his journal 
article (2005) and his book (2007) is that the increasing number of options in the media environment allow people to self-select out of news and only consume entertainment. This self-selection of entertainment versus news preference, he concludes, is the best predictor of whether they will turn out to vote. News consumers vote more often, while entertainment viewers vote less. Prior used ANES 1996 and 2000 data for a part of his study for the 2005 journal article. Chapter 4 completes the study using 2016 data to see how news versus entertainment consumers turnout with this new information source available to them, one that allows for incidental news exposure. As two other recent studies suggest, even a small increase in exposure to news has the potential for increasing political participation (Bimber et al. 2014; Ksiazek, Malthouse, and Webster 2010).

Since Prior's study was completed before the explosive growth of social media, an additional media channel capable of delivering news and entertainment, social media may provide accidental news exposure for entertainment choosers and have an impact on both political knowledge and the likelihood they vote. Some research since the Prior study has supported the idea of social media as a source of accidental news, even from viewpoints with which one might disagree (Bakshy et al. 2012; Bimber et al. 2014; Gentzkow and Shapiro 2011; Gil de Zúñiga, Jung, and Valenzuela 2012; Kim 2011; Ksiazek, Malthouse, and Webster 2010; Mitchell et al. 2013). While this dissertation does not look specifically at the issue of incidental news exposure, the results of the 
study in Chapter 4 will provide important information to guide further examination of this topic.

In Chapter 5, we turn to the question of whether the use of social media can predict whether an individual turns out to vote. Past research indicates that individuals who consume traditional news media like TV, radio and newspapers are more likely participate in politics, including the act of voting (Gil de Zúñiga, Molyneux, and Zheng 2014; Luskin 1990; Popkin 1994; Prior 2007; Zaller 1992). This dissertation study looks at whether consumption of social media acts in a similar manner by increasing the odds that an individual votes. Understanding whether or not exposure to news via social media increases the likelihood of voting is important. First, it goes to a central question outlined in the introduction about whether information delivered via social media is having an effect on political participation. Many of the heightened concerns resulting from the 2016 election assume it does. Second, on the positive side, if social media does deliver political information it could serve as a substitute for information from traditional media. For example, younger voters tend to turn out in lower numbers than older voters. If these voters are able to access political information via social media, and this increases their odds of turning out to vote, it would be a positive outcome for democratic participation.

Data for this study comes from the 2016 ANES, which asked respondents pre-election if they intended to vote and followed up post-election to ask if they in fact voted. In terms of social media consumption, the question described above in Chapter 3 regarding how often people consumed social media is utilized. The 
study controls for news consumption from non-social media sources like newspaper, television, radio and the Internet. This is included in the regression models to improve estimates of the relationship between the consumption of social media and voting by controlling for any relationship from traditional news sources. When used in a logistic regression model, controls allow a more precise examination of the effect of the variable of interest on the dependent variable above any effect from the variables being controlled.

The approach the ANES survey took in their question on traditional news use, by combining all news sources (traditional, online and social media), also fits with the 'hybrid media system' idea proffered by Chadwick (2013) and described briefly above. His argument is that as new media sources and technologies are introduced, they overlap with existing sources and have characteristics of those sources. So, for example, with social media we still see the inclusion of video stories on social media (like television) and links to news articles written by newspapers, magazines and other new media sources. In addition, it addresses some of the criticism put forward by Mitchelstein and Boczkowski (2010), specifically that the tendency has been to examine news sources in isolation from one another, an artifact they argue of research into traditional media.

In the final chapter, insights and conclusions gleaned from the dissertation are synthesized to better understand the central question of the relationship between social media use and an individual's political participation. Specifically, the dissertation concludes that social media use is not related to voter turnout in either a positive or negative manner, while traditional news media use continues 
to be related to voting. This includes when social media access is considered along with an individual's content preference. Specific limitations are discussed along with recommendations for how these limitations could be mitigated in future studies. Finally, based on the results and analysis from the paper, suggestions are presented for future research that builds on these results or reexamines questions and issues raised by this paper. Primary among these are studies looking at social media as it relates to a voter's age, the amount of exposure to news and political information needed to spur participation, and how information gathered from social media, along with the source of such information, is recalled by the user. 


\section{Chapter 2: Review of Literature}

In a democracy, voting plays an important role as a way for citizens to participate in governing. In addition to providing the ability to select our representatives, voting allows people to signal policy preferences and express public opinion, and in some cases to even directly enact new laws (Dahl 2006; Gainous and Wagner 2014; Manin, Przeworski, and Stokes 1999; Przeworski 1999; Wolfinger and Rosenstone 1980). For elected officials, voting provides legitimacy and authority to rule, and provides political opponents the assurance that the opportunity exists to replace those in power via elections (Manin, Przeworski, and Stokes 1999; Przeworski and Stokes 1999). Many factors influence an individual's decision to participate in elections. For example, a voter's age has been found to affect a person's decision to vote, with turnout increasing generally as age increases (Smets and van Ham 2013; Wolfinger and Rosenstone 1980). In a similar way, education affects turnout. Those with more education vote more often than those with less (Leighly and Vedlitz 1999; Smets and van Ham 2013). Finally, political knowledge, a sense of civic duty and political interest have all been found to positively affect turnout. The more people know and care about politics the more likely they are to participate (Delli Carpini and Keeter 1996; Downs 1957; Geys 2006; Leighly and Vedlitz 1999; Luskin 1990; Manin, Przeworski, and Stokes 1999; Prior 2007; Smets and van Ham 2013; Zaller 1992) 
In government and politics, exposure to news and political information is widely accepted as a necessary component to forming public opinion and increasing political participation (Gil de Zúñiga, Molyneux, and Zheng 2014; Luskin 1990; Popkin 1994; Prior 2007; Zaller 1992). It helps citizens make decisions, choose representatives and understand if the government is representing their interests (Delli Carpini and Keeter 1996; Downs 1957; Manin, Przeworski, and Stokes 1999). Being informed leads to greater participation in political life, but it also requires engaged citizens (Delli Carpini and Keeter 1997). Downs (1957) argues that people will not spend precious time seeking out information about politics but instead will rely on receiving information accidentally from sources like family, friends, co-workers and the media. Research has supported the positive relationship between exposure or access to news from traditional sources, like newspapers, television and radio, with turning out to vote (Delli Carpini and Keeter 1997; Gainous and Wagner 2014; Gentzkow 2006; Gil de Zuniga, Jung and Valenzuela 2012; Popkin 1994; Prior 2007; Smets and Van Ham 2013). This positive relationship is less clear for a new form of news delivery, social media. Research during the past 10 years into whether use of social media for news and political information increases political participation and voter participation has been mixed. Some studies find a positive relationship (Bimber et al. 2014; Bimber and Copeland 2013; Bode 2012; Bode et al. 2014; Bond et al. 2012; Broockman and Green 2014; Gainous and Wagner 2014; Gil de Zúñiga, Molyneux, and Zheng 2014; Holt et al. 2013; Pasek, more, and Romer 2009; Vitak et al. 2011; Xenos, Vromen, and Loader 2014; Zhang, 
Seltzer, and Bichard 2013) while others do not (Bimber et al. 2014; Broockman and Green 2014; Dimitrova and Bystrom 2013; Green and Gerber 2015; Kushin and Yamamoto 2010; Towner 2013).

How a person processes information may also have an effect on news choices and how they, in turn, are motivated to act on on the information they receive. Researchers across several disciplines have developed similar models related to how people receive and process information for both political and nonpolitical purposes (Bartels 1996; Kahneman 2011; Kahneman, Slovic, and Tversky 1982; Kuklinski and Quirk 2000; Lau and Redlawsk 2001; Petty and Cacioppo 1986). They have identified several heuristics people use, and biases that result from that use, which affect decision-making. In political science research, the idea of political heuristics has been identified as a way people can use cues to help make decisions, instead of having to fully understand a policy or candidate's position on issues (Bartels 1996; Kulinski and Quirk 2000; Lau and Redlawsk 2001). Examining each of these approaches provides a different foundation for understanding how information delivered via social media may affect an individual's decisions.

This literature review lays the groundwork for examining whether social media have an impact on an individual's likelihood of turning out to vote. It begins by examining the research on voting in general and the various factors that influence the decision to participate in an election. Next, it discusses the role of information in the decision-making process. Specifically, it looks at the role of the traditional media as an information source and its relationship to voter turnout. It 
examines several concepts related to how individuals process information and discusses the role this may play in the differences between traditional media and social media as sources of news and political information. It then looks at research during the past 10 years and the mixed results related to social media as an information source, as well as its relationship to political participation and voting. Finally, it outlines research that suggests the increase in media options has led to greater political polarization and lower voter participation.

\section{Importance of Voting to Democracy}

Stripped down to its most basic terms, democracy is simply that "rulers are elected" (Przeworski 1999). This is done through elections where citizens have the ability to choose representatives and change leadership (Dahl 2006; Gainous and Wagner 2014; Manin, Przeworski, and Stokes 1999; Przeworski 1999; Wolfinger and Rosenstone 1980). Elections also give our representatives the authority to rule and assures opponents - those who lost the election - that the opportunity for change in the future exists (Manin, Przeworski, and Stokes 1999;

Przeworski and Stokes 1999). In terms of legitimacy for democracy, the presence of competitive elections is the most basic indicator. Przeworski calls this "the miracle of democracy" because "conflicting political forces obey the results of voting" (Przeworski 1999, 5). Further, Clucas and Valdini argue that meaningful elections provide a method for expressing opinion, help inform politicians, and give voters choices (Clucas and Valdini 2015).

Once in power, officials pursue policies designed, first and foremost, to 
maximize votes, an additional indicator of the importance of voting. Their job is to make sure voters are aware of the benefits they receive from the policies the elected official supports and enacts. After all, voters are self-interested but on Election Day can only consider government benefits they know about (Downs 1957). In addition, one method for examining whether an election is meaningful is to look at how many citizens turn out to vote. Clucas and Valdini (2015) argue that voters choosing not to vote is an indication of a breakdown in communication and "one way to conceptualize meaningfulness" (75).

There are other aspects of participation in a democracy. Writing letters, online activism and protesting, for example, are ways citizens indicate opinions and preferences to elected officials. Delli Carpini and Keeter (1996) describe the difference between focusing on a simple measure, like voting, and a more complex list of participation features as thin and thick definitions of citizenship. Research into political participation has been adding new features over the past two decades. With technological changes, like the Internet and social media, academics seem compelled to add new methods of participation, like online petitions, blogging or political social media posts. Their attempt broadens the definition enough to capture more people in the participation net (Bode et al. 2014; Broockman and Green 2014; Gainous and Wagner 2014; Gil de Zúñiga, Molyneux, and Zheng 2014; Holt et al. 2013; Pasek, more, and Romer 2009; Tang and Lee 2013; Vitak et al. 2011; Xenos, Vromen, and Loader 2014; Zhang, Seltzer, and Bichard 2013). The general interest of this dissertation is on the basic, core behavior in a democracy: voting. It is the most important value of 
democracy, as described above. Brady, Verba and Schlozman (1995) call voting "the easiest political act" and "the least demanding form of political activity" (Brady, Verba, and Schlozman 1995, 282-83).

\section{Information and Political Decision-Making}

Anthony Downs (1957) argues that the first step a voter takes is to gather information about issues or candidates. Information is a key component of the decision-making process, and for a voter to know why and how they should vote, they need information (Downs 1957). Access and exposure to political information via news and the media is generally accepted as important to political participation as well as helping the public form opinions on civic issues (Gil de Zúñiga, Molyneux, and Zheng 2014; Luskin 1990; Popkin 1994; Prior 2007; Zaller 1990). This helps individuals make political decisions, like choosing representatives or even enacting legislation through the initiative process. It also helps them understand whether government is representing their interests and responding to their preferences (Downs 1957; Delli Carpini and Keeter 1996; Manin et al 1999). As Delli Carpini and Keeter (1996) state, “...democracy functions best when its citizens are politically informed" (1). Political information and knowledge are two of the most important factors that affects voter turnout. Individuals who are more knowledgeable about government, politics and how it works are more likely to turn out to vote (Delli Carpini and Keeter 1997; Downs 1957; Manin, Przeworski, and Stokes 1999; Prior 2007).

This participation, though, requires citizens to be "active and engaged" 
according to Delli Carpini and Keeter (1996). Downs (1957), however, argues that individuals will not seek out this information but instead rely on receiving it as a by-product from friends and family, from non-political activities, and from the media. Samuel Popkin, in The Reasoning Voter (1994), relies on the by-product concept from Downs to explain how voters get information. In what he calls "lowinformation rationality," voters combine "in an economical way, learning and information from past experiences, daily life, the media, and political campaigns" (Popkin 1994, 7).

Luskin (1990) believes a person's political sophistication, their political knowledge, is contingent on three things: information, ability, and motivation. One must first be exposed to the information, then have the ability to understand it, and finally have the motivation or "reason enough to make the effort" to process it (Luskin 1990, 335). He has very little faith in the ability of the broadcast media to deliver proper exposure, calling broadcast news "brief and shallow" (Luskin 1990, 335). Based on previous research, he believes newspapers are far better at delivering information that is retained by individuals. Luskin concludes that exposure to information is not the biggest challenge, rather is it motivation and ability to understand and organize it. "Sophistication, in these results, is much less a function of the information to which people are exposed than of what they can and are motivated to make of it" (Luskin 1990, 352).

John Zaller's (1992) model for public opinion formation provides another way to look at the role information plays in the political process. Zaller says there are two key components to opinion formation: information and predisposition. He 
notes that people can never know all the information about an issue and so we rely on snippets of information from family, friends and the media. This is similar to Downs (1957) and Popkin (1994). Further, Zaller says this information comes down from political elites - politicians, journalists etc. - and comes second or third hand. "Even when we learn from friends or family members about some aspect of public affairs, often we may still be secondhand consumers of ideas that originated more distantly among some type of elite" (Zaller 1992, 6). Awareness of politics by the general public varies greatly from person to person. In addition, "the average overall levels of information are quite low" (Zaller 1992, 18). This is important because too often researchers build models about political behavior that assume an equal and higher level of awareness by individuals. Any look at political information and how it interacts with politics needs to recognize that the level of awareness is, in fact, very small. "More succinctly, there is a high variance in political awareness around a generally low mean" (Zaller 1992, 18).

These approaches are similar to the two-step flow of information model established by Katz (1957) whereby political elites and the media serve as sources of political information and thus affect what is presented and how it is framed. This means systems that deliver information are important to the process of democracy because they provide what people know and how they understand what they know (Bennett 2011; lyengar and Kinder 1987; Williams and Delli Carpini 2011). Traditional media, like newspapers, television and radio, affect what citizens think about and how they judge public officials and the government by focusing and framing issues (lyengar and Kinder 1987). The advent of social 
media has changed the traditional gatekeeping role of the media and allows citizens to gather and disseminate information in an entirely new way. This raises questions about whether social media acts in a similar manner as traditional media, and thus if existing theories and models can be applied. Agenda setting, for example, is one area researchers are examining. Utilizing concepts from Katz's (1957) two-step flow of information model along with concepts from agenda setting research, Feezell (2017) found that agenda-setting effects could be delivered via social media. Further, she found that such effects were particularly strong for those with lower political interest who received the information incidentally (Feezell 2017). Understanding the potential relationships between social media and political participation and decision-making is therefore important.

There are questions around the connection between political knowledge and citizen participation, particularly, how research has measured political knowledge and whether this captures what is intended. Looking specifically at the judicial branch of government, Gibson and Caldeira (2009) argue that increased access to information about courts and judicial confirmations due to coverage by cable news served to increase the role of ordinary citizens in the judicial process. Further, exposure to this information has helped solidify the legitimacy of the judicial branch. Most importantly, through their analysis Gibson and Caldeira are far more positive about the political knowledge of the general United States citizen, in particular related to the courts. They argue that existing measurement techniques using open-ended questions are not accurately measuring such 
knowledge. In fact, they demonstrate that closed-ended multiple-choice questions produce a better measurement.

Gibson and Caldeira take specific aim at how the American National Election Study (ANES) measures political knowledge by asking what people know about specific political and judicial figures, like the Supreme Court Chief Justice, Speaker of the House and Vice President. The survey presents these individual's names without context and asks respondents what job or position they hold. Further, the ANES is very strict about what they consider accurate answers. Using the 2004 ANES as an example, respondents were asked about William Rehnquist, then Chief Justice of the U.S. Supreme Court. Through correspondence with ANES, Gibson and Caldeira learned that the only answer considered accurate was 'Chief Justice' or 'Chief Justice of the Supreme Court.' Simply saying 'Justice' was considered incorrect, as was saying 'Court' and not 'Supreme Court' (Gibson and Caldeira 2009). By comparison, during the 2006 Samuel Alito confirmation, Gibson and Caldeira tested an open-ended approach versus a closed-ended multiple choice approach to a similar question. Only seven percent of respondents who received the open-ended question could identify John Roberts as the chief justice. Among those who received a list of three choices, however, 46.3 percent were able to correctly identify Roberts as the chief justice. Similar results were found with questions about the Senate Majority Leader and former Chief Justice William Rehnquist.

Use of measurements of political knowledge from the ANES, then, should be limited to "only the simplest and grossest inferences" (Gibson and Caldeira 
2009, 23). Thus, as you will see in Chapter 3 , political knowledge measurements are used only as one of several descriptive measures comparing those who prefer traditional media to those who prefer social media for news and information. In addition, the study in Chapter 4 uses it as one of two measurements to examine the relationship between the media environment and politics.

\section{Heuristics as Information Shortcuts}

As described above, models developed to understand political participation, whether via voting or public opinion, rely on the input of information. It makes sense that in order to form an opinion or make a decision at the ballot box, people must have some information about the issue or candidate. As Zaller (1992) argues, levels of knowledge related to politics are quite low, however. It is important to note that Zaller utilized questions from ANES surveys over the years and to keep in mind the criticism of this approach explained above by Gibson and Caldeira (2009). Still, based on the general belief that political knowledge by Americans was lacking, political scientists attempted to acknowledge that, and at the same time understand how (and why) people make political decisions. To do this, they turned to heuristics as a possible explanation. Heuristics are mental shortcuts an individual uses to make decisions. Based on research into the use of heuristics, Kahneman (2011) writes that "The technical definition of heuristic is a simple procedure that helps find adequate, though often imperfect, answers to difficult questions" (98). 
A 1996 study by Larry Bartels argues that heuristics do not achieve the goals of an informed electorate and in fact can lead to specific biases that benefit certain candidates. Bartels sought to directly examine the belief that information shortcuts allow voters to act "as if they were fully informed" (Bartels 1996, 194). He points out that while political scientists rely on this idea, very little had been done to empirically test whether it was true. Using data from the American National Election Survey from the 1972 presidential election through the 1992 presidential election, Bartels created hypothetical "fully informed" vote probabilities and found that shortcuts do not allow voters to act as if fully informed. In fact, he was able to identify specific biases that benefit certain types of candidates. In his analysis, Democratic candidates received a two percentage point advantage and incumbents did five percentage points better than with a hypothetical fully-informed electorate (Bartels 1996).

Kuklinski and Quirk (2000) point out that in response to low voter knowledge of politics, political scientists generally offer two explanations. The first relies on heuristics and the second is that political opinion ends up being rational because individual errors tend to cancel each other out. In the field of political science, researchers have identified several types of heuristics that may be useful to voters. These include items like party label, the demographics of the candidate and her supporters, the idea that the candidate's personal character reflects the candidate's political character, and public statements by politicians as well as interest groups. Kuklinski and Quirk (2000) argue that citizens regularly fail to use these political heuristics at all. First, people do use heuristics but not in 
a thoughtful manner, rather they use them automatically and without regard to accuracy. Second, people lack the context to use heuristics properly. For example, a political heuristic noted as typical by Kuklinski and Quirk (2000) is judging the viability of a candidate based on their success in early primary states. They argue that in order for a voter to properly use this heuristic they must understand the particular nuances of the early primary states, like whether it is conservative or liberal. With political knowledge being so low, voters likely lack this information and thus do not use the heuristic properly or simply do not use it at all. Finally, the information needed by the voter to use a heuristic might not be available to them. Consider a politician's statements or the position of an interest group. If a voter does not have this information, it cannot be used as a heuristic for easier decision-making. In the end, Kuklinski and Quirk explain that they are not against heuristics, rather they question the generally positive light they are put in by researchers and whether voters, in fact, can become competent through the use of heuristics.

In 2001, Lau and Redlawsk continued the examination of whether heuristics actually work to help mitigate the lack of voter knowledge. Heuristics in political decision making have become so popular, they argue, that the idea can been seen as "new conventional wisdom" (Lau and Redlawsk 2001, 952). Their study, however, found heuristics to only be valuable to those voters who already possessed high political knowledge. For low-information voters, on the other hand, heuristics actually made decision making less accurate (Lau and Redlawsk 2001). 
A contemporary change in how people are receiving political information provides a new opportunity to consider the potential ramifications of heuristics on political decision-making. If people with low political knowledge rely on social media for news and political information, and use heuristics to process this information, it may affect their decision-making. Take, for example, the opportunity to create information echo chambers. Prior (2007) argues that more media choice allows greater opportunity to self-select the information one receives. Some believe this could allow people to only consume information they agree with and to avoid information that challenges their worldview (Gainous and Wagner 2014; Marichal 2012; Sunstein 2009). Other researchers do not see this as a potential problem because, they argue, the Internet and social media actually create greater opportunities to be exposed to new and alternative opinions, as well as to spread information (Bakshy et al. 2012; Gentzkow and Shapiro 2011; Kim 2011).

Gainous and Wagner (2014) argue that because social media allows an individual to decide who they want to friend or follow, ideological echo chambers, or one-sided information flow as they describe it, is the likely result. Since this has been the case with other traditional media and the Internet they "...have no reason to expect selectivity to be different when deciding which information to consume via social media" (Gainous and Wagner 2014, 122). At the same time, they acknowledge that, at the point of their writing, there was little research related to content choice and social media. Sunstein (2009) makes a similar argument to suggest echo chambers may occur. His view is based not on the 
results of studies specific to social media but rather by relating it to how people consume information from other sources. In fact, he acknowledges that research has shown that echo chambers are not necessarily more likely for those with access to the Internet than for those without. Basing his view on simply access to the Internet also demonstrates how much the online world has changed since he developed his opinion. Finally, Marichal (2012) also bases his concern for the potential for echo chambers on the past political behavior of individuals offline. He suggests that platforms like Facebook groups will only encourage and expand this behavior because it makes it so much easier.

Studies that have sought to examine the question directly, however, have found different results. Gentzkow and Shapiro (2011), for example, found that online ideological segregation was low overall. Further, it was significantly lower than the ideological segregation people develop in face-to-face relationships and social networks. It was higher, however, than the segregation that occurs from consumption of offline newspapers. They attribute these results to the fact that online news consumers visit multiple sites online and that, at the time of their research, the Internet news ecosystem was dominated by large and relatively moderate news sites. Finally, they found that users who do visit sites that cater to a specific ideological slant are also heavy consumers of news in general and are thus being exposed to moderate or even different viewpoints.

Bakshy et al. (2012) examined Facebook friend networks and its news feed algorithm to see if the potential for echo chambers was present. They concluded that a person's existing friend network, not the algorithm or the 
individual's consumption choices, were more likely to cause a potential echo chamber. Still, they were positive in their conclusion about the potential for exposure to ideologically different viewpoints on social media. "Our work shows that social media exposes individuals to at least some ideologically cross-cutting viewpoints" (Bakshy et al. 2012, 1131). Messing and Westwood (2014) suggest that it is the endorsement of news from our social network online that most influences a decision to consume it. Thus, a person may be more likely to engage with content outside their normal partisan views because of such an endorsement. These social endorsements helped reduce an individual's partisan content choice decisions.

The reliance on heuristics may also contribute to the latest concern related to social media and politics: 'fake news'. In the wake of the 2016 election, people are concerned about the ability of social media sites like Facebook and Twitter to spread false and misleading information. The issue is whether this information could sway an election to one candidate over another. To examine this, Allcott and Gentzkow (2017) used web referral data combined with a post-election survey. Part of this survey presented respondents with 15 news headlines about the election and asked them if they recalled seeing or hearing about them. They also asked if the headline was true. The 15 news headlines were randomly chosen from a database created by the research team that included true and false news headlines that appeared during the election. These were evenly weighted to include stories beneficial and harmful to both presidential candidates. 
It also included 'placebo' headlines the researchers made up so that it was possible to swap in either candidate's name (Allcott and Gentzkow 2017).

The results present an interesting first look at the potential effect of 'fake news' on political decisions. First, they found "a meaningful rate of false recall" for the placebo articles (Allcott and Gentzkow 2017, 12). In fact, recall for the placebo headlines was the same as for the false news headlines that actually appeared during the election. This suggests respondents overstate their true recall of fake news, which was likely lower. Second, they determined that social media was not their top source of election news. Third, the most circulated fake news stories were still only seen by "a small fraction of Americans" (Allcott and Gentzkow 2017, 22). Finally, for these stories to have affected the election result it would have required 0.7 percent of Clinton voters and nonvoters to shift to Trump (Allcott and Gentzkow 2017). Thus, despite the concerns over the issue of fake news being a prevelant storyline from the 2016 election, the effect of those stories appears to be minimal at best.

\section{Factors Affecting Voter Turnout}

Chapter 3 of this dissertation uses descriptive statistics to examine the similarities and differences between those who prefer traditional media for news and information and people who prefer social media. Previous research has found several factors affecting why people turnout to vote. Two of the three most studied variables related to voter turnout are education level and age. In a metaanalysis of studies conducted between 2000 and 2010, which examined 
individual-level voter turnout in national elections, Smets and van Ham (2013) found that 67 out of the 90 studies included education as a variable and 65 included age. Their analysis indicates support for a statistically significant effect between more education and higher voter turnout. Leighly and Vedlitz (1999) found education was also a factor positively related to turnout in their study of voters in Texas, and that the factor remained positive across four major ethnic groups. The same was true for age, where turnout increases as one gets older (Smets and van Ham 2013). The studies looking at age did find that turnout begins to decline at an older age, most likely due to a general withdrawal from social life by the elderly, so the effect is in fact curvilinear. This meta-analysis of recent studies confirms the original results by Wolfinger and Rosenstone (1980) in their seminal work, Who Votes?, which also identified education and age as key factors for voter turnout.

The 'resource model' of political participation developed by Brady, Verba and Scholzman (1995) sought to improve on simply relying on socio-economic factors like income, education and occupation. The resource model includes items like time, money and civic skills. This model was developed to help explain additional ways voters gain political knowledge, which as demonstrated above is important to voter turnout. For example, Brady, Verba and Scholzman (1995) explain how civic skills gained from participation in non-political community organizations, like churches, are valuable for increasing participation in politics. Using the resource frame, Verba et al. (1993) also identified the availability of political resources as being the most important factor when comparing 
participation of African-Americans, Latinos, and Anglo-Americans, not the race of the individual. Other factors, similar to civic participation, have been examined and found to positively affect turnout, including past turnout, the propensity to vote and a sense of civic duty and caring who wins (Geys 2006; Smets and van Ham 2013). Psychological factors, like civic duty and political interest, have also been found to be predictors of political participation across multiple racial and ethnic groups. Leighly and Vedlitz (1999), for example, found these to be strong predictors for Asian-Americans, African-Americans, Mexican-Americans and whites in their study of voters in Texas. Finally, Geys (2006) in his meta-analysis of 83 aggregate-level studies on turnout found that "voting may be habit-forming" (646) based on statistically significant results for seven of the eight studies he examined that looked at previous turnout.

\section{Social Media versus Traditional News}

A key way that people develop interest and gain knowledge about politics is via the media. Media exposure is generally accepted as important for increasing political participation (Delli Carpini and Keeter 1997; Gainous and Wagner 2014; Gentzkow 2006; Gil de Zúñiga, Jung, and Valenzuela 2012; Popkin 1994; Prior 2007; Smets and van Ham 2013). The nature of the media system that delivers this information, therefore, has an effect on voter turnout. Prior (2007) argues that the media environment is a key consideration and the best predictor of voter turnout. He found that greater media choice has allowed greater opportunity to self-select out of exposure to news and political information, allowing entertainment choosers to avoid it altogether. The result is 
that those most interested in news and politics, who are more partisan by nature, turn out to vote, leading to polarization in our political system (Prior 2007). The issue of self-selection out of news and political information due to increased media choice is a key contention this dissertation will examine and is discussed in greater detail below.

There are differences between traditional media and social media as information sources. These differences may mean that traditional media and social media play different roles in the media ecosystem. Further, there may be differences in how individuals process information from these sources. In addition, users vary by social media platform in some situations. Twitter users, for example, have been found to be more engaged in politics, have higher interest in politics, and trust traditional media less (Bode and Dalrymple 2014). By its design, social media is different than traditional media in several ways, including the ability to interact with others, select sources of information and avoid gatekeepers in the traditional media (Carr and Hayes 2015; Gainous and Wagner 2014; Marichal 2012). As discussed above, the ability to self-select has led some to argue that information echo chambers are the natural result, while others say social media will lead to greater exposure to divergent views. The growth of cable news networks also created a similar opportunity.

Chadwick (2013) argues that as media shifts and changes over history, there is a period where the system is a hybrid of the new and the old. He demonstrates how this is the case over time with changes from print to broadcast, then to cable and the Internet. We see this with regard to the Internet, 
social media, and traditional media via examples like news organizations and reporters using social media, as well as the ability to embed video. Social media, then, may not yet be a distinct media platform with its own specific effects on attitude formation and behavior. Harder, Paulussen and Van Aelst (2016) found an example of Chadwick's hybrid media concept in their examination of the use of Twitter in Belgian elections. Twitter was dominated by traditional media and political actors, an example, they argue, of Chadwick's theory of a hybrid media system. Marichal (2012) also points to a similar concept by saying sites like Facebook blur the line between mass and interpersonal communication.

Social media may also present a new opportunity for individuals to be accidentally exposed to news and information, something Downs (1957) argued is an important way people receive information. Focusing specifically on social media, a 2013 Pew study found that many Facebook users visit the site for purposes other than political information, yet they are exposed to it in their news feed (Mitchell et al. 2013). This aligns with research from Gil de Zúñiga, Jung, and Valenzuela (2012) which found that social media, similar to television, is not primarily used for news consumption. People visit and use these mediums for other purposes first. Work by Feezell (2017) also supports the possible role social media can play in delivering information to those with less interest, specifically that it can have an agenda-setting effect on these individuals. This suggests the possibility that social media could serve to deliver accidental political information and have a positive effect on turnout and participation.

This type of secondhand political information, however, if received and 
interpreted from other people, may have drawbacks. Research by Carlson (2018) suggests that people receiving second and third-hand political information may receive less information because those who pass it along edit parts out. Further, this information may be more distorted. "The substantive results suggest that the amount and quality of political information declines as it propagates through more people" (Carlson 2018, 351-2). Carlson did not look at behaviors or decisions that result from lower quality information and she acknowledges this is an important next step in research in this area. The nature of social media is people and organizations sharing information. Carlson's findings demonstrate why it is important to better understand the relationship between receiving information via social media and political decisions and participation. How is lower-quality second or third-hand information received via social media related to a person's vote decision?

\section{Information Processing and Social Media}

The nature of social media and how individuals process information from it may also have an effect on political participation. From the field of behavioral economics, Kahneman and Tversky (Kahneman, Slovic, and Tversky 1982; Tversky and Kahneman 1975, 1981) identified several heuristics people use, and biases that result from that use, which affect decision-making. Kahneman (2011) later developed these ideas and others in the field into the concepts of System 1 or 'fast' thinking, and System 2 or 'slow' thinking. At the most basic level, the first system makes quick decisions while the second requires more thought and 
analysis (Kahneman 2011). From the field of social psychology, Petty and Cacioppo (1986) introduced the Elaboration Likelihood Model (ELM) to help examine persuasion and attitude change. The ELM offers a similar explanation for information processing. Finally, as discussed above, political science research has examined the use of political heuristics to provide voters with shortcuts when making decisions or forming opinions on candidates and issues (Bartels 1996; Kuklinski and Quirk 2000; Lau and Redlawsk 2001).

\section{Tversky and Kahneman: Heuristics and Biases}

As early as 1973 , Tversky and Kahneman began looking at the issue of heuristics in decision making. They identified two types of heuristics: representativeness and availability. With regard to 'representativeness', individuals judge the probability that two things are similar. This includes whether they are similar in class or result from one another. People look for "...the degree of similarity between them" (Tversky and Kahneman 1975, 3). If they are similar, probability is judged to be high, and if not then it is low. With 'availability' individuals judge the probability of an event based on how easily they can recall similar circumstances. For each of these heuristics, Tversky and Kahneman outline biases which render these approaches less reliable. When it comes to the representative heuristic, they identified six biases. For example, with the 'illusion of validity' people are more confident in their prediction if the outcome of that prediction matches closely with the information or evidence they are provided. With regard to the availability heuristic, they identified four bias. One example is a bias due to the retrievability of instances. People judge the frequency of 
possible outcomes as being higher the more easily they can retrieve examples. This is true even if the outcome they are comparing it to occurs just as frequently. Tversky and Kahneman point out that these biases occur even when accuracy is encouraged and respondents are rewarded for answers that are correct. (Tversky and Kahneman 1975, 27). The biases are consequences of reliance on heuristics. Their conclusion is not that heuristics are necessarily bad, but rather they lead to predictable biases which we need to better understand.

In his book Thinking, Fast and Slow, Kahneman (2011) brings together his decades of research - much of it with Tversky - along with that of others to build an argument that humans use two different systems to make decisions. He dubs these, simply, System 1, which makes fast decisions, and System 2, which requires deeper thought. System 1 "operates automatically and quickly, with little effort or no effort and no sense of voluntary control" (Kahneman 2011, 20). He further notes that System 1 has limitations including that it has systematic biases and cannot be turned off. System 2, on the other hand, "allocates attention to the effortful mental activities that demand it, including complex computations" (Kahneman 201121). System 2 requires deeper thinking about a problem, is able to compare items, and follows rules. He explains that this higher level of thinking requires much more effort and thus is not used for every decision we make. There are times, however, that System 1 will call on System 2 for deeper analysis of a situation. One of the limitations of System 2, though, is "laziness, a reluctance to invest more effort than is strictly necessary" (Kahneman 2011, 31). So, in the end, many of the decisions made by System 2's deeper analysis are 
still driven by System 1. Heuristics are an example of System 1 decision-making. Kahneman explains, however, that System 2 has the opportunity to endorse or reject the use of a heuristic. Since System 2 is generally lazy, though, it often does not take the effort to do this analysis. Due to its nature, social media is presented in small pieces that are easy to consume. If consumption of information and news via social media utilizes a person's System 1 thinking it may lead to a reliance on heuristics and thus be prone to bias.

\section{Elaboration Likelihood Model}

In the field of social psychology, Petty and Cacioppo (1986) sought to organize the work done in the area of persuasion and attitude change through their Elaboration Likelihood Model (ELM). The ELM outlines two different routes to persuasion, the 'central route' and the 'peripheral route.' In the central route, individuals engage with information and give it greater thought and consideration. For the peripheral route, far less examination is given to the information presented. Petty and Cacioppo argue that when certain cues are present that deem elaboration more likely, an individual utilizes the central route, when elaboration is less likely the person uses the peripheral route. They conclude that attitude change that takes place from the use of the central route lasts longer, is more resistant and better predicts the individual's behavior than that which occurs from information processed via the peripheral route (Petty and Cacioppo 1986). Again, applying this to consumption of news and information from social media, the peripheral route may be used more for information from this kind of 
source. While social media posts often provide the opportunity for an individual to click through to a longer article or piece of information, the post content is first evaluated by the peripheral route of the ELM and thus deeper consideration from the central route is subject to this evaluation.

\section{Heuristics and Political Decision Making}

As discussed previously, political heuristics have long been considered one method that individuals in general, and low-information voters in particular, rely on to make political decisions. The value of these, however, is questionable. Research has indicated that reliance on heuristics isn't an accurate replacement for full information and can lead to benefits for certain candidates, like incumbents (Bartels 1986). Further, citizens may not have the proper information or ability to utilize heuristics properly (Kulinski and Quirk 2000). In fact, reliance on heuristics may be harmful to low-information voters who use them to make political decisions (Lau and Redlawsk 2001).

As the youngest of the communication tools, little is known about how individuals access news via social media and whether it 'acts' like traditional media in terms of political decision-making. There are reasons to expect social media to act the same as news consumption via newspaper, television, and radio. Information from social media can build awareness and bring issues and candidates to the attention of voters. It can encourage them to click a link and read more via an online news article or to visit a candidate's website. Some of the political heuristics examined above could be activated by exposure to 
messages via social media, like statements by candidates or interest groups, political party membership, and candidate demographics. Applying the research described above, however, suggests that there are reasons to expect social media to act differently. First, social media seems perfectly designed to engage Kahneman's System 1 (fast thinking) and the peripheral route in the ELM. Scrolling through a Facebook or Twitter feed and reading posts does not entail slow thinking. Little analysis of the post content is being done, instead individuals likely rely on gut instincts as they read and react to them. The nature of social media consumption suggests that people are using the peripheral route to consume information from this source, making behavior and attitude change less likely. Processing in this manner may not provide the in-depth engagement needed to influence attitudes and behavior and instead it may simply rely on existing attitudes. Consumption of news and information from traditional sources like newspapers and television, on the other hand, may involve System 2 or central route processing. Thus, it may be more likely to allow for attitude change and to influence behavior. Finally, as the research into political heuristics suggests, the use of these shortcuts does not lead to good political decision making by individuals. Increased reliance on social media, then, may be increasing the use of these heuristics which do not appear to work.

\section{Social Media and Voter Turnout/Political Participation}

The use of social media as a news source has grown dramatically over the past decade (Mitchell et al. 2016; Purcell and Rainie 2014). The consumption 
of news online is increasing and Americans generally feel better informed because of online news opportunities (Mitchell et al. 2016; Purcell and Rainie 2014). The relationship between social media news consumption and political participation, however, is unclear. Results of initial studies during the past 10 years suggest that in some instances there is a positive relationship between social media use and participation. Others suggest little to no relationship.

Previous research in this area has shown that individuals who consume news online do not act much differently from those who utilize newspapers, radio and television (Mitchelstein and Boczkowski 2010; Vargo et al. 2014). Bode (Bode 2016) concludes, however, that while learning political information online is possible, it does not always occur for the general public. Other studies have found a positive link between social media and political activities like contacting a politician, going to a rally or signing a petition (Bode et al. 2014; Broockman and Green 2014; Gainous and Wagner 2014; Gil de Zúñiga, Molyneux, and Zheng 2014; Holt et al. 2013; Pasek, more, and Romer 2009; Vitak et al. 2011; Xenos, Vromen, and Loader 2014; Zhang, Seltzer, and Bichard 2013). These previous studies do not include voting as a variable, however. Those that do include voting have found some relationship between turnout and news consumption online or via social media (Bimber et al. 2014; Bimber and Copeland 2013; Bode 2012; Bond et al. 2012; Gainous and Wagner 2014). One interesting note about these studies is that each one uses a different approach to measuring voter turnout: A survey of undergraduates (Bode 2012); ANES data (Bimber and Copeland 2013) and British Election Studies data (Bimber et al. 2014); And data from Facebook 
matched to voter file turnout data from states (Bond et al. 2012). The last study, Gainous and Wagner (2014), doesn't use voter turnout to measure the relationship, rather it measures the relationship between social media and its impact on elections from the candidate side. It looked at which candidates used Twitter as part of their campaign strategy and had more electoral success in 2010.

Other work in this area has found less support for a link between getting information from social media and political participation. These studies, however, did not include voting in their analysis (Broockman and Green 2014; Dimitrova and Bystrom 2013; Green and Gerber 2015; Kushin and Yamamoto 2010). For example, while the 2008 presidential election has been lauded for the role social media played in Obama's victory, Kushin and Yamamoto (2010) suggest this was not the case. While they did not measure turnout, their examination of political participation found that Internet sources of information played a greater role than social media. Other studies, on whether advertising or social pressure on Facebook increase voter turnout, also found little effect (Green and Gerber 2015). Dimitrova and Bystrom (2013) found that social media use did not predict intent to participate in the 2012 lowa Caucus for Republicans. This was also the case, however, for most traditional news, which exerted little influence on the decision to caucus. Boulianne (2015) found that online and social media information had an indirect effect on voting and political engagement via civic awareness, but little direct effect.

Two studies did look at voting and came away with no relationship 
(Towner 2013) and mixed results (Bimber et al. 2013), respectively. The first found that only television exposure increased the likelihood of voting for young adults. The second looked at digital news consumption and voting across five elections - 1996, 1998, 2000, 2004 and 2008. In all elections except 2008, they found a significant relationship between voting and Internet news consumption. In 2008, they did not. The project utilized ANES data from those elections, and one criticism the authors made was that the survey needed to develop a better measurement of digital news. Those ANES surveys also did not include specific questions about social media news use because that form of communication did not exist yet or had only recently begun. This is a general problem among many of these early projects, which lump social media news as a source within a more general Internet news category.

Although results are mixed, there appears to be potential for even a little news to make an impact on involvement. Based on a sample of nearly 25,000 respondents, (Ksiazek, Malthouse, and Webster 2010) identified almost half as 'news avoiders' who see very little news but greatly benefit from even small doses of news. This result seems to mirror that of Bimber et al. (2014) where there was a larger effect of Internet news consumption on voting behavior for those with low interest than those already interested. Further, Warren, Sulaiman and Jaafar (2014) based on an examination of online civic engagement and social media in Malaysia suggest that the use of social media by civic organizations could lead to greater online civic participation. In addition, they suggest that online civic participation may help foster greater trust in government 
and other civic institutions. Finally, Marichal (2012) argues that early research in this area suggests that a site like Facebook might help with mobilizing voters but it will not necessarily help us be better citizens.

There may be a couple explanations for why the results thus far are inconsistent. First, each study approaches political participation and voting differently. However, when looking at only the seven studies that included voting, five of them found a positive relationship (Bimber et al. 2014; Bimber and Copeland 2013; Bode 2012; Bond et al. 2012; Gainous and Wagner 2014). One that did not, Bimber et al. (2014), found mixed results. That study, however, focused mostly on online news and not social media and used election data from years when social media either did not exist or was so young not many were using it. Second, social media is a relatively young information platform, which may explain some of the differences. It also points to why the question still needs further examination. It is being adopted in greater numbers as time goes by, initially by younger voters but over time older ones, as well.

Social media could serve as a substitute for political information from traditional media and encourage participation by younger voters. If these voters are able to access political information via social media, and this increases their odds of turning out to vote, it would be positive for democratic participation. If social media can act as a new source of information perhaps it will motivate greater turn out by these younger voters. Turnout has traditionally been low among younger voters (Rubenson et al. 2004). Recent research into the use of social media and political participation by these voters suggests the opportunity 
for increasing political participation (Bode et al. 2014; Holt et al. 2013; Xenos, Vromen, and Loader 2014), although these studies did not look at voting. Other research, though, found the opposite, that it does not help increase turnout (Towner 2013). This shift to social media as a news source for younger voters appears to be fundamental. Thus, as Gainous and Wagner (2014) argue, the difference between younger and older voters in terms of their social media use is not something people will out-grow. Instead, as the young demographic ages they most likely will continue this practice, at least until some unknown future technology comes along. Therefore, understanding the relationship between age, social media use, and voter turnout is important to understanding the overall effect it may have on political participation now and in the future.

A second factor that may affect the relationship between exposure to social media and voting behavior is the individual's political interest, which has been found to be a strong predictor of voter turnout (Brady, Verba, and Schlozman 1995; Chew 2016; Pinkleton and Austin 2010; Smets and van Ham 2013; Zaller 1992). Some initial work into the relationship between news exposure from social media and political participation suggests that even low doses of news increases political participation, like voting, for those with less interest in politics (Bimber et al. 2014; Ksiazek, Malthouse, and Webster 2010). Certainly, exposure to news and political information isn't a panacea for increasing turnout. As Wolfinger and Rosenstone (1980) point out, small changes in the costs or benefits of voting likely won't encourage participation. However, as sources of news and information shift, we need to understand the effect those 
changes have on turnout and political participation.

\section{Relative Entertainment Preference}

Where citizens get news and political information is always changing. From newspapers, to radio, television, cable and the Internet, the method of delivery by the media has changed over time. For those interested in politics and communication, the effect of these changes on knowledge and participation is important. During the broadcast news era when there were only three major TV stations to accompany print and radio, there was a greater opportunity for individuals who were not seeking news to encounter it anyway (Downs 1957; Prior 2005, 2007). This led to higher voter turnout because this exposure, while accidental and likely limited, encouraged more individuals to turn out to vote. The growth of cable television and the pre-social network Internet had the opposite effect. It allowed those who prefer entertainment to find such content without bumping into news.

Prior $(2005,2007)$ argues that greater media choice presented by new sources, like cable television and the Internet, leads to people to segment themselves voluntarily. Those who prefer news and have access to both television and the Internet become more knowledgeable over time, and knowledge is a key to turnout. Those who prefer entertainment avoid news and turn out to vote less, leading to a turnout gap between those who prefer news and those who select entertainment (Prior 2005, 2007). Prior believes this began with the growth of cable television, as broadcast television offered fewer choices 
and thus greater opportunity for people to encounter news and political information accidentally. Matthew Gentzkow (2006) is less supportive of the idea that broadcast television provided opportunity for this kind of information. He argues that broadcast television actually caused a decline in voter turnout from the beginning because it offered more media options than just print and radio (Gentzkow 2006). While Prior and Gentzkow may disagree on when the increase in media choice caused a reduction in knowledge and turnout, in the end they both support the idea that it did have this result.

The change in the media environment through expansion of choices is the key to Prior's argument. He defines the media environment as "the media available to people at a particular place and time and by the properties of these media. For a new medium to be available, the technology for local access must exist" (Prior 2007, 9). In his research, Prior uses information about when certain areas of the country received cable television and compares it to voter turnout in those areas. It is the mere presence of cable and the choice to access it that is important. A change in this media environment that allows more choice gives voters the opportunity to self-select media that rarely, if ever, includes news and political content. This, in turn, changes the mix of who goes to the polls. This is driven by consumption choices which are voluntary. Further, Prior argues that these changes are due to the media environment and content choices, not by any lack of faith in the news media or elections. He found that as news viewership declined during this period of an expansion in media choice, faith in government and elections remained relatively steady. "The 'inadvertent audience' 
is becoming an anachronism. And if that is true, then the very argument at the core of the Downsian by-product learning is aging fast" (Prior 2007, 31).

This self-selection of entertainment versus news preference, he concludes, is the best predictor of the whether they will turn out to vote. News consumers vote and entertainment viewers do not. Gainous and Wagner (2014) argue this to be true for social media as well. However, Prior's study was completed before the explosive growth of social media, an additional media channel capable of delivering news and entertainment, social media may provide accidental news exposure for entertainment choosers and affect the likelihood they vote. The latest referenced work in his book is from 2006 and the book itself was published in 2007. Some research since the Prior study has supported the idea of social media as a source of accidental news, even from viewpoints with which one might disagree (Bakshy et al. 2012; Bimber et al. 2014; Feezell 2017; Gentzkow and Shapiro 2011; Gil de Zúñiga, Jung, and Valenzuela 2012; Kim 2011; Ksiazek, Malthouse, and Webster 2010; Mitchell et al. 2013). In fact, in her research regarding the agenda-setting potential of news via social media, Feezell (2017) concludes that "it is likely that social media are able to subvert selective avoidance and convey a modicum of political information to the uninterested" (Feezell 2017, 10). Understanding media environments and their effect on political decisions, according to Prior (2007), is going to be one of the most important factors in understanding American politics.

\section{Conclusion}


Understanding the relationship between social media use and the likelihood of voting is important. Voting is a key component of democracy and consuming political information and news from traditional media sources has been shown to increase participation. It is easy to see why people would assume a new source like social media may act in a similar manner. That relationship, however, is unclear. There are, of course, differences between social media and traditional news media. Social media, by design, encourages interaction between users, while the traditional news media tends to be one direction, with limited opportunities for audience members to interact with stories. Further, social media reduces the gatekeeping function that traditional news media controlled by allowing any user to share and promote content of any kind. In addition, there may be differences in how an individual processes messages from social media versus traditional news media based on length and the amount of attention a person pays to social media content.

As outlined in this review of literature on the topic, results examining the relationship between social media use and political participation have been mixed. Some studies have found a positive relationship between the use of social media and political participation, including civic activism like contacting politicians and signing petitions. A few studies have found this relationship to exist with turning out to vote as well, which is the specific interest of this dissertation. Several other studies, however, have not found this relationship. There are several possible explanations for these mixed results, including the nature of the studies, who they surveyed, and how they measured political participation. The 
young age of social media platforms and how the use has grown over the short time they have existed may also help explain the differences. As adoption grows, the relationship between social media use and politics may change. Finally, the addition of social media to the overall media environment provides many new ways for individuals to self-select content based on preference for news or entertainment. Prior's $(2005,2007)$ examination of the relationship between content preference and political knowledge and turnout occurred prior to this explosive growth. The relationship between social media and political participation, then, is still not clear.

Since increased concerns from the 2016 election over the effect of fake news, Twitter bots, Russian financed advertising on Facebook, and even President Trump's unconventional use of Twitter, hinge on there being a relationship between exposure to information from social media and election outcomes, examining the relationship is important. The lack of a relationship does not make these issues less important overall, but it puts them in proper context and provides us with information for additional study of these topics. Althought this dissertation does not address these issues from the 2016 election directly, it does provide important context to help us undertand them. It also informs the next steps in examination of these subjects. 


\section{Chapter 3: The Social Media User and Traditional News User Compared}

The primary goal of this dissertation is to better understand the relationship between social media, news and political information, and the key political behavior of voting. A first step in understanding this question is looking at similarities and differences between those who prefer social media, those who prefer traditional media news sources, and those who prefer both equally. Because a key component to forming political opinion and participating in politics is information about government and politics (Gil de Zúñiga, Molyneux, and Zheng 2014; Luskin 1990; Popkin 1994; Prior 2007; Zaller 1992), understanding if social media can provide this information is important. While the connection between information from traditional media and political participation and opinion is clear, research into a connection for social media is mixed (Bimber et al. 2014; Broockman and Green 2014; Delli Carpini and Keeter 1996; Dimitrova and Bystrom 2013; Gainous and Wagner 2014; Gentzkow 2006; Gil de Zúñiga, Jung, and Valenzuela 2012; Green and Gerber 2015; Kushin and Yamamoto 2010; Popkin 1994; Prior 2005, 2007; Smets and van Ham 2013; Towner 2013). Further, some argue that expanding the media environment leads to a greater ability for people to self-select out of receiving news and political information altogether, and this leads to greater polarization (Prior 2007; Gentzkow 2006).

This chapter asks: Are there differences in demographics as well as political attitudes and behaviors based on which media source someone prefers? After outlining how the sample was divided into categories of preferred media, 
the chapter looks at two specific areas to examine this question. First, it looks at whether demographics, like age, sex, and education level, are related to which media source is preferred. Second, it examines whether there may be a relationship between the choice of preferred media and political attitudes and behaviors, including political knowledge, trust in government, civic engagement, party identification and partisanship, and voting habits. Examining these groups will help us better understand social media and traditional media consumers. It will also lay the groundwork for the two studies that follow in Chapter 4 and Chapter 5.

\section{Data and Methods}

Data for this project comes from the 2016 Time Series Study from the American National Election Studies (ANES). This is the $30^{\text {th }}$ study ANES has conducted of Presidential elections since 1948. The sample was selected from the population of U.S. citizens age 18 or older using probability sampling. The survey consists of a pre-election interview conducted during the two months before the November election, and a post-election interview in the two months after the election. The interviews were conducted both face-to-face and via an Internet questionnaire. For the face-to-face mode, the sample was addressbased with in-person recruitment and interviews. For the Internet mode, it was primarily address-based sample and mail recruitment, but also included some random-digit dialing telephone sampling and recruitment and Internet interviews. To improve the accuracy of the significance tests as well as make the sample 
nationally representative, the Complex Sample package in SPSS was utilized. This approach uses weights, stratum and the primary sample unit to create an analysis plan file used during data analysis.

\section{Grouping By Preferred Media Source}

Respondents to the 2016 ANES were broken into three groups: Those who prefer social media; those who prefer traditional news media; and those who consume each equally. Two questions from the survey were utilized. The first question asked respondents, "During a typical week, how many days do you use social media such as Twitter or Facebook?" Respondents could answer from zero up to seven days. The second question asked respondents, "During a typical week, how many days do you watch, read, or listen to news on TV, radio, printed newspapers, or the Internet, not including sports?" Again, respondents could answer from zero up to seven days. It is important to point out the difference in how these questions were asked. The social media use question asks generally about any social media use. The traditional news media question asks specifically about using these sources to access news. Thus, this chapter is comparing a person's preference for social media in general to their preference for traditional news media.

Using these questions, a new variable was computed and named "Media Preference Score." This was determined by taking the number of days per week the respondent indicated they used social media and subtracting the number of days they used traditional news media. 


\section{Days Per Week Social Media Use <MINUS> \\ Days Per Week Traditional News Media Use = \\ Media Preference Score}

Based on the "Media Preference Score", another variable was created, "Preferred Media Group." If the respondent's score was a positive number, the respondent was coded as "Prefers Social Media." If it was negative, they were coded as "Prefers Traditional News Media." If the score was zero they were coded as "Prefers Both Equally." Table 3.1 shows the unweighted frequencies as well as the frequencies for each group with weighting applied to make the sample nationally representative. One thing that is immediately clear is that traditional news media is still the most popular. Those that prefer traditional news media to social media outnumber the other groups by approximately 2 -to- 1 . When one considers that the 'Prefers Both Equally' category also includes traditional news media sources, it becomes more clear. Still, those that make up the 'Prefers Social Media' group amount to 26.8 percent of the total weighted sample.

\begin{tabular}{|lc|c|}
\hline \multicolumn{3}{|c|}{ Table 3.1: Preferred Media Groups } \\
\hline Preferred Media Group & \# of Respondents \\
Unweighted & Weighted \\
\hline Social Media & 1020 & 1123 \\
Traditional News Media & 2090 & 2011 \\
Both Equally & 1083 & 1063 \\
TOTAL & 4193 & 4197 \\
\hline 2016 American National Election Study \\
\hline
\end{tabular}

One initial concern regarding the final category - preferring both equally was the potential for some respondents to have answered 'zero' for both the 
number of days consuming social media and 'zero' for the number of days consuming traditional news media. These individuals do not consume social media or traditional news media at all, and thus may be different from an individual who consumes five days of each, for example. Yet both would also be placed in the category "Prefers Both Equally." A crosstab analysis was run to determine how many respondents answered 'zero' for both social media use and traditional news media use (See Table 3.2). Based on this analysis, only 21 out of the 1,083 respondents, less than two percent, fall into this category. These cases were, therefore, left in the sample for the subsequent analysis. An additional note of interest about Table 3.2: The second largest single cell on the table indicates that 767 respondents completely shun social media and only get information from traditional news media, while the largest group access both traditional news media and social media every single day of the week (930 respondents). 


\begin{tabular}{|c|c|c|c|c|c|c|c|c|c|c|}
\hline \multicolumn{11}{|c|}{$\begin{array}{l}\text { Table 3.2: Days Per Week Using Social Media by } \\
\text { Days Per Week Using Traditional News Media }\end{array}$} \\
\hline \multicolumn{11}{|c|}{ Days per week using traditional news media } \\
\hline \multirow{9}{*}{$\begin{array}{l}\text { Days per } \\
\text { week } \\
\text { using } \\
\text { social } \\
\text { media }\end{array}$} & & 0 & 1 & 2 & 3 & 4 & 5 & 6 & 7 & TOTAL \\
\hline & 0 & 21 & 45 & 44 & 63 & 63 & 157 & 98 & 767 & 1258 \\
\hline & 1 & 4 & 19 & 5 & 15 & 17 & 34 & 21 & 119 & 234 \\
\hline & 2 & 2 & 11 & 11 & 15 & 12 & 21 & 15 & 75 & 162 \\
\hline & 3 & 3 & 13 & 23 & 25 & 20 & 33 & 16 & 89 & 222 \\
\hline & 4 & 2 & 8 & 9 & 15 & 11 & 31 & 17 & 76 & 169 \\
\hline & 5 & 1 & 10 & 22 & 19 & 24 & 45 & 20 & 126 & 267 \\
\hline & 6 & 3 & 6 & 7 & 11 & 20 & 35 & 21 & 76 & 179 \\
\hline & 7 & 32 & 72 & 90 & 116 & 96 & 273 & 93 & 930 & 1702 \\
\hline Total & & 68 & 184 & 211 & 279 & 263 & 629 & 301 & 2258 & 4193 \\
\hline
\end{tabular}

\section{Media Preference and Demographics}

Age

Age is an important demographic to examine for two reasons. First, previous research has shown that social media use, especially for news and political information, is related to the age of the individual. Regarding the 2016 Presidential Election, for example, Pew Research Center found in January of 2016 that social media was the top source of information for those ages 18 to 29 (Gottfried et al. 2016). Thirty-five percent of respondents in that age group indicated it was the most helpful source of information. Social media slipped to third on the list for those age 30-49 while it was near the bottom of the list for those over 50-years-old (Gottfried et al. 2016). More recent work from Pew Research Center, however, shows that social media is increasing as a news source among those over the age of 50. A study published in September of 2017 
noted a 10 percent increase - from 45 percent to 55 percent - of those 50 years or older who get news from social media sites, while those 18-49 remained constant at 78 percent (Shearer and Gottfried 2017).

We should expect, therefore, that respondents to the ANES 2016 study would show a similar breakdown based on age and preferred media group, and this is the case. To examine this variable, a new variable was created to place respondents into age groups based on decades. As Table 3.3 indicates, among respondents $18-29$ years old, the majority (51.6 percent) fall into the 'Prefers Social Media' group, with 'Prefers Traditional News Media' (24.9 percent) and 'Prefers Both Equally' (23.4 percent) a distant second and third respectively. As one looks across the row for 'Prefers Social Media' in Table 3.3, the trend expected by previous research holds true as well, with the percentage of each age group getting smaller the older the group. In a similar manner, the percentage in the "Prefers Traditional News Media" category for each group increases as the groups get older. 
Table 3.3: Preferred Media Group by Age Group (\%)

\begin{tabular}{|c|c|c|c|c|c|c|}
\hline \multirow{2}{*}{$\begin{array}{c}\text { Preferred } \\
\text { Media Group }\end{array}$} & \multicolumn{6}{|c|}{ Age } \\
\hline & $18-29$ & $30-39$ & $40-49$ & $50-59$ & $60-69$ & $70+$ \\
\hline Social Media & $\begin{array}{l}51.6 \\
(290)\end{array}$ & $\begin{array}{l}36.8 \\
(246)\end{array}$ & $\begin{array}{l}25.7 \\
(133)\end{array}$ & $\begin{array}{l}14.4 \\
(93)\end{array}$ & $\begin{array}{l}10.7 \\
(66)\end{array}$ & $\begin{array}{l}4.3 \\
(21)\end{array}$ \\
\hline $\begin{array}{l}\text { Traditional } \\
\text { News Media }\end{array}$ & $\begin{array}{l}24.9 \\
(130)\end{array}$ & $\begin{array}{l}33.7 \\
(209)\end{array}$ & $\begin{array}{l}42.7 \\
(219)\end{array}$ & $\begin{array}{l}59.1 \\
(392)\end{array}$ & $\begin{array}{l}64.1 \\
(413)\end{array}$ & $\begin{array}{l}76.2 \\
(362)\end{array}$ \\
\hline Both Equally & $\begin{array}{l}23.4 \\
(142)\end{array}$ & $\begin{array}{l}29.5 \\
(199)\end{array}$ & $\begin{array}{l}31.6 \\
(164)\end{array}$ & $\begin{array}{c}26.5 \\
(176)\end{array}$ & $\begin{array}{c}25.3 \\
(163)\end{array}$ & $\begin{array}{l}19.6 \\
(90)\end{array}$ \\
\hline TOTAL & 99.9 & 100 & 100 & 100 & 100.1 & 100 \\
\hline$N$ & 562 & 654 & 516 & 661 & 642 & 473 \\
\hline
\end{tabular}

\section{Education}

Education is an additional area where we might expect to see some difference in preferred media. For example, Pew Research Center found a strong use of all types of TV news (cable, network and local) by those with a high school education or less. Sixty-five percent watched local TV news, 59 percent cable news, and 55 percent network news. College graduates, on the other hand, used these TV sources less and showed a preference for Internet news sites and apps. Only 45 percent of college graduates watched local TV news, 51 percent cable news, and 42 percent network news. Among college graduates, though, 65 percent indicated they utilized news websites or apps (Gottfried et al. 2016). Education level is also of interest because it has been found to be related to 
voter turnout. Generally speaking, as an individual's education level increases so does the likelihood they will turn out to vote (Leighly and Vedlitz 1999; Smets and van Ham 2013).

The education level variable in the ANES data was collapsed into seven groups from an original list of 13. This is illustrated by Tables 3.4 and 3.5. Although not as pronounced as within the age group differences, there is still a general trend related to the respondent's education level and their use of social media. As education level increases, the percentage of those that prefer social media for each age group decreases. Of particular interest is the sharp drop that occurs once an individual completes any college degree. For those with some college or less, but who have not completed a degree, 30.2 percent prefer social media, with this percentage dropping to 24.9 percent for those with an Associates Degree and 24.2 percent if one has a Bachelor Degree. Unlike age, however, in no single education group does 'Prefers Social Media' have a plurality, with traditional news media being the most preferred for all education groups. 
Table 3.4: Preferred Media Group by Education Level: No College Degree (\%)

\begin{tabular}{|c|c|c|c|}
\hline \multirow[b]{2}{*}{$\begin{array}{c}\text { Preferred } \\
\text { Media Group }\end{array}$} & \multicolumn{3}{|c|}{ Education Level } \\
\hline & $\begin{array}{l}\text { No High } \\
\text { School } \\
\text { Diploma }\end{array}$ & $\begin{array}{c}\text { H.S. } \\
\text { Diploma } \\
\text { or } \\
\text { G.E.D. }\end{array}$ & $\begin{array}{l}\text { Some } \\
\text { College }\end{array}$ \\
\hline Social Media & $\begin{array}{l}29.2 \\
(66)\end{array}$ & $\begin{array}{l}30.3 \\
(228)\end{array}$ & $\begin{array}{l}30.2 \\
(237)\end{array}$ \\
\hline $\begin{array}{l}\text { Traditional } \\
\text { News Media }\end{array}$ & $\begin{array}{c}50.4 \\
(149)\end{array}$ & $\begin{array}{l}48.6 \\
(401)\end{array}$ & $\begin{array}{l}41.8 \\
(402)\end{array}$ \\
\hline Both Equally & $\begin{array}{l}20.4 \\
(52)\end{array}$ & $\begin{array}{l}21.1 \\
(167)\end{array}$ & $\begin{array}{l}28.0 \\
(248)\end{array}$ \\
\hline TOTAL & 100 & 100 & 100 \\
\hline$N$ & 267 & 796 & 887 \\
\hline \multicolumn{4}{|c|}{$\begin{array}{l}\text { Pearson's Chi-Square }=66.26,9.59 \mathrm{~d}(\mathrm{p}< \\
.000) \text {; Test of significance is for complete } \\
\text { crosstabulation between Preferred Media } \\
\text { Group and Education Level; Percentages } \\
\text { based on complex samples plan; Unweighted } \\
\text { count in parentheses; } 2016 \text { American National } \\
\text { Election Study }\end{array}$} \\
\hline
\end{tabular}




\begin{tabular}{|lcccc|}
\hline \multirow{4}{*}{$\begin{array}{c}\text { Table 3.5: Preferred Media Group by Education Level: } \\
\text { Associates Degree or Higher (\%) }\end{array}$} \\
\hline $\begin{array}{c}\text { Preferred } \\
\text { Media Group }\end{array}$ & $\begin{array}{c}\text { Education Level } \\
\text { Associates } \\
\text { Degree }\end{array}$ & $\begin{array}{c}\text { Bachelor } \\
\text { Degree }\end{array}$ & $\begin{array}{c}\text { Masters } \\
\text { Degree }\end{array}$ & $\begin{array}{c}\text { Doctorate } \\
\text { Degree }\end{array}$ \\
\hline Social Media & 24.9 & 24.2 & 20.3 & 10.6 \\
& $(144)$ & $(220)$ & $(98)$ & $(20)$ \\
Traditional & 48.2 & 48.5 & 48.4 & 62.4 \\
News Media & $(286)$ & $(467)$ & $(251)$ & $(111)$ \\
& & & 31.4 & 27 \\
Both Equally & 27 & 27.2 & $(139)$ & $(48)$ \\
\cline { 2 - 5 } & $(164)$ & $(258)$ & 100.1 & 100 \\
TOTAL & 100.1 & 99.9 & 179 \\
$N$ & 594 & 945 & 488 & 179 \\
\hline $\begin{array}{l}\text { Pearson's Chi-Square }=66.26,9.59 d \\
\text { significance is for complete crosstabulation between }\end{array}$ \\
$\begin{array}{l}\text { Preferred Media Group and Education Level; Percentages } \\
\text { based on complex samples plan; Unweighted count in } \\
\text { parentheses; 2016 American National Election Study }\end{array}$ \\
\hline
\end{tabular}

\section{Gender}

Previous research has also identified differences in preferred social media platforms based on gender. For example, women tend to use Facebook, Instagram and Snapchat more than men. On the other hand, men tend to use Twitter, YouTube and LinkedIn more (Shearer and Gottfried 2017). With regard to the 2016 Presidential Election, 44 percent of people utilized social media for political information, with men (47 percent) using it slightly more than women (41 percent) (Gottfried et al. 2016).

In our analysis, more women prefer social media to traditional news media, as indicated by Tables 3.6. This is illustrated not just by comparing the "Prefers Social Media" and "Prefers Traditional News Media" groups but also by the "Prefers Both Equally" which shows that females like an equal amount of 
social media in their mix as well. Still, for both sexes, the top preference remains traditional news media. This preference is particularly true for men, where a majority - 55.4 percent - prefer traditional media. For women, only a plurality of 41.2 percent prefer traditional media.

\begin{tabular}{|lcc|}
\hline \multirow{2}{*}{ Table 3.6: Preferred Media Group by Gender (\%) } \\
\hline \multirow{2}{*}{ Preferred Media Group } & \multicolumn{2}{|c|}{ Gender } \\
\cline { 2 - 3 } & Male & Female \\
\hline Social Media & 22.3 & 30.8 \\
& $(378)$ & $(633)$ \\
Traditional News Media & 55.4 & 41.2 \\
& $(1140)$ & $(939)$ \\
Both Equally & 22.3 & 28.0 \\
& $(444)$ & $(1076)$ \\
TOTAL & 100.00 & 100.00 \\
$N$ & 1962 & 2204 \\
\hline Pearson's Chi-Square $=90.280,5.52$ df (p < .000); \\
Percentages based on complex samples plan; \\
Unweighted count in parentheses; 2016 American \\
National Election Study
\end{tabular}

\section{Party Identification}

Finally, we turn to party identification to see if there is a media preference based on this variable. The Pew Research Center has previously identified differences among preferred media based on political party. For example, during the 2016 Presidential Election, they found that Republicans identified cable television news as more helpful than Democrats, while the latter preferred local television news (Gottfried et al. 2016). Democrats also utilized late night comedy shows for political information more than Republicans (Gottfried et al. 2016). 
Overall, social media use for information about the 2016 election was pretty similar across party identification. Forty-one percent of Republicans used social media for information, 44 percent of Democrats, and 48 percent of Independents (Gottfried et al. 2016).

Within party affiliation, our analysis finds a similar breakdown across the thre party groups (see Table 3.7). Within each party group, traditional news media is the most preferred but only reaches a majority for Republicans. Independents and non-affiliated voters show some slight difference from Democrats, Republicans and the Other category as it relates to social media. In the Independents/NAV group, slightly more respondents prefer social media, with nearly one-third of them falling in the "Prefers Social Media" group. This compares with a nearly identical percentage of Democrats (21.4) and Republicans (21.1). Slightly more respondents affiliated with the two major parties indicate a preference for traditional media, with 53.1 percent of Republicans and 49.2 percent of Democrats falling in this group. Independents and non-affiliated voters (44.3 percent) lag behind. 


\begin{tabular}{|c|c|c|c|}
\hline \multicolumn{4}{|c|}{$\begin{array}{l}\text { Table 3.7: Preferred Media Group by Party } \\
\text { Affiliation (\%) }\end{array}$} \\
\hline \multirow{2}{*}{ Preferred Media Group } & \multicolumn{3}{|c|}{ Party Affiliation } \\
\hline & DEM & REP & IND/NAV \\
\hline Social Media & $\begin{array}{l}21.4 \\
(184)\end{array}$ & $\begin{array}{l}21.1 \\
(136)\end{array}$ & $\begin{array}{l}30.9 \\
(118)\end{array}$ \\
\hline Traditional News Media & $\begin{array}{c}49.2 \\
(472)\end{array}$ & $\begin{array}{l}53.1 \\
(364)\end{array}$ & $\begin{array}{l}44.3 \\
(226)\end{array}$ \\
\hline Both Equally & $\begin{array}{c}29.4 \\
(255)\end{array}$ & $\begin{array}{r}25.8 \\
(175) \\
\end{array}$ & $\begin{array}{r}24.9 \\
(117) \\
\end{array}$ \\
\hline TOTAL & 100 & 100 & 100.1 \\
\hline$N$ & 911 & 675 & 461 \\
\hline \multicolumn{4}{|c|}{$\begin{array}{l}\text { Pearson's Chi-Square }=20.87,3.86 \mathrm{~d}(\mathrm{p}<.05) \text {; } \\
\text { Percentages based on complex samples plan; } \\
\text { Unweighted count in parentheses; } 2016 \text { American } \\
\text { National Election Study }\end{array}$} \\
\hline
\end{tabular}

\section{Media Preference and Political Attitudes and Behaviors}

In this section, possible relationships between a respondent's choice of preferred media and political behaviors and attitudes are examined. These include political knowledge, trust in government, and partisanship. It also includes behaviors, like civic engagement, the respondent's intention to vote in the general election, and finally whether the respondent turned out to vote. For example, as discussed in Chapter 2, previous research has found a positive relationship between turning out to vote and both political knowledge and a sense of civic duty. If a respondent's choice of preferred media is related to these factors, we might expect the choice of preferred media to also affect the decision to vote. In addition, looking at each of these factors gives us a better overall 
understanding of any differences between individuals based on their preferred media group.

\section{Political Knowledge}

According to past research, political knowledge is one of the most important factors affecting voter turnout. Further, consumption of news and information from traditional media is one way that individuals become more knowledgeable about government (Delli Carpini and Keeter 1997; Downs 1957; Prior 2005, 2007; Manin, Przeworski, and Stokes 1999). Understanding the relationship between preferred media group and political knowledge, then, is an important first step to examining the relationship between social media and turning out to vote.

To measure political knowledge, a new variable was created by summing the correct results from seven questions related to U.S. government and politics. The questions included: how many years are in a U.S. Senate term; which federal budget line item is the lowest among foreign aid, Medicare, national defense, and Social Security; which party has the most members in the U.S. House; which party has most members in the U.S. Senate; which office Joe Biden holds; which office Paul Ryan holds; and who John Roberts is (See Appendix A). Each respondent has a score from zero to seven based on these results. As Table 3.8 indicates, those respondents who included more traditional media in their consumption diet scored higher than those preferring social media. The "Prefers Traditional News Media" group and the "Prefers Both Equally" 
demonstrate a similar pattern of scores on the political knowledge variable. This is particularly clear looking first at the low end of the scale, specifically those who only answered one question correctly. Within the "Prefers Social Media" group, 14.1 percent answered one out of seven correctly, while the percent drops dramatically for those in the other two groups. In the same way, at the other end of the scale, only 6.0 percent of those with more social media in their diet answered six out of seven question correctly. The percentage increases to 12.4 percent for those with more traditional media consumption and 13.3 percent for those who prefer both equally. 


\begin{tabular}{|lccc|}
\hline \multicolumn{4}{|c|}{ Table 3.8: Political Knowledge Score by } \\
Preferred Media Group (\%)
\end{tabular}

\section{Trust}

Bode and Dalrymple (2014) found that Twitter users are less trusting of the mainstream media. Might this distrust extend to another institution, the government? If so, it could influence voting behavior. Hetherington (Hetherington 
1999) found that the level of trust a voter has in government can affect their vote decision. Those more distrustful of government are more open to voting for challengers or third parties. Additional work in a representative democracy, but not the United States, suggests that social media may be able to help increase online civic participation, and that engaging citizens in online civic activities can foster greater trust in government institutions (Warren, Sulaiman, and Jaafar 2014). Respondents to the 2016 ANES were asked the following question about their trust in government: "How often can you trust the federal government in Washington to do what is right?" As illustrated in Tables 3.9, people were able to answer "Always"; "Most of the time"; "About half the time"; "Some of the time"; and "Never." This question was used to examine the relationship between trust in government and the respondent's media preference. Looking at the results of the cross-tabulation between Trust in Government and Preferred Media Group, the first outcome that is most obvious is overall trust in government across all groups is quite low. In addition, there is no clear difference based on which media type is preferred. As Table 3.9 indicates, the percentage for each preferred media group is similar for each level of trust in government. Perhaps most importantly, this is the only variable examined that was not statistically significant as it relates to preferred media groups. 


\begin{tabular}{|c|c|c|c|}
\hline \multicolumn{4}{|c|}{$\begin{array}{l}\text { Table 3.9: Trust in Government by } \\
\text { Preferred Media Group (\%) }\end{array}$} \\
\hline \multirow[b]{2}{*}{ Trust in Government } & \multicolumn{3}{|c|}{ Preferred Media Group } \\
\hline & $\begin{array}{l}\text { Social } \\
\text { Media }\end{array}$ & $\begin{array}{l}\text { Traditional } \\
\text { News Media }\end{array}$ & $\begin{array}{l}\text { Both } \\
\text { Equally }\end{array}$ \\
\hline Always & $\begin{array}{l}0.8 \\
(12)\end{array}$ & $\begin{array}{l}2.4 \\
(37)\end{array}$ & $\begin{array}{l}2.2 \\
(16)\end{array}$ \\
\hline \multirow[t]{2}{*}{ Most of the time } & 9.5 & 10.5 & 8.0 \\
\hline & $\begin{array}{l}(98) \\
35.1\end{array}$ & $\begin{array}{l}(235) \\
30.4\end{array}$ & $\begin{array}{l}(88) \\
34.6\end{array}$ \\
\hline About half the time & (356) & $(640)$ & (365) \\
\hline \multirow[t]{2}{*}{ Some of the time } & 42.8 & 44.0 & 42.0 \\
\hline & $(435)$ & (895) & (471) \\
\hline \multirow[t]{2}{*}{ Never } & 11.7 & 12.8 & 13.1 \\
\hline & (111) & (278) & (142) \\
\hline TOTAL & 99.9 & 100.1 & 99.9 \\
\hline$N$ & 1012 & 2085 & 1082 \\
\hline \multicolumn{4}{|c|}{$\begin{array}{l}\text { Pearson's Chi-Square }=21.506,1.796 d(p<.10) \text {; Percentages } \\
\text { based on complex samples plan; Unweighted counts in } \\
\text { parentheses; } 2016 \text { American National Election Study }\end{array}$} \\
\hline
\end{tabular}

\section{Civic Engagement}

Brady, Verba and Scholzman (1995) argue that individuals can learn civic skills from non-political engagement in their communities. They included this in their 'resource model' of political participation, an attempt to improve turnout models beyond simply variables like education and financial resources. Including civic engagement in this analysis, then, gives a more rounded description of those in the different preferred media groups in an area of interest to political scientists. Using three questions from the 2016 ANES related to involvement in the community, a new variable - Civic Engagement - was created. The questions covered working with others on an issue in your community, attending 
a meeting about an issue related to your local schools or community, and devoting time to volunteer work. Each respondent received a score from zero to three which is the sum of their positive answer to each question. See Appendix B for the specific questions in this scale.

Results show that those with more traditional news media in their mix of media consumption tend to be more involved in civic activities in their communities. (See Table 3.10) Overall, however, civic engagement based on these three questions is low. Across the three groups, 40 percent to 47.8 percent of respondents had zero civic engagement.

\begin{tabular}{|lccc|}
\hline \multicolumn{4}{c}{$\begin{array}{c}\text { Table 3.10: Civic Engagement Score by } \\
\text { Preferred Media Group (\%) }\end{array}$} \\
\cline { 2 - 4 } Civic Engagement Score & \multicolumn{3}{c|}{ Preferred Media Group } \\
\cline { 2 - 4 } & $\begin{array}{c}\text { Social } \\
\text { Media }\end{array}$ & $\begin{array}{c}\text { Traditional } \\
\text { News Media }\end{array}$ & $\begin{array}{c}\text { Both } \\
\text { Equally }\end{array}$ \\
\hline Zero & 46.6 & 47.8 & 40.9 \\
& $(392)$ & $(797)$ & $(369)$ \\
One & 25.4 & 22.0 & 23.7 \\
& $(216)$ & $(393)$ & $(230)$ \\
Two & 13.8 & 13.5 & 13.5 \\
& $(129)$ & $(255)$ & $(140)$ \\
Three & 14.2 & 16.8 & 22.0 \\
& $(121)$ & $(335)$ & $(210)$ \\
TOTAL & 100 & 100.1 & 100.1 \\
Mean & 0.96 & 1.0 & 1.2 \\
$N$ & 858 & 1780 & 949 \\
\hline Pearson's Chi-Square $=2$ 26.924, 3.012d (p<.05); Percentages \\
based on complex samples plan; Unweighted counts in \\
parentheses; 2016 American National Election Study \\
\hline
\end{tabular}




\section{Partisanship}

Partisanship as it relates to media choice is important to examine for a several reasons. First, Prior $(2005,2007)$ found that those preferring news over entertainment tend to be more partisan. These individuals also turn out to vote more than those preferring entertainment. He credits this for the increase in polarization in the electorate. A second reason is that increased polarization has had an effect beyond just loyal party members. Smidt (2017) found that independents "are as aware of party differences and as loyal in their party support as strong partisans were prior to polarization" (379). Polarization has allowed independents to behave like partisans without actually joining a political party. This has led, he argues, to a decline in the traditional idea of the "floating voter" that may reward or punish a politician or party in the short term, eliminating a moderating factor in American politics. The final reason relates to how messages from social media may be analyzed by the receiver. As discussed in Chapter 2, several researchers have identified dual process models for information processing (Kahneman 2011; Petty and Cacioppo 1986; Tversky and Kahneman 1975, 1981). One process is quicker and relies on cues and heuristics. The other is more slow, analytic and rational. An important heuristic in the processing of political messages is party identification and partisanship. If social media messages are being evaluated by the faster process, individuals may be relying on the party heuristic. Comparing preferred media groups to party (see above) and partisanship preferences, then, is useful. In the 2016 ANES, 
those identifying as Republican or Democrat were asked, "Would you call yourself a strong [Democrat/Republican]?"

The results indicate that those preferring social media are less partisan than those who prefer traditional news media and those who prefer both equally. As Table 3.11 indicates, this difference is quite large. Less than 50 percent of those preferring social media consider themselves strong Democrats or Republicans. On the other hand, among those in the other categories, which include more traditional news media, over 60 percent consider themselves strong Republicans or Democrats. This heavier reliance on traditional news sources versus social media and the relationship with partisanship is similar to Prior's original contention that those who prefer news to entertainment tend to be more partisan. A preference for news may be an indicator of increased partisanship.

\begin{tabular}{|c|c|c|c|}
\hline \multirow[b]{2}{*}{$\begin{array}{l}\text { "Would you call yourself a strong } \\
\text { [Democrat / Republican]" }\end{array}$} & \multicolumn{3}{|c|}{ Preferred Media Group } \\
\hline & $\begin{array}{l}\text { Social } \\
\text { Media }\end{array}$ & $\begin{array}{l}\text { Traditional } \\
\text { News Media }\end{array}$ & $\begin{array}{l}\text { Both } \\
\text { Equally }\end{array}$ \\
\hline Yes & $\begin{array}{l}49.3 \\
(291)\end{array}$ & $\begin{array}{l}63.7 \\
(850)\end{array}$ & $\begin{array}{l}61.3 \\
(444)\end{array}$ \\
\hline No & $\begin{array}{l}50.7 \\
(302)\end{array}$ & $\begin{array}{l}36.3 \\
(479)\end{array}$ & $\begin{array}{l}38.7 \\
(270)\end{array}$ \\
\hline TOTAL & 100 & 100 & 100 \\
\hline$N$ & 593 & 1329 & 714 \\
\hline
\end{tabular}




\section{Vote Intention and Turnout}

Finally, the primary research question of this dissertation is the relationship between social media and whether an individual turns out to vote. Comparing preferred media groups to vote intention and to whether the respondent reported turning out to vote gives us our first look at this question. As Table 3.12 indicates, compared to those who prefer social media, a higher percentage of those who prefer traditional news media, as well as those who prefer both traditional news and social media equally, expressed an intention to vote in the 2016 Presidential Election. At the same time, 89 percent of those preferring social media did say they intended to vote in the election.

\begin{tabular}{|lccc|}
\hline \multicolumn{4}{|c|}{ Table 3.12: Vote Intention by Preferred Media Group (\%) } \\
\hline \multirow{2}{*}{$\begin{array}{c}\text { "Does respondent intend to vote for } \\
\text { president?" }\end{array}$} & \multicolumn{3}{c|}{ Preferred Media Group } \\
\cline { 2 - 4 } & $\begin{array}{c}\text { Social } \\
\text { Media }\end{array}$ & $\begin{array}{c}\text { Traditional } \\
\text { News Media }\end{array}$ & $\begin{array}{c}\text { Both } \\
\text { Equally }\end{array}$ \\
\hline Yes & 89 & 95.3 & 94 \\
& $(767)$ & $(1740)$ & $(919)$ \\
No & 11 & 4.7 & 6 \\
& $(88)$ & $(83)$ & $(47)$ \\
TOTAL & 100 & 100 & 100 \\
$N$ & 855 & 1823 & 966 \\
\hline $\begin{array}{l}\text { Pearson's Chi-Square }=39.041,12.521 d \\
\text { complex samples plan; Unweighted counts in parentheses; 2016 American } \\
\text { National Election Study }\end{array}$ \\
\hline
\end{tabular}

Similar to the results for the intention to vote, a higher percentage of respondents in the Prefers Traditional News Media group and the Prefers Both Equally group reported that they actually turned out to vote in the 2016 Presidential Election. As Table 3.13 shows, for these two groups more than 86 
percent indicated that they voted. Among those in the Prefers Social Media group, only 78 percent reported having voted. All three groups, however, did see a drop from the percentage saying they intended to vote and those that reported they cast a ballot. According to the Pew Research Center (DeSilver 2017), approximately 86.8 percent of registered voters turned out in 2016 . However, only about 64 percent of United States citizens who are eligible to vote actually register in the first place. These means that turnout among eligible United States citizens was only approximately 55.7 percent.

\begin{tabular}{|lccc|}
\hline \multicolumn{4}{|c|}{ Table 3.13: Voter Turnout by Preferred Media Group (\%) } \\
\hline \multirow{2}{*}{ "Did respondent vote in 2016?" } & \multicolumn{3}{c|}{ Preferred Media Group } \\
\cline { 2 - 4 } & $\begin{array}{c}\text { Social } \\
\text { Media }\end{array}$ & $\begin{array}{c}\text { Traditional } \\
\text { News Media }\end{array}$ & $\begin{array}{c}\text { Both } \\
\text { Equally }\end{array}$ \\
\hline Yes & 78.0 & 87.6 & 86.6 \\
& $(581)$ & $(1463)$ & $(779)$ \\
No & 22.0 & 12.4 & 13.4 \\
& $(148)$ & $(183)$ & $(111)$ \\
TOTAL & 100 & 100 & 100 \\
$N$ & 729 & 1646 & 890 \\
\hline Pearson's Chi-Square $=40.543,12.753 d$ & $(p<.000) ;$ & Percentages based on \\
complex samples plan; Unweighted counts in parentheses; 2016 American \\
National Election Study
\end{tabular}

\section{Limitations}

There are two limitations to consider regarding the analysis completed above. The first is the differences between the two questions used to create the preferred media groups. The question measuring traditional news media use specifically asks the respondent about news media consumption from these traditional sources. It even goes as far to tell them to exclude sports. Therefore, it 
cues the respondent into thinking about their news consumption. The social media question, on the other hand, asks a more general question about social media use during a typical week. Respondents are not asked to think only about news on social media. So, when considering the results above, keep in mind that those who prefer traditional news media were answering as it relates to news and those preferring social media were considering all of their uses of social media. This, of course, is a general limitation of using data collected by another individual or group versus conducting a new study designed to specifically address the research questions and hypotheses of interest. However, the comparison of the two groups still adds important information to our understanding of media preference and the variables examined in this chapter. People choose where to access information and this choice illustrates the importance they give to each type and source of information.

Second, as outlined in Chapter 2, the approach the ANES uses to measure political knowledge can be problematic. As Gibson and Caldeira (2009) found, open-ended question are not as accurate as closed-ended multiple choice questions. Open-ended questions result in less recall by individuals. These people, however, may have a general idea of the person or institution being asked about that is better captured by using closed-ended multiple choice questions. They suggest, then, that open-ended political knowledge questions should be used for "only the simplest and grossest inferences" (Gibson and Caldeira 2009, 23). 


\section{Conclusion}

What does the examination of these factors in Chapter 3 illuminate about traditional media, social media and the users who prefer them for information? Table 3.25 summarizes the findings for the two main groups. First, it tracks with the trend in other research that younger people prefer social media while a preference for traditional news media increases as the respondents get older. This doesn't mean that there are not older respondents who prefer social media more, but as Table 3.4 indicates, clearly a higher percentage of those in the older decade groups prefer traditional news media. This likely has to do with which media sources they utilized during formative years. Review of the research on use and age during the past decade also illustrates that an increasing number of older Americans are adopting social media as an information source.

\begin{tabular}{|cc|}
\hline \multicolumn{2}{|c|}{ Table 3.14: General Tendencies by Preferred Media Group } \\
\hline Prefers Social Media & Prefers Traditional Media \\
Younger & Older \\
Female & Male \\
College or Less & All Education Levels \\
Party ID: Independent & All Parties, Especially R and D \\
Less Partisan Among R and D & More Partisan Among R and D \\
Political Knowledge: Lower & Political Knowledge: Higher \\
Civic Engagement: Lower & Civic Engagement: Higher \\
Voting Habits: Less & Voting Habits: More \\
\hline
\end{tabular}

Next, females tend to prefer social media more than males, while a high percentage of male respondents preferred traditional news media. In fact, a majority of male respondents preferred traditional news media, while a higher 
percentage but not a majority of females prefer social media. With regard to education, across all levels, traditional news media was preferred by the highest percentage of respondents. This included 50 percent of those without a high school diploma, the second highest percentage among a group behind only those with a doctorate degree. There were clear trends, however, related to social media use. In the education groups with some college or less, the percentage preferring social media was higher. As education completion level increased, the percentage preferring social media decreases. With a fairly consistent percentage preferring traditional news media across all groups, it appears that the decrease in social media preference is related to a shift to preferring both equally.

Party identification and partisanship provide interesting results. A higher percentage of registered Republicans and Democrats prefer traditional news media, although it is also the preferred media group for Independents and nonaffiliated voters but at a lower level. Independent/NAVs, however, show a higher percentage preferring social media than those in the two major parties. Add in the results from partisanship, which is a question only asked of those identifying as part of one of the major political parties, and the results come into focus even more. A higher percentage of those who consider themselves 'strong' Republicans or Democrats prefer traditional news media. Among those preferring social media a lower percentage consider themselves a 'strong' member of their party. In fact, it is nearly identical to the percentage that do not consider themselves strong partisans. In a way, this confirms the results Prior (2005, 
2007) found in his original studies. Those who prefer news and political information tend to be more partisan.

Looking at Political Knowledge, those respondents with more traditional news media in their mix, in this case those preferring traditional news media as well as those preferring both sources equally, score better on the political knowledge measurement. The direction of this relationship is not clear. It may be that more knowledgeable people are naturally interested in traditional news media sources. Another explanation may be that traditional news media sources provide better information as it relates to the questions about government and politics that are part of the political knowledge measurement. The examination of Civic Engagement provides a similar result. It is important to point out that overall, based on the three questions asked about civic engagement, this kind of engagement is low across all groups. However, those with more traditional news media in their preference do participate more that those with a preference for social media.

Finally, vote intention and self-reported turnout in the 2016 General Election favor those who prefer traditional news media or prefer both equally. While all groups said they intended to vote and then did vote at a high rate, the percentage was lower on both measures for those preferring social media. All three groups, in fact, saw a drop between vote intention and reported voter turnout.

Generally speaking, it is possible that many of these habits and attitudes are driven by age. Older generations grew up with traditional news media and 
developed the habit of using it for news and information. That habit appears to have remained, even as new sources have come into the media environment. Knowing that traditional news sources are positively related to political knowledge and participation helps explain the path from traditional news consumption through political knowledge to voter participation. Younger people, on the other hand, have grown up in a media environment that includes social media along with traditional news media. Their consumption habits reflect this. 


\section{Chapter 4: Content Preference and Social Media Use}

As outlined in Chapter 2, political knowledge is an important factor in voter turnout (Delli Carpini and Keeter 1996; Downs 1957; Manin, Przeworski, and Stokes 1999; Prior 2005, 2007). Exposure to political information and news from the media is generally accepted as contributing to political knowledge (Gil de Zúñiga, Molyneux, and Zheng 2014; Luskin 1990; Popkin 1994; Prior 2005, 2007; Zaller 1992). Therefore, political information and knowledge are two of the most important factors affecting voter turnout, with people who are more knowledgeable about government being more likely to vote (Delli Carpini and Keeter 1996; Downs 1957; Manin, Przeworski, and Stokes 1999; Prior 2005, 2007). Prior $(2005,2007)$ argues that the expansion of media choice created by

cable television and the Internet gave individuals the opportunity to avoid political information and the news and self-select primarily entertainment content. This self-selection leads to lower political knowledge and voter turnout for those preferring entertainment. Gentzkow (2006) agrees that the increase in media choices leads to a reduction in knowledge and voter turnout, although he believes it began earlier, with the start of broadcast television. Both agree that expansion of media choice leads to lower political knowledge and voter turnout. Prior's study, however, was completed before access to the Internet became common among American households and before the explosive growth of social media. In fact, part of his study relied on ANES data from the 1996 and 2000 elections, making it approximately 20 years old. This chapter examines whether 
his contention remains true in the age of social media and increased Internet access. This will help better understand the overall research goal of this dissertation, the relationship between social media, news and political information, and voter turnout.

The advent of social media and the increase in access to the Internet since Prior's first studies have the potential to either reinforce the relationship he found between media expansion and knowledge/turnout or provide greater opportunity for accidental exposure to news and information. Internet access at home, for example, has become nearly ubiquitous. According to data from the 2016 ANES, 89 percent of those surveyed had Internet access at home. Media habits related to TV entertainment have also changed. The advent of on-demand viewing via cable television, and the rapid growth of online streaming options like Netflix, Hulu and Amazon, give people even more opportunities to choose entertainment. Add Internet viewing options, like YouTube, Vimeo and social media-based video, and the entertainment choices have become much more numerous since the early part of the century. At the same time, growth in access to the Internet and the advent of social media has also provided greater opportunities to be accidentally exposed to news and political information. Research conducted since Prior $(2005,2007)$ supports social media as a source for such news, including information from differing viewpoints (Bakshy et al. 2012; Bimber et al. 2014; Gentzkow and Shapiro 2011; Gil de Zúñiga, Jung, and Valenzuela 2012; Kim 2011; Ksiazek, Malthouse, and Webster 2010; Mitchell et al. 2013). Studies suggest that even small increases in this kind of content can 
have a positive effect on political participation (Bimber et al 2014; Ksiazek, Malthouse and Webster 2010).

\section{Relative Entertainment Preference}

Prior $(2005,2007)$ examined two hypotheses. First, access to cable television increases the knowledge gap between those that prefer news content and those that prefer entertainment. Second, access to the Internet and cable television increases the turnout gap between people that prefer news and those that prefer entertainment. It is important to note that for Prior the access to cable or the Internet is what is important, not necessarily how much the individual used them. For his research, Prior $(2005,2007)$ created a measurement he calls 'Relative Entertainment Preference' (REP). This measurement is a ratio of the respondent's news and entertainment consumption. He first tested hypotheses related to REP through a series of questions on the News \& Entertainment Survey (N\&E). Data for this panel survey of 2,358 randomly selected people in the United States was collected by Knowledge Networks via the Internet in 2002 and 2003. This method allowed him to ask a robust set of questions about political knowledge, events and institutions. He also collected data about entertainment viewing by asking which of 10 television genres respondents liked best, with each genre description including the specific name of two shows representative of that genre. For example, respondents were asked if they liked "Comedy/Sitcoms like Friends or The Simpsons" (Prior 2005, 580). News was included as one of the 10 genres. This process was repeated three more times 
with the remaining genres from the set and resulted in a list of genre preferences for the individual.

To check his results from the N\&E Study, Prior replicated the study utilizing data from the 1996 and 2000 American National Election Study (ANES) surveys. For this study, news viewing was measured as the average the number of days per week the respondent said they watched local or national news. Entertainment viewing consisted of average exposure to certain entertainment television shows. Each of the ANES studies approached this question slightly differently. In 1996, respondents were asked about their average daily viewing of Jeopardy or Wheel of Fortune as well as Dr. Quinn Medicine Woman (Prior 2005, 2007). For the 2000 survey, it consisted of the "average exposure to Jeopardy, Wheel of Fortune, and 'television talk shows such as Oprah Winfrey, Rosie O’Donnell, or Jerry Springer"' (Prior 2005, 125). Prior expressed concerns over the limited number of shows listed in these questions as well as the absence of questions about specific genres, with the exception being talk shows. He suggested that many people may have underestimated their entertainment preference because the shows they do watch were not specifically mentioned (Prior 2005, 2007).

Based on the answers to these questions, Prior calculated REP as a respondent's total entertainment viewing divided by the sum of their entertainment viewing and news viewing:

\section{REP = Entertainment Viewing / (Entertainment Viewing + News Viewing)}


The other variables of interest were the respondents' access to cable television and access to the Internet. It is important to note that these variables only measured access and not how much the respondent used the Internet or watched cable television. For the dependent variables, Prior measured political knowledge by summing the correct answers on 14 questions related to government, institutions and people. These included questions, for example, about who controlled the U.S. House of Representatives and what job William Rehnquist held. Turnout was self-reported for the U.S. House election (1996 ANES). Prior chose the House election turnout to reduce the likelihood of overreporting. For an unexplained reason, he did not include turnout from the 2000 ANES as a variable.

For his analysis, REP, access to cable television, access to the Internet and the respective interactions between REP and the other two variables, were regressed against political knowledge and whether the respondent voted. Prior found that the interaction of REP and access to cable was in the direction predicted and significant for political knowledge in both 1996 and 2000, and for voter turnout in 1996. Those preferring entertainment scored lower on the political knowledge scale and their turnout was lower. Content preference and access to cable combined to create a gap in knowledge and voter turnout. The results were not significant for the interaction with access to the Internet for either political knowledge in 1996 and 2000 nor turnout in 1996. Prior concludes that this replication supports the findings of the original N\&E Survey and his 
hypotheses about content preferences, political knowledge and voter turnout.

\section{Relative Entertainment Preference In The Social Media Age}

This chapter repeats the Prior study using 2016 data from ANES to see if REP remains the best predictor of political knowledge and voter turnout in the age of social media. For independent variables, it maintains a similar but different measurement for REP, entertainment and news preferences on television. The 2016 ANES survey asked a different type of question about which television entertainment shows and news shows respondents watched regularly. This repeat study maintains similar dependent variables, including political knowledge and voter turnout. It replaces cable access, however, with social media use. Further, because Internet access at home is nearly universal, this independent variable was also dropped from the study. As noted above, 89 percent of survey respondents $(3,790$ out of 4,252$)$ indicated they have Internet access at home. As a comparison, according to Prior (2007) only 62 percent of respondents reporting having access to the Internet in the 2000 ANES study. Due to these differences, it is not possible to complete a pure replication of the original Prior study. Instead, this chapter repeats the study as closely as possible.

Based on the analysis above and support for Prior's original hypotheses, the following two hypotheses are proposed for this research project:

Hypothesis 1: The increase in the media environment due to social media will increase the knowledge gap between those that prefer news and those 
that prefer entertainment.

Hypothesis 2: Likewise, there will be an increase in the voter turnout gap between those that prefer news and those that prefer entertainment.

\section{Data and Methods}

As with Chapter 3, data for this project comes from the 2016 ANES.

Respondents are U.S. citizens age 18 or older and were selected using probability sampling. The survey consists of a pre-election interview completed two months before the November election, and a post-election interview during the two months after the election. Both face-to-face and Internet collection methods were utilized. The Complex Sample package in SPSS was used to improve the accuracy of the significance tests and make the sample nationally representative. To do this, an analysis plan file is created using weights, stratum and the primary sample unit. This plan file is then used with the Complex Samples package when running the analyses.

\section{Measuring Relative Entertainment Preference}

The 2016 ANES included a list of 48 television shows and asked whether the respondent had viewed that show over the past month. The list included 17 news programs and 31 entertainment shows. For each category, 10 shows were selected based on their Nielsen ratings during the 2016-17 television year. By selecting the most popular 10 shows in each category from those presented by 
ANES, the odds are increased that the respondent may have been asked about shows they watched. As discussed above, Prior expressed concern that the questions he utilized to measure REP from the 1996 and 2000 ANES may have limited the measurement. This approach, including more specific television shows and utilizing the most popular shows, should help improve measurement of REP. Entertainment viewing is operationalized as the average number of TV programs from a list of 10 popular entertainment shows that the respondent recalls watching during the past month (Table 4.1). For news viewing, it is the average number of news programs from a list of the 10 most popular (Table 4.2).

\begin{tabular}{|c|}
\hline $\begin{array}{c}\text { Table 4.1: Top Ten Entertainment TV Shows from the } \\
\text { American National Election Study }\end{array}$ \\
\hline $\begin{array}{c}\text { Sunday Night Football } \\
\text { Big Bang Theory } \\
\text { NCIS } \\
\text { Blue Bloods } \\
60 \text { Minutes } \\
\text { Dancing With The Stars } \\
\text { The Voice } \\
\text { Hawaii Five-O } \\
\text { Empire } \\
\text { Madam Secretary }\end{array}$ \\
\hline
\end{tabular}




\begin{tabular}{|c|}
\hline $\begin{array}{c}\text { Table 4.2: Top Ten News TV Shows from the } \\
\text { 2016 American National Election Study }\end{array}$ \\
\hline NBC Nightly News w/Lester Holt \\
ABC News w/David Muir \\
CBS News w/Scott Pelley \\
CBS Face the Nation \\
O'Reilly Factor \\
NBC Meet the Press \\
The Kelly File \\
Hannity \\
Rachel Maddow Show \\
Anderson Cooper 360 \\
\hline
\end{tabular}

Based on the respondent's score on these entertainment and news variables, certain cases were dropped from the analysis. Since an REP score is dependent on the individual consuming entertainment and news content, cases were dropped for those respondents who scored zero on both the entertainment and news viewing variables. Those who scored zero on entertainment but a score greater than zero on news were retained, since they expressed a clear preference for news. In a similar way, respondents who scored more than zero on entertainment but were zero on news were also retained.

In addition to REP, the primary independent variable of interest is use of social media. For use of social media, the ANES variable asking how many days per week the respondent used social media (also utilized in Chapters 3 and 4) was recoded so that those that responded zero were coded as $0=$ Does not use social media $(N=1261)$ and those who responded one through seven were coded $1=$ Uses social media $(\mathrm{N}=2935)$. As discussed above, Prior only 
measured if the respondent had access to cable and the Internet, not if they used it or how often. For this study, the use of social media variable was made dichotomous and indicates at least some minimal use. This helps distinguish it from Internet access. After all, someone with Internet access technically also has access to social media if they chose to use those platforms.

\section{Additional Variables Included in the Model}

Several additional variables related to political knowledge and voter turnout were included in the regression models. These include level of education, gender, and age. Education was coded into seven categories based on how much schooling the respondent had completed. Age was separated into six groups by decade, with 18 and 19-year-olds included with those in their 20s, and $70+$ included in one category. See Appendix C for details on variable questions.

\section{Dependent Variables}

The dependent variables are the respondent's political knowledge and whether the respondent turned out to vote. Political knowledge is operationalized as the number of correct answers the respondent provided to seven question related to United States government and politics. These questions covered a range of questions about United States political institutions and individuals; for example if the respondent could recall what office Paul Ryan holds, which party has the most members in each chamber of Congress, and which federal programs the government spends the most money on. (See Appendix A) 
Voter turnout is a summary variable in ANES that indicates whether the respondent voted in 2016 or did not vote in 2016 . It is based on questions asked both pre-election, for those who voted absentee or other pre-election day methods, as well as post-election questions about turnout. For example, respondents were asked which statement best described them as it relates to voting in the election: "I did not vote (in the election this November)"; "I thought about voting this time, but didn't"; "I usually vote, but didn't this time"; "I am sure I voted." Based on the recorded results for each of these, ANES collapsed the responses into two variables, "Did not vote in 2016" and "Voted in 2016." For this study, this variable was recoded to be dichotomous with those who did not vote coded $0(\mathrm{~N}=444)$ and those who voted coded $1(\mathrm{~N}=2887)$.

\section{Analytic Plan}

The Results section begins with descriptive statistics on all variables used in the study. Both political knowledge and voter turnout were regressed on use of social media, and the interaction between REP and the use of social media. As indicated above, additional variables related to political knowledge were added to the model. Linear regression models show whether political knowledge varied depending on whether the respondent used social media, their content

preference (REP), and the interaction between REP these two variables. Further, logistic regression models examine whether voter turnout is related to social media use, along with REP and its interaction with social media use.

\section{Results}




\begin{tabular}{|c|c|c|c|}
\hline \multicolumn{4}{|c|}{$\begin{array}{c}\text { Table 4.3: Descriptive Statistics } \\
\text { Internet Access, Social Media Use, Voter Turnout }\end{array}$} \\
\hline & Yes & No & Total \\
\hline Internet Access & 3790 & 462 & 4252 \\
\hline Social Media Use & 2935 & 1261 & 4196 \\
\hline Voted in 2016 & 2887 & 444 & 3331 \\
\hline
\end{tabular}

\begin{tabular}{|lccc|}
\hline \multicolumn{4}{|c|}{$\begin{array}{c}\text { Table 4.4: Descriptive Statistics } \\
\text { Relative Entertainment Preference }\end{array}$} \\
\hline \multirow{3}{*}{$\begin{array}{l}\text { Relative Entertainment } \\
\text { Preference }\end{array}$} & Mean & SD & $\mathrm{N}$ \\
\cline { 2 - 4 } & .635 & .336 & 3212 \\
\hline Unweighted count; American National Election Survey \\
\hline
\end{tabular}

Table 4.5: Descriptive Statistics - Gender

\begin{tabular}{|lccc|}
\hline & Female & Male & Total \\
\cline { 2 - 4 } Gender & 2232 & 1987 & 4219 \\
\hline $\begin{array}{l}\text { Unweighted count; } \\
\text { Survey }\end{array}$ & & \\
\hline
\end{tabular}

\begin{tabular}{|c|c|c|c|}
\hline \multicolumn{4}{|c|}{$\begin{array}{l}\text { Table 4.6: Descriptive Statistics } \\
\text { Political Knowledge Scale }\end{array}$} \\
\hline & Mean & SD & $\mathrm{N}$ \\
\hline Political Knowledge & 3.84 & 1.70 & 3470 \\
\hline
\end{tabular}


Table 4.7: Descriptive Statistics - Age Group

\begin{tabular}{|ccccccc|}
\hline $18-29$ & $30-39$ & $40-49$ & $50-59$ & $60-69$ & $70+$ & TOTAL \\
\hline 652 & 761 & 620 & 781 & 769 & 567 & 4271 \\
\hline
\end{tabular}

Unweighted Count; 2016 American National Election Study

\begin{tabular}{|cccccccc|}
\hline \multicolumn{8}{|c|}{ Table 4.8: Descriptive Statistics - Education Level } \\
\hline $\begin{array}{c}\text { No High } \\
\text { School } \\
\text { Diploma }\end{array} \begin{array}{c}\text { H.S. } \\
\begin{array}{c}\text { Diploma } \\
\text { or } \\
\text { G.E.D. }\end{array}\end{array}$ & $\begin{array}{c}\text { Some } \\
\text { College }\end{array}$ & $\begin{array}{c}\text { Associates } \\
\text { Degree }\end{array}$ & $\begin{array}{c}\text { Bachelor } \\
\text { Degree }\end{array}$ & $\begin{array}{c}\text { Masters } \\
\text { Degree }\end{array}$ & $\begin{array}{c}\text { Doctorate } \\
\text { Degree }\end{array}$ & Total \\
\hline 282 & 810 & 899 & 601 & 955 & 499 & 181 & 4227 \\
\hline Unweighted count; American National Election Survey & & \\
\hline
\end{tabular}

The results for Hypothesis 1 are illustrated in Table 4.9. This hypothesis predicted that the increase in content choices provided by social media would lead to a decrease in knowledge for those who prefer entertainment over news. The results do not support the hypothesis. In fact, for social media use the result was not in the direction predicted, in addition to not being statistically significant. For REP and the interaction between REP and social media use, the results were in the direction predicted but not statistically significant. Among the additional variables, education and age were both statistically significant and 
positively associated with political knowledge. Gender was also statistically significant but had a negative relationship.

\begin{tabular}{|c|c|c|}
\hline \multicolumn{3}{|c|}{$\begin{array}{c}\text { Table 4.9: Linear Regression Estimating } \\
\text { Change in Political Knowledge }\end{array}$} \\
\hline & $\mathrm{B}$ & SE \\
\hline Social Media Use & 0.212 & 0.174 \\
\hline Relative Entertainment Preference & -0.348 & 0.249 \\
\hline REP x Social Media Use & -0.297 & 0.284 \\
\hline Education & $0.337^{\star \star \star}$ & 0.021 \\
\hline Age & $0.182^{\star * *}$ & 0.026 \\
\hline Gender & $-0.545^{\star \star \star}$ & 0.076 \\
\hline
\end{tabular}

\section{Voter Turnout}

The results for Hypothesis 2 are presented in Table 4.10. This hypothesis predicted that use of social media would have a negative effect on turnout for those who prefer entertainment over news. It was not supported. The use of social media was in the direction predicted but was not statistically significant. Similar to the results for political knowledge, the use of social media, REP, and the interaction between REP and social media were not significant. Finally, similar to the results for political knowledge, both education level and age were statistically significant and positively associated with turnout. Unlike political knowledge, gender was not statistically significant. 


\begin{tabular}{|lll|}
\hline \multicolumn{3}{|c|}{$\begin{array}{c}\text { Table 4.10: Logistic Regression Estimating } \\
\text { Odds of Turning Out To Vote }\end{array}$} \\
\hline \multirow{2}{*}{ Social Media Use } & Exp(B) & SE \\
\cline { 2 - 3 } Relative Entertainment Preference & .751 & 0.416 \\
REP $\times$ Social Media Use & .611 & 0.504 \\
Education & 1.246 & 0.566 \\
Age & $1.321^{\star \star *}$ & 0.049 \\
Gender & $1.351^{\star \star *}$ & 0.052 \\
\hline NOTE: $+p<.10,{ }^{*} p<.05,{ }^{* *} p<.01,{ }^{* \star *} p<.001$ \\
\hline
\end{tabular}

\section{Discussion}

In this study, Relative Entertainment Preference (REP) did not predict an individual's political knowledge nor whether they would turn out to vote.

Further, the interaction between REP and the main variable of interest, the use of social media, was also not related to political knowledge and voter turnout. In other words, the increase in the number of options in the media environment did not increase the gap in political knowledge between those who prefer news and those preferring entertainment. In a similar manner, a person's content preference of entertainment versus news was not related to whether the person turned out to vote. There was no support for either hypothesis.

This result does not support the previous findings of Markus Prior (2005, 2007). Prior found that the interaction between a person's content preference (REP) and access to the Internet as well as access to cable, predicted political knowledge and voter turnout. Further, that relationship was negative so that the interaction of REP and access to the Internet or cable had a negative relationship 
with political knowledge and with turning out to vote. Preferring entertainment led to a gap in political knowledge and voting. Since Prior $(2005,2007)$ first completed his studies on content preferences and political knowledge and turnout, there has been an explosive growth in the media environment. The Internet has become a big ecosystem offering more options for news and nonnews content alike. Further, social media became an integral part of most individuals' online activities in some manner. With so many new options in the media environment, there are more opportunities to avoid news and choose entertainment. This should continue to widen the gap between those who prefer entertainment and those preferring news. This was not true in this study as it relates to political knowledge and voter turnout.

In the regression models, the use of social media and content preference did not have a significant effect on knowledge and turnout individually. Nor did the interaction between the two. For social media, this can be viewed as both good and bad. It is good because social media, at this point, is not discouraging political knowledge and turnout. Unlike cable and the Internet in Prior's original study, the interaction between content preference and this variable of interest does not create a greater gap in knowledge and turnout between those preferring entertainment and those who prefer news. On the other hand, social media is not acting like other traditional media sources by providing information that leads to participation.

In a way, the results around social media are consistent with previous research: A mixed bag. As noted in Chapter 2 and briefly in the introduction to 
this chapter, some previous research has found a positive relationship between social media use and political knowledge and participation (Bode et al. 2014; Broockman and Green 2014; Gainous and Wagner 2014; Gil de Zúñiga, Molyneux, and Zheng 2014; Holt et al. 2013; Pasek, more, and Romer 2009; Vitak et al. 2011; Xenos, Vromen, and Loader 2014; Zhang, Seltzer, and Bichard 2013). Other research has not (Broockman and Green 2014; Dimitrova and Bystrom 2013; Green and Gerber 2015; Kushin and Yamamoto 2010). It may be that these newer platforms for information in the media environment need time to be adopted by individuals. Further adoption also encourages content creators to shift content to these new platforms, or find ways to deliver their content in new and interesting ways. Conversely, perhaps these sources, in particular social media, merely act as secondary or tertiary sources of information and do not provide enough on their own to increase political knowledge and spur voter turnout.

Next, REP in Prior's studies acted as a kind of 'booster' that interacted with cable and Internet access to increase political knowledge and turnout for news consumers, and decrease it for those preferring entertainment. This was not the case in this study. One question raised by this result regarding REP is whether the measurement is valid. This approach to measuring REP assumes that content preference, via television viewing choices, is a zero-sum game. While the amount of time a person allocates to television may be fixed each week or month, the relative value of news/information and entertainment might be different. Perhaps one news show, or 30 or 60 minutes per week, is all an 
individual needs to be informed enough to participate politically. If so, the fact that they watch, say, four of the 10 entertainment shows surveyed but only one of the news shows, may not affect political knowledge and turnout.

There has been such an explosion of new information sources and people may simply be getting news from places other than television. Recent work by the Pew Research Center found that people get news online in a variety of ways. Thirty-six percent utilize a news organizations website or mobile app, 35 percent of Americans get at least some news from social media, and 20 percent use a search engine. Further, people are utilizing more than one site to get news, with 25 percent saying they used two or more sites, an increase of nine points over the previous year (Shearer and Gottfried 2017). Overall, news access online has increased and is now the second most accessed source for news, although television is still the top choice. As of July 2016, thirty-eight percent of Americans accessed news online via news websites, phone apps or social media. Fiftyseven percent of Americans still prefer television, radio sits at 25 percent, and print newspaper readership has declined to only 20 percent (Mitchell et al. 2016). This is an additional criticism of Prior's original study. He focused on news choice as it relates to television and did not measure news from other sources, like newspaper and radio.

Another possibility is that entertainment choosers are being exposed to news and information in other manners, and getting the news and political information they need to increase political knowledge and spur turnout from other sources. As discussed above, social media may be able to provide what Downs 
called incidental exposure to information. The design of this study is such that we are unable to say that this is the case. Its results, however, suggest that future studies should try to develop ways to measure if people are getting news and information accidentally from social media and other Internet use.

\section{Limitations}

There are several limitations to take into consideration regarding this study. This section will look at those and provide suggestions for improvement and future examination. First, following the lead of Prior's original study, this repeat chose to consider use of social media as a dichotomous, yes or no, variable. Further, because Prior chose the access approach with regard to the Internet, this study chose to not include the Internet as a variable of interest, as household access is already so high. It did not measure how often respondents used social media nor their content preferences when they go on the Internet. The study in Chapter 5 does use an approach that measures how often a respondent uses social media, however it does not consider content preference. A potential weakness of Prior's original work in this area is that he only focused on access. For the Internet, this may have been appropriate, since it was still very early in the history and use of the Internet. Today, Internet access is nearly universal. For cable, he also used access as the indicator and relied on the REP measurement as a way to gauge use of television viewing. Back then, it had the relationship he described of increasing the gap in political knowledge and turnout. Today, it appears the growth in the media environment from social media 
has not followed suit in terms of content preference, political knowledge and turnout. As stated above, perhaps the amount of use of each platform, as well as which sources people prefer, needs to be part of future analysis.

How Relative Entertainment Preference is measured may also need to be improved. Comparing the number of television shows in each genre may not be the best measurement of preference. As discussed above, someone may only watch one television news program, and get informantion from other places such as newspapers or radio, but could conceivably watch more than one entertainment show. While this indicates a preference for entertainment based on Prior's definition of REP, perhaps only a little news exposure is necessary for political knowledge and to spur turnout. Prior's measurement in the N\&E Survey was a better approach because it asked people to choose from genres and to choose from an 'available' list. Individuals' thus weighed options against one another. For REP to be relied on, a better measurement should be developed to account for all news options (television, radio, newspaper, Internet) and all entertainment options (books, movies, video games etc.). The 2016 ANES includes a stand-alone questions about news use per week on television, newspapers, radio and Internet, as described in previous chapters. But it does not include a similar question for general 'entertainment media' use. The measurement scale for these variables also does not neatly match that for television viewing. For other media sources, respondents were asked about weekly use, while the television show viewing is a monthly measurement. As discussed in Chapter 2, issues around the measurement of political 
knowledge have been raised by other academic researchers. Specifically, Gibson and Caldeira (2009) point out that the use of open-ended questions, asked without any context, do not adequately measure a respondent's political knowledge. In fact, they specifically criticize the American National Election Study for using such questions. In their own work, Gibson and Caldeira (2009) found the use of closed-ended multiple choice questions provide a better measurement of political knowledge. Since the study in this chapter relies on ANES data and their questions around political knowledge, these criticisms need to be kept in mind.

Finally, data for this study was collected during the 2016 U.S. presidential election. Presidential elections in general produce higher voter turnout. In fact, this is one reason Prior $(2005,2007)$ utilized self-reported turnout for the House of Representative elections when using ANES data for his studies. Since presidential elections have higher turnout, it may be harder to isolate particular variable effects related to turnout. Further, self-reporting carries its own concerns related to over-reporting by individuals. Future studies should consider ways to mitigate these issues by potentially focusing on lower turnout elections and using official turnout reports from elections officials to see if people actually cast a ballot. 


\section{Chapter 5: Social Media, Traditional News Media, and the Odds of Turning Out to Vote}

In this final study, we address the central research question of this dissertation directly: What is the effect of social media on voter turnout? Specifically, this study examines if consumption of social media acts in a similar manner to consuming news from traditional media sources and increases the odds an individual will vote. News and political information from traditional sources has been identified as increasing the odds a voter turns out to vote by several studies over the past decades (Brady, Verba, and Schlozman 1995; Smets and van Ham 2013; Wolfinger and Rosenstone 1980). This study also takes into consideration the results of the analysis in Chapter 3 to help devise the hypotheses and identify additional variables to use in the regression models.

As outlined previously, voting is an important component of democracy, providing a way for citizens to participate in governance by choosing representatives, expressing opinion and to even enacting new laws directly (Dahl 2006; Gainous and Wagner 2014; Manin, Przeworski, and Stokes 1999; Przeworski 1999; Wolfinger and Rosenstone 1980). Whether an individual decides to participate depends on many factors. Two, in particular, that have been identified as influencing this choice are age and education. As voters get older, turnout increases, and the more education they have completed the more likely they are to vote (Leighly and Vedlitz 1999; Smets and van Ham 2013; Wolfinger and Rosenstone 1980). In addition, political knowledge also affects turnout, with individuals who are more knowledgeable being more likely to vote 
(Delli Carpini and Keeter 1996; Downs 1957; Geys 2006; Leighly and Vedlitz 1999; Luskin 1990; Manin, Przeworski, and Stokes 1999; Prior 2005, 2007; Smets and van Ham 2013). Where individuals gather political information and whether it increases the odds they will vote is the focus on this chapter. Traditional news media sources, like newspapers, television, radio, and the Internet, have been found to have a positive effect on voter turnout (Delli Carpini and Keeter 1997; Gainous and Wagner 2014; Gentzkow 2006; Gil de Zuniga, Jung and Valenzuela 2012; Popkin 1994; Prior 2007; Smets and Van Ham 2013). With the rapid growth over the past 10 years of social media like Facebook and Twitter, some research has examined whether it also has a positive effect on voting. Some of these studies have found a positive relationship between social media and participation, including aspects beyond voting like signing a petition or communicating with an elected official (Bimber et al. 2014; Bimber and Copeland 2013; Bode 2012; Bode et al. 2014; Bond et al. 2012; Broockman and Green 2014; Gainous and Wagner 2014; Gil de Zúñiga, Molyneux, and Zheng 2014; Holt et al. 2013; Pasek, more, and Romer 2009; Vitak et al. 2011; Xenos, Vromen, and Loader 2014; Zhang, Seltzer, and Bichard 2013). Other studies have not found this positive relationship (Bimber et al. 2014; Broockman and Green 2014; Dimitrova and Bystrom 2013; Green and Gerber 2015; Kushin and Yamamoto 2010; Towner 2013).

The relationship between social media use and voter turnout is also important because more and more individuals are using it for news and political information. Social media is increasing as a source of news, passing traditional 
sources like cable television, local television and print newspapers. As of August 2017, 67 percent of Americans reported using social media to get some of their news (Shearer and Gottfried 2017). This is particularly true for those under the age of 50 years old, but older voters are also using it more for political information (Gottfried et al. 2016; Shearer and Gottfried 2017). This connection between social media use and age was also examined in Chapter 3 , where we demonstrated that those in the 'Prefers Social Media' group tended to be younger while those preferring traditional news media were older. Because age is associated with both voter turnout and the use of social media, it is an important variable to consider for the study in this chapter.

In a similar way, education is an important factor related to voter turnout, with turnout increasing the more education a person has completed. The analysis of preferred media groups in Chapter 3 also identified a trend between education levels and choice of media. Specifically, the preference for social media was higher for those who had not completed a college degree of any kind, and declined for those with an Associates Degree and Bachelor Degree. Overall, however, all education groups had a higher percentage of individuals preferring traditional news media. At the same time, the analysis in Chapter 3 identified slightly better political knowledge for those who include more traditional news sources in their media diet. The percentage of those in the Prefers Social Media group was higher for low scores on the political knowledge scale than the other two groups. In the same way, it was lower for the other end of the scale. Political knowledge appears to be positively linked to the choice of media group, which is 
consistent with previous research. Since higher political knowledge is also related positively to voter turnout, this is important to consider.

Finally, in Chapter 4 we examined whether the increase in the media environment after the growth in Internet access and social media use was related to increasing the gap in political knowledge and voter turnout between those preferring entertainment and those preferring news. Unlike previous results in similar work by Prior $(2005,2007)$, the study in Chapter 4 did not find this relationship. At the same time, it also did not find a positive relationship between social media use and political knowledge nor voter turnout. While it is good that the addition of social media to the mix of options is not discouraging political knowledge and participation, it also does not appear to be related to increasing turnout. According to this study, then, social media is not acting like traditional media and providing political information and news that leads to participation.

The study in Chapter 4 considered social media use as a dichotomous variable, simply whether the respondent used it or did not. This was done to repeat the Prior $(2005,2007)$ study as closely as possible. In that original study, mere access to cable and the Internet were measured. The study here in Chapter 5 considers the number of days each week a person uses social media and the number of days respondents use traditional news media. As discussed in Chapters 1 and 2, there has been an increase in the use of social media in general as well as for news and political information. The amount of use may matter for a couple of reasons. First, while people visit social media for a variety of purposes, many not related to news or politics, they are still exposed to this 
type of information in their news feed (Mitchell et al. 2013). This provides an opportunity for accidental exposure to such information, and the more a person is on social media the more likely they are to receive accidental news. Second, for many people social media is growing as a source for news and political information (Gottfried et al. 2016). This is particuarly true for voters younger that 50 years old (Shearer and Gottfried 2017). It is replacing traditional news media sources, like television, newspaper and radio, as the preferred information source for many voters. Measuring the number of days each week a respondent uses social media as well as traditional news media, then, is a better measurement than simply whether or not they use it.

Based on the previous research as well as the analysis completed in Chapter 3 and Chapter 4 , the following two hypotheses are offered here in Chapter 5:

Hypothesis 3: Increased consumption of social media will not increase the likelihood the individual turned out to vote.

Hypothesis 4: Increased consumption from traditional news sources will increase the likelihood the individual turned out to vote.

\section{Data and Methods}

As with the analysis completed in Chapter 3 and Chapter 4, data for this study is taken from the 2016 American National Election Studies (ANES) survey. 
The ANES surveys U.S. citizens aged 18 and older via the Internet and face-toface methods, with respondents being selected using probability sampling. Both a pre-election and post-election survey are completed with the respondents.

\section{Dependent Variable}

The dependent variable measures whether the respondent voted in the 2016 Presidential election. Respondents were asked during the post-election survey which statement best described them as it relates to voting in the election: "I did not vote (in the election this November)"; "I thought about voting this time, but didn't"; "I usually vote, but didn't this time"; "I am sure I voted." Based on the recorded results for each of these, ANES collapsed the responses into two variables, "Did not vote in 2016" and "Voted in 2016." For this study, this variable was recoded to be dichotomous so that $0=$ "Did not vote" and $1=$ "Voted".

\section{Independent Variables}

The two variables of interest for this study are Social Media Use and Traditional News Media Use. Both of these were measured during the preelection survey. To measure social media use, respondents were asked, "During a typical week, how many days do you use social media such as Twitter or Facebook?" and could answer zero through seven days. To measure traditional news media use, they were asked, "During a typical week, how many days do you watch, read, or listen to news on TV, radio, printed newspapers, or the Internet, not including sports?" As with the social media question, respondent 
could answer from zero up to seven days.

\section{Additional Model Variables}

In addition to consumption of social media and traditional news media, this study also includes three control variables, education level, age, and gender. As discussed above, education level and age have both been found to be positively related to voter turnout. Further, analysis in Chapter 3 illustrated a potential relationship between those variables and the choice of preferred media. This was also true for gender in Chapter 3, where a higher percentage of women were identified as preferring social media than men.

\section{Analytic Plan}

The Results section begins with descriptive statistics on all variables used in the study. A logistic regression model (Table 5.7) is used to show if the odds the individual turned out to vote vary depending on consumption of social media and traditional news media. It includes the control variables in addition to the variables measuring social media use and traditional news media use. This model shows how all of the variables of interest relate to voter turnout. 


\section{Results}

\begin{tabular}{|lccc|}
\hline \multicolumn{4}{|c|}{ Table 5.1: Descriptive Statistics } \\
\hline \multicolumn{4}{|c|}{ Weekly Social Media and Traditional News Media Use } \\
\cline { 2 - 4 } & Mean & SD & N \\
\cline { 2 - 4 } $\begin{array}{l}\text { Weekly Social Media Use } \\
\text { Weekly Traditional News } \\
\text { Media Use }\end{array}$ & 3.87 & 3.06 & 4196 \\
\hline \begin{tabular}{l} 
Unweighted count; American National Election Survey \\
\hline
\end{tabular} & & 1.96 & 4267 \\
\hline
\end{tabular}

\begin{tabular}{|c|c|c|c|}
\hline & Female & Male & Total \\
\hline Gender & 2232 & 1987 & 4219 \\
\hline
\end{tabular}

\begin{tabular}{|c|c|c|c|}
\hline \multicolumn{4}{|c|}{ Table 5.3: Descriptive Statistics - Voter Turnou } \\
\hline & Yes & No & Total \\
\hline Voted in 2016 & 2887 & 444 & 3331 \\
\hline
\end{tabular}

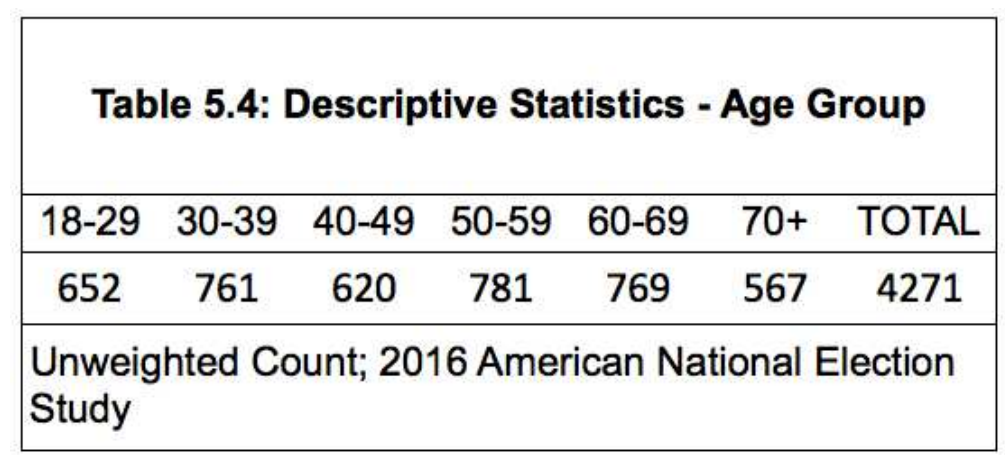




\begin{tabular}{|lclllllll|}
\hline \multicolumn{8}{|c|}{ Table 5.5: Descriptive Statistics } & Education Level \\
\hline $\begin{array}{l}\text { No High } \\
\text { School } \\
\text { Diploma }\end{array}$ & $\begin{array}{c}\text { H.S. } \\
\text { Diploma } \\
\text { or } \\
\text { G.E.D. }\end{array}$ & $\begin{array}{c}\text { Some } \\
\text { College }\end{array}$ & $\begin{array}{c}\text { Associates } \\
\text { Degree }\end{array}$ & $\begin{array}{c}\text { Bachelor } \\
\text { Degree }\end{array}$ & $\begin{array}{c}\text { Masters } \\
\text { Degree }\end{array}$ & $\begin{array}{c}\text { Doctorate } \\
\text { Degree }\end{array}$ & Total \\
\hline 282 & 810 & 899 & 601 & 955 & 499 & 181 & 4227 \\
\hline Unweighted count; American National Election Survey \\
\hline
\end{tabular}

Both Hypothesis 3 and Hypothesis 4 are examined in Table 5.6. The first hypothesis looked at whether social media use increased the odds an individual turned out to vote and predicted that it would not increase those odds. As Table 5.6 shows, there was no statistically significant relationship between social media use and voter turnout. This supports Hypothesis 3 . Further, there is a statistically significant relationship between the use of traditional news media and turning out to vote. The odds of voting increase significantly $(14.9 \%)([100(1-1.149) \%])$ with every additional day a person consumes news from traditional news media $(\operatorname{Exp}(b)=1.149, p<.001)$. Hypothesis 4 is supported. Consuming news from traditional news media sources increases the odds of voting by about 15 percent. Social media consumption, however, is not statistically significant with regard to increasing the odds of turning out to vote. Education level and age, however, are both statistically significant and increase the odds an individual will turn out to vote. 


\begin{tabular}{|lll|}
\hline \multicolumn{4}{|c|}{$\begin{array}{c}\text { Table 5.6: Logistic Regression Estimating Odds of } \\
\text { Turning Out To Vote After Media Use }\end{array}$} \\
\hline & Exp(B) & SE \\
\cline { 2 - 3 } Weekly Social Media Use & 1.013 & 0.025 \\
Weekly Traditional News Media Use & $1.149^{\star \star *}$ & 0.035 \\
Education & $1.298^{\star \star *}$ & 0.045 \\
Age & $1.308^{\star \star *}$ & 0.045 \\
Gender & 1.053 & 0.138 \\
\hline NOTE: $+\mathrm{p}<.10,{ }^{*} \mathrm{p}<.05,{ }^{* *} \mathrm{p}<.01,{ }^{* * *} \mathrm{p}<.001 ;$ \\
Unweighted $\mathrm{N}=3169$ & \\
\hline
\end{tabular}

\section{Discussion}

The media environment has changed considerably over the past 15 years. Consumption habits have shifted away from newspapers and toward Internet sources, although television consumption remains high especially among older citizens. Add into that mix the advent and rapid growth of social media, like Facebook and Twitter, and citizens have more and more places to get news and political information. In fact, a growing number of individuals report that they get news from social media, and this includes a growing number of older voters (Gottfried et al. 2016; Shearer and Gottfried 2017). Whether social media, then, acts like traditional media and increases the odds 
a person votes is an important question as more and more people use it for news and information. As discussed in Chapter 2 and briefly in the beginning of this chapter, previous studies looking at the relationship between social media and political participation have found mixed results. Some have identified a positive relationship, including a positive relationship with voter turnout (Bimber and Copeland 2013; Bode 2012; Bond et al. 2012; Gainous and Wagner 2014). Others have found a positive relationship but only with non-voting activities, like contacting an elected official or signing a petition (Bode et al. 2014; Broockman and Green 2014; Gainous and Wagner 2014; Gil de Zúñiga, Molyneux, and Zheng 2014; Holt et al. 2013; Pasek, more, and Romer 2009; Vitak et al. 2011; Xenos, Vromen, and Loader 2014; Zhang, Seltzer, and Bichard 2013).

As the study in Chapter 5 indicates, at this point increased consumption of social media does not increase the odds an individual will turn out to vote. While the results for social media in each model it was included in were in a positive direction, they were not significant. On the other hand, despite the growth in media options, traditional news media continues to be one of the best predictors of voter turnout. This variable was statistically significant in every model it was included. Therefore, these results lead one to conclude that as it relates to voter turnout, social media is not acting in a similar manner as traditional media by increasing the odds an individual will vote. On a positive note, while social media does not increase the odds a voter turns out, it also does not decrease the odds. It is not acting to discourage participation in the political process.

Finally, although not the focus of this study, the results reinforce the role 
age and level of education play in turnout. This is interesting for age in particular because of the increased use of social media by those in younger age groups. One potential result was that social media could help increase turnout for younger voters if it acted like traditional media. That is not the case. One suggestion for future research is to focus on only younger voters to see if increased social media use might serve the same role as traditional news media related to voter turnout just for this subgroup. This would also help understand the behavior of these younger generations as they age. Does social media remain an important information source as they get older? 


\section{Chapter 6: Conclusions, Limitations and Discussion of Future Research}

The goal of this dissertation is to clarify the relationship between social media, news and political information and examine if social media have an impact on whether an individual turns out to vote. It examined this question in three different ways. First, it looked at the similarities and differences between individuals who prefer social media, those who prefer traditional news media in newspapers, on TV and radio, and the Internet, and those preferring both equally. Next, it examined whether the increase in options in the media environment created by the addition of social media platforms affected political knowledge and voter turnout. Specifically, whether a person's preference for entertainment or news is related to political knowledge and turnout in the social media era. Finally, it tested the question directly by analyzing whether the use of social media is related to an increase in the odds of whether a person turns out to vote. Based on the results of these studies, there is additional information about the relationship between social media and political participation that will help inform future studies into this issue. In Chapter 6, these results are analyzed, limitations to the studies are discussed, and suggestions for future research in this area are proposed.

\section{Discussion of Key Findings}

Overall, the studies in this dissertation demonstrate that the use of social media has no relationship, neither a positive nor negative, with political 
knowledge and voter turnout. The use of traditional news media, like television, newspapers, radio and the Internet, on the other hand, continues to increase the odds an individual will vote. Further, the addition of social media to the media environment is not creating a gap in political knowledge or in voter turnout for those who have a preference for entertainment versus news.

Differences in the demographics, and political attitudes and behaviors between those who prefer social media and those who prefer tradition news media were identified. These provide additional information on the relationship between social media and political participation, and point to new directions research should consider. For example, those who prefer social media are younger, tend to be female, and demonstrated lower political knowledge and civic engagement. Vote intention and self-reported turnout favors those preferring traditional media or who prefer both social media and traditional media equally. Vote intention and turnout percentage was lower for those preferring social media.

\section{Relative Entertainment Preference}

Expansion of options in the media environment from the growth of social media did not increase the gap in political knowledge or voter turnout based on content preference. There was no difference in political knowledge nor in voter turnout based on a person's Relative Entertainment Preference or use of social media, nor from the interaction of the two variables. As discussed in Chapter 4, this result does not support Prior's original findings and contention that content 
preference is the best predictor of political knowledge and voter turnout. It also does not support his belief that an increase in media options creates a gap in political knowledge and voter turnout based on the preference of entertainment over news content.

Finally, no relationship was found between social media use and turning out to vote. The use of social media does not increase the odds that a person will turn out to vote. On the other hand, it also does not have a negative relationship and decrease those odds. Traditional news, on the other hand, continues to be a predictor of voter turnout, along with a person's age and education level.

\section{Social Media as a News Source}

If social media does not act like traditional news media and increase the likelihood of voting, is it acting instead like entertainment? Past research found that people go on social media for purposes other than news and political information yet they encounter it there incidentally (Mitchell et al. 2013). Based on the results in Chapter 5, it appears that incidental information from social media is not spurring voter turnout. It is important to note that the dissertation study did not directly examine social media and incidental exposure to news and political information. If social media is acting more like entertainment, it isn't distracting from news and political information and increasing the gap between voter turnout and political knowledge. As Chapter 4 found, in the social media age Relative Information Preference did not predict political knowledge nor voter turnout. At this point, it is a good news/bad news situation for social media, at 
least in regards to voter turnout and political knowledge. The bad news is that it isn't increasing either turnout or knowledge. The good news is that it is also not increasing the gap in turnout (Ch. 4 and 5) and knowledge (Ch. 4). Traditional news media, on the other hand, continues to be positively related to voter turnout. It will be interesting to see if once social media passes traditional news sources as the preferred news source - if in fact it does - whether it eventually acts like traditional news.

\section{Implications}

\section{Living in a Hybrid Media World}

One possible interpretation of the results of these studies is that we are living in what Chadwick (2013) calls a hybrid media system. This occurs in the period after new media sources or platforms are introduced and, for a period of time, the new and the old take on characteristics of each other. As the studies in this dissertation suggest, it may be difficult to single out the effects of one particular media type when they have adopted similarities from the others. With social media being barely more than a decade old, thinking of the results through the lens of the hybrid media system may help understand the mixed results.

For example, Chadwick argues that while more people are getting political news online, the original source of that content is usually traditional sources, like newspapers, television or cable news stations, or radio. This makes it more difficult to gauge whether online consumption is the one having the effect. This mixing of the old and the news is only increasing, too. Consider that the online 
video giant Netflix has recently announced its plans to add a news magazinestyle show similar to CBS's long-running 60 Minutes or ABC's 20/20 (Teodorczuk 2018). Further, it raises the question of what individuals consider the source of news content. If they read a story from the Washington Post or CNN on Twitter or a friend posts the story on Facebook, do they consider that as getting news from social media? Finally, social media content may simply be having a reinforcing effect on news and information gleaned from traditional news sources.

\section{Social Media, Fake News, and Propaganda}

As discussed in Chapter 2, the ideas of fast and slow thinking, and the limitations of political heuristics, raise serious questions about social media as a reliable source of political information. It also raises questions about the possible use of social media for propaganda purposes. First, reliance on social media for news and political information could cause people to digest and act upon information from unreliable sources. Kahneman explains that our System 1 thinking is driven by ideas we pick up over our lives, and we may not even be aware of the source for these ideas. "What psychologists do believe is that all of us live much of our life guided by the impressions of System 1 - and we often do not know the source of these impressions" (Kahneman, 2011, 64). According to Petty and Cacioppo, however, attitude and behavior change occurs best when the central route is engaged. If social media is mostly engaging the peripheral route it may only be reinforcing existing habits and attitudes. This would help explain the results from the studies in this dissertation, which found that social 
media use was not related to voter turnout while traditional news media use continues to have a positive relationship.

A second possibility is that social media may be having an effect through an indirect route. First, information passed along via social media has the potential to be distorted. Carlson (2017) suggests that a distortion of the news occurs as people share social media posts about news and that the further down the chain of sharing one is the less information one receives.

Feezell (2018) established that agenda setting can occur from information presented on Facebook. In her study, individuals who were shown political information demonstrated a higher level of salience with the issue presented than those who did not see the information. Further, the result was particularly true for those with low political interest. Raising the salience of a topic would encourage individuals to pay closer attention to news stories about that topic from other sources, including traditional news media. Further, Chadwick (2013) points out the role of inter-media agenda setting whereby information or story ideas from posts from bloggers are picked up by traditional news media and become stories. He points out that while blogging is not as prominent as the early 2000 s, much of that content has now moved to social media sites like Facebook and Twitter. Thus, through agenda-setting, political information presented on social media may be having an indirect effect by focusing an individual's attention on specific issues or influencing coverage by the broader media.

An additional way social media could have an indirect relationship is if the information consumed via those platforms mixes with news and information 
consumed from other sources, and the individual does not recall the sources. This brings to mind an argument made by Kathleen Hall Jamieson (1992) in her book Dirty Politics: Deception, Distraction and Democracy. Jamieson argues that voters gather pieces of information over time but forget where they come from. These ideas mix together and voters forget if the source is a legitimate news source or one designed to persuade. "Like pack rats, voters gather bits and pieces of political information and store them in a single place. Lost in the storage is a clear recall of where this or that 'fact' came from" (Jamieson 1992, 17). Jamieson's specific concern is with information from political ads mixing with news and voters forgetting which is which. With the advent of social media, where we are reading ideas and views from individuals mixed with those from news media sources, this problem may be compounded even further. Did I hear that idea from someone on Facebook or from a news article? Kahneman is worried as well about whether our System 1 can tell the difference. "But do you discriminate sufficiently between 'I read in The New York Times...' and "I heard at the watercooler...'? Can your System 1 distinguish degrees of belief?" (Kahneman 2011, 114) He uses the old idea of a chat at the watercooler, but social media has become our watercooler magnified.

Recent studies around the issue of 'fake news' have helped focus what is known about social media and the spread of false, or intentionally false, information. A recent review of existing literature on fake news (Lazer et al. 2018) found that little is known about how it affects people and how far such 'fake news' reaches. They point out that knowing how many people were potentially exposed 
to such news doesn't tell us how many read it or how many it had an effect on. Little is also known about what effect it has on political behavior (Lazer et al. 2018). Some research has looked at who tends to read such news. Research by Guess, Nyhan and Reifler (2018) found a lack of evidence for the idea that those with less political knowledge only consumed such information. In fact, fake news consumers tended to be heavier consumers of hard news. Further, as Alcott and Gentzkow (2017) point out, people's recall of fake news stories is not reliable. In their study of fake news stories conducted shortly after the 2016 Presidential Election, they found that respondents were equally as likely to recall and believe a real fake news article topic from the election as they were a placebo article topic created by the researchers. They suggest that this finding indicates that respondents overstate their recall of real fake news articles from the election.

While the results from this dissertation do not directly address these issues they do provide additional points to consider. Presently, it appears there is no direct relationship between social media and the odds of someone turning out to vote. Knowing this allows us to focus, instead, on potential ways social media may have an indirect effect or to compound effects from other information sources, as discussed above. Further, it is not creating a gap in political knowledge for those who prefer social media to traditional news media sources. News and information that is related to political knowledge continues to come from newspapers, television, radio and the Internet. It may be that social media simply reinforces this existing knowledge, but perhaps it may also introduce topics or stories that lead people to traditional news sources for more 
information.

Taken together, these results suggest that there are numerous ways that information from social media could have an indirect and potentially damaging effect on those who rely on it for political information. Could information from social media be working in a secondary manner? Perhaps social media is used to activate partisans or hardcore supporters who then advocate or promote views to others. Another possibility is that political information disseminated by social media could be used to change the media agenda to focus on particular issues or to distract from specific stories. The co-mingling of information received and processed quickly from social media with news and political information from traditional sources is occurring, and via this route social media may in fact be having an effect on political participation. More than any other type of media, social media allows for the mixing of news, entertainment and opinion all in one feed. This makes the untangling of information sources important and finding a way to examine these potential indirect effects would be valuable. In the discussion that follows around design limitations and ideas for future research, suggestions are offered that may help in this regard. These include utilizing a population-based survey experiment approach, examining the amount of news and the length of news content and its relationship to political participation, and looking at news consumption from social media and information recall. 


\section{Limitations and Recommendations}

\section{Research Design}

The research design approach for this dissertation, along with the analysis of the results, raises some questions related to design. As researchers continue to examine questions related to media use and behavior generally, and political behavior specifically, improving design and looking for new and innovative techniques will help address these. This section of the final chapter addresses these and provides suggestions. First is how researchers approach the examination and measurement of specific news and information sources. Isolating a specific channel is challenging, and may be impossible, with false recall, agenda setting, and how individuals interpret and act on information. As discussed above, in a hybrid media system described by Chadwick (2015) the content may come from a traditional media source but be distributed online. The results in this dissertation suggest that traditional news sources still play a large role in not only the media diets of Americans but in their political knowledge and political participation. Trying to examine a specific media platform, then, may also remove that channel from the role it is playing relative to the others.

An additional limitation to the use of the ANES data is it relies heavily on self-reporting. Measurements of social media use and traditional news media use are both self-reported. Voter turnout is self-reported. This approach relies on individuals to provide accurate information. Are people distinguishing where they've received information? Are they accurately reporting it when asked on a survey? One possible solution is to rely more on controlled studies. This could be 
done in a traditional lab situation, where individuals are exposed to specific messages from specific platforms. This approach offers its own downsides, in particular the fact that it does not put the person in a real world situation. Another option is a population-based survey experiment as advocated by Mutz (2011). This approach combines traditional large sample surveys with greater control of the treatments they are exposed to and the variables affecting respondents. Subjects and questions for these kinds of studies are developed in a similar fashion as traditional surveys but subjects are randomly assigned to different treatment groups (Mutz 2011).

Some researchers are finding innovative ways to create studies using actual social media platforms. Feezell (2018), for example, used the groups function in Facebook for her study on agenda setting. She created a control group and a treatment group and randomly assigned participants to them. Study participants received news stories posted to their group in their regular Facebook feed, replicating a way people might be exposed to news on this platform. By creating the groups, she was able to provide different stories to each group. It is an interesting approach that offers better control and puts the content in an actual social media platform. An additional step that could be taken using this framework is create a group that gets news from online-only sources and compare it to another that receives news from traditional news sources posted to Facebook.

Next, when it comes to the self-reporting of voter turnout, one option is to utilize existing sources that prove someone has voted, like voter lists from the 
election offices of the Secretary of State or from individual counties. This approach offers additional information about the participants, which is another advantage. Using these lists confirms that the person actually cast a ballot. It would also allow the grouping of participants based on their vote history, which allows the inclusion of a new variable measuring the frequency that somebody votes over time, or specific elections they vote in. For example, vote history shows whether an individual only votes in the General Election in a presidential year or if they consistently vote in every election. Practically speaking, anonymity of participants could be protected by grouping people by their vote history and choosing a random sample from each group.

Finally, a better measurement is needed for how much news exposure is needed to spur participation. Prior's original approach of asking individuals to choose from among several types of programming and repeating this question multiple times, required people to compare what they preferred and select each time from a list of several genres. When Prior $(2005,2007)$ used ANES data to address the same question, he had to rely on the questions ANES asked. In his case, the findings supported his original contention regarding content preference, political knowledge and voter turnout. The study in this dissertation did not. As discussed in Chapter 4, perhaps Relative Entertainment Preference (REP) measurement is not the best because it assumes an equal amount of news and entertainment has the same effect. For example, the effect of one entertainment TV show may not be the same as one news program. The REP measurement assumes this is the case. Maybe just a little news is all someone needs. The 
greater number of choices in the present media environment may be having an effect on political knowledge and participation but measuring an individual's content preference using the approach in this dissertation should be improved. Future studies that rely on the REP concept should either use an approach similar to Prior's original one or find a better way to measure content preference using existing data. The next section discusses potential future studies, one of which is to better understand the amount of news in a person's media diet is needed to spur turnout. That suggestion stems from the concerns expressed here.

\section{Future Studies}

The results from the studies in this dissertation suggest several areas of interest for additional research.

\section{Age, Social Media Use and Turnout}

Although overall social media use did not predict turnout, perhaps it does for certain subgroups based on age. This could be the case because younger groups have adopted social media as a news source more quickly and in greater numbers than older generations. This was demonstrated by the descriptive statistics in Chapter 3 and is also a trend evident in research conducted by the Pew Research Center (Mitchell et al. 2017; Shearer and Gottfried 2017). The first step would be to isolate specific age groups and examine if there is a relationship between social media use and turnout. If there is, looking further at news and 
political information consumption habits, including how often, how much and from what sources, would help better understand the current relationship for younger voters. It would also help understand how social media may eventually have a similar relationship for older voters as they adopt more of it in the media diet and it replaces traditional news media sources.

\section{Amount of News Needed to Spur Political Participation}

As discussed above, the use of Relative Entertainment Preference as a measurement of content preference between news and entertainment raises the basic question of how much exposure to news and political information is needed to affect political participation. This is a baseline need for this area of research. Before the rise of cable television, when there were only a few broadcast channels, radio, newspapers and magazines, researchers didn't seem to question that 30 minutes of local news and 30 minutes of national news via television, along with newspaper and radio, was enough exposure to create a positive relationship with voter turnout. With the incredible change in the media environment over the past 20 years, from the growth of the Internet and social media to the decline in newspaper subscriptions, better understanding how much exposure to political information is needed in this new environment is an important step. A main question related to this is how to measure this consumption in a meaningful way. 


\section{Content Length and Political Participation}

By their nature, social media posts contain less and may be processed more quickly by individual's, utilizing the peripheral route described by Petty and Cacioppo (1986) or System 1 as described by Kahneman (2011). If this is the case, these posts may not be enough to motivate a person to vote or even to change an attitude. As Petty and Cacioppo (1986) argue, attitude change is more likely from information processing by the central route, which requires deeper thinking. Thus, are short posts or headlines enough to have an effect on political knowledge and/or behavior? Additional research in this area could compare political habits and knowledge of individuals exposed to only short social media posts to those that read more deeply on a subject. This area also probes the issue of incidental exposure discussed above. Can incidental exposure via social media act as a way to spur voter turnout? Are short tweets or Facebook posts providing enough information to increase political knowledge and influence the decision to go to the polls, or are they simply reinforcing existing attitudes and beliefs? Examining these questions would help us better understand how the existing literature on incidental exposure applies to social media or whether this new form of communication acts differently.

\section{Social Media and Information Recall}

Finally, research on the subject of information and source recall needs to continue to be done. As both Jamieson (1992) and Kahneman (2011) warn, content may be absorbed but we forget the original source. This could lead 
people to mix information from legitimate news sources with information from social media posts by friends, family or untrustworthy sources, and not remember which is which. Recent studies in this area demonstrate why this is a concern. For example, while older and younger news consumers click links at a similar rate, the younger news consumers are less likely to remember the source of the story (Mitchell et al. 2017). Further, recent work on 'fake news' by Allcott and Gentzkow (2017) found a significant amount of false recall of news stories and headlines from the 2016 presidential election. While, at this point, social media does not have a direct relationship with voter turnout, it may be having an indirect one and information recall could be one of the ways.

\section{Conclusion}

The 2016 U.S. presidential election brought significant attention to social media and its role in the political process. It did so through several sensational aspects, including Russian-paid Facebook advertising, the use of digital bots to spread information, and the prolific and sensational use of Twitter by Donald Trump. While the sensational stories grab the headlines, there is still a need to better understand the basic relationship between social media, news and political information, and political habits and attitudes. The media environment has changed dramatically in the 21st Century. This, in turn, has changed media habits. The use of traditional news media like newspapers, television and radio has declined and shifted to online sources like news websites and social media. This changes where we get political information, and because of the importance 
of information to voting behavior it may have an effect on this important part of democracy.

The analysis of the existing literature and the new studies presented in this dissertation provide important insights into how to proceed with additional examination of the relationship between social media use, traditional news media use, and political participation. It examined the fundamental relationship between social media, news and political information to better understand how these changes may affect democracy and voter turnout. The results show that unlike traditional news media use, the use of social media does not increase the odds an individual will turn out to vote. Even with a significant increase in the number of options available in the media environment driven by social media and the Internet, a person's traditional news media use is still related to the odds they turn out to vote. Further, at this point the use of social media and an individual's content preference of entertainment versus news is not related to political knowledge nor voter turnout. While social media does not appear to have a positive effect on turnout, the good news is that it does not appear to discourage a person from voting either. The dissertation does, however, outline several ways that those who prefer social media differ from those who prefer traditional news media. These include demographics like age and gender, as well as political habits and attitudes like partisanship and political knowledge. More work, however, needs to be done. This dissertation has helped clarify the situation and laid the groundwork for additional examination of social media, our changing media environment and its relationship with democracy. 
To this end, the dissertation offers specific suggestions on how to improve future studies from a methodological standpoint, and offers ideas for next steps to better understand the research question. In terms of design and methods, future studies should utilize methods that reduce issues related to self-reporting of variables like social media use, traditional news media use, and turning out to vote. This can be accomplished, in part, by creating research scenarios that use the actual social media platforms we are interested in examining. Future studies should also attempt to implement treatment groups via population-based survey methods in order to better measure potential relationships between media use and variables of interest. Lastly, the results of this dissertation suggest areas for future research. This includes examining social media and information recall. Do people remember where they received news, and how is that related to political participation? In addition, future studies need to look at the indirect ways that social media may be related to political habits and attitudes. For example, agenda-setting might explain how social media influences what traditional news media outlets cover. Additional research in these areas will help better understand the relationship between an individual's social media use, their use of traditional news media sources, and whether they turn out to vote in an everexpanding media environment. 


\section{References}

Allcott, Hunt, and Matthew Gentzkow. 2017. Social Media and Fake News in the 2016 Election. National Bureau of Economic Research.

Bakshy, Eytan, Itamar Rosenn, Cameron Marlow, and Lada Adamic. 2012. "The Role of Social Networks in Information Diffusion.” In ACM, 519-28. http://dl.acm.org.proxy.lib.pdx.edu/citation.cfm?id=2187836.2187907 (February 25, 2017).

Bartels, Larry. 1996. "Uniformed Votes: Information Effects in Presidential Elections." American Journal of Political Science 40(1): 194-230.

Bennett, W. Lance. 2011. News: The Politics of Illusion. Chicago: University of Chicago Press.

Bimber, Bruce, and Lauren Copeland. 2013. "Digital Media and Traditional Political Participation Over Time in the U.S." Journal of Information Technology \& Politics. http://www-tandfonlinecom.proxy.lib.pdx.edu/doi/full/10.1080/19331681.2013.769925 (February 25, 2017).

Bimber, Bruce, Marta Cantijoch Cunill, Lauren Copeland, and Rachel Gibson. 2014. "Digital Media and Political Participation." Social Science Computer Review. http://journals.sagepub.com.proxy.lib.pdx.edu/doi/abs/10.1177/089443931 4526559 (February 25, 2017).

Bode, Leticia. 2012. "Facebooking It to the Polls: A Study in Online Social Networking and Political Behavior." Journal of Information Technology \& Politics. http://www-tandfonlinecom.proxy.lib.pdx.edu/doi/full/10.1080/19331681.2012.709045 (February 25, 2017).

- 2016. "Political News in the News Feed: Learning Politics from Social Media." Mass Communication and Society. http://www-tandfonlinecom.proxy.lib.pdx.edu/doi/full/10.1080/15205436.2015.1045149 (February $25,2017)$.

Bode, Leticia, and Kajsa E. Dalrymple. 2014. "Politics in 140 Characters or Less: Campaign Communication, Network Interaction, and Political Participation on Twitter." Journal of Political Marketing. http://www-tandfonlinecom.proxy.lib.pdx.edu/doi/full/10.1080/15377857.2014.959686 (February $25,2017)$.

Bode, Leticia, Emily K. Vraga, Porismita Borah, and Dhavan V. Shah. 2014. "A New Space for Political Behavior: Political Social Networking and Its 
Democratic Consequences." Journal of Computer $\square$ Mediated Communication 19(3): 414-29.

Bond, Robert M. et al. 2012. "A 61-Million-Person Experiment in Social Influence and Political Mobilization." Nature 489(7415). https://www-ncbi-nlm-nihgov.proxy.lib.pdx.edu/pmc/articles/PMC3834737/ (February 25, 2017).

Boulianne, Shelley. 2015. "Social Media Use and Participation: A Meta-Analysis of Current Research." Information, Communication \& Society 18(5): 52438.

Brady, Henry, Sidney Verba, and Kay Lehman Schlozman. 1995. "Beyond SES: A Resource Model of Political Participation." The Amerian Political Science Review 89(2): 271-94.

Broockman, David E., and Donald P. Green. 2014. "Do Online Advertisements Increase Political Candidates' Name Recognition or Favorability? Evidence from Randomized Field Experiments." Political Behavior 36(2): 263-89.

Carlson, Taylor N. 2018. "Modeling Political Information Transmission as a Game of Telephon." The Journal of Politics 80(1): 348-52.

Carr, Caleb T., and Rebecca A. Hayes. 2015. "Social Media: Defining, Developing, and Divining." Atlantic Journal of Communication. http://wwwtandfonline-com.proxy.lib.pdx.edu/doi/full/10.1080/15456870.2015.972282 (February 25, 2017).

Chadwick, Andrew. 2013. The Hybrid Media System: Politics and Power. Oxford: Oxford University Press.

Chew, Fiona. 2016. "The Relationship of Information Needs to Issue Relevance and Media Use." Journalism Quarterly.

http://journals.sagepub.com.proxy.lib.pdx.edu/doi/abs/10.1177/107769909 407100318 (February 25, 2017).

Clucas, Richard A., and Melody Ellis Valdini. 2015. The Character of Democracy: How Institutions Shape Politics. New York: Oxford University Press.

Dahl, Robert Alan. 2006. On Political Equality. New Haven: Yale University Press.

Delli Carpini, Michael X., and Scott Keeter. 1996. What Americans Know about Politics and Why It Matters. Yale University Press.

DeSilver, Drew. 2017. U.S. Trails Most Developed Countries in Voter Turnout. Pew Research Center. http://www.pewresearch.org/fact- 
tank/2017/05/15/u-s-voter-turnout-trails-most-developed-countries/ (May 14, 2018).

Dimitrova, Daniela V., and Dianne Bystrom. 2013. "The Effects of Social Media on Political Participation and Candidate Image Evaluations in the 2012 lowa Caucuses." American Behavioral Scientist. http://journals.sagepub.com.proxy.lib.pdx.edu/doi/abs/10.1177/000276421 3489011 (February 25, 2017).

Donath, Judith, and Boyd Danah. 2004. "Public Displayes of Connection." bt technology Journal 22(4): 71-82.

Downs, Anthony. 1957. An Economic Theory of Democracy. New York: Harper Collins.

Facebook Reports Second Quarter 2017 Results. 2017. Facebook. https://investor.fb.com/investor-news/press-releasedetails/2017/Facebook-Reports-Second-Quarter-2017Results/default.aspx (September 15, 2017).

Feezell, Jessica T. 2017. "Agenda Setting through Social Media: The Importance of Incidental News Exposure and Social Filtering in the Digital Era." Political Research Quarterly.

Gainous, Jason, and Kevin M. Wagner. 2014. Tweeting to Power: The Social Media Revolution in American Politics. New York: Oxford University Press.

Gentzkow, Matthew. 2006. "Television and Voter Turnout.” The Quarterly Journal of Economics 121(3): 931-72.

Gentzkow, Matthew, and Jesse M. Shapiro. 2011. "IDEOLOGICAL SEGREGATION ONLINE AND OFFLINE." The Quarterly Journal of Economics 126(4): 1799-1839.

Geys, Benny. 2006. "Explaining Voter Turnout: A Review of Aggregate-Level Research." Electoral Studies 25(4): 637-63.

Gibson, James L., and Gregory A. Caldeira. 2009. Citizens, Courts, and Confirmations: Positivity Theory and the Judements of the American People. Princeton University Press.

Gil de Zúñiga, Homero, Nakwon Jung, and Sebastián Valenzuela. 2012. "Social Media Use for News and Individuals' Social Capital, Civic Engagement and Political Participation." Journal of Computer-Mediated Communication 17(3): 319-36. 
Gil de Zúñiga, Homero, Logan Molyneux, and Pei Zheng. 2014. "Social Media, Political Expression, and Political Participation: Panel Analysis of Lagged and Concurrent Relationships." Journal of Communication 64(4): 612-34.

Goff, David H. 2013. "A History of the Social Media Industries." In The Social Media Industries, ed. Alan B. Albarran. Routledge, 17-45.

Gottfried, Jeffrey, Michael Barthel, Elisa Shearer, and Amy Mitchell. 2016. The 2016 Presidential Campaign - a News Event That's Hard to Miss. Pew Research Center. http://www.journalism.org/2016/02/04/the-2016presidential-campaign-a-news-event-thats-hard-to-miss/ (February 15, 2016).

Green, Donald P., and Alan S. Gerber. 2015. Get out the Vote: How to Increase Voter Turnout. Washington D.C.: Brookings Institution Press.

Guess, Andrew, Brendan Nyhan, and Jason Reifler. 2018. Selective Exposure to Misinformation: Evidence from the Consumption of Fake News during the 2016 US Presidential Campaign. https://www.dartmouth.edu/ nyhan/fakenews-2016.pdf (January 14, 2018).

Harder, Raymond A., Steve Paulussen, and Peter Van Aelst. 2016. "Making Sense of Twitter Buzz (PDF Download Available)." Digital Journalism 4(7): 933-43.

Hetherington, Marc J. 1999. "The Effect of Political Trust on the Presidential Vote, 1968-96." The American Political Science Review 93(2): 311-26.

Holt, Kristoffer, Adam Shehata, Jesper Strömbäck, and Elisabet Ljungberg. 2013. "Age and the Effects of News Media Attention and Social Media Use on Political Interest and Participation: Do Social Media Function as Leveller?" European Journal of Communication 28(1): 19-34.

lyengar, Shanto, and Donald R. Kinder. 1987. "News That Matters: AgendaSetting and Priming in a Television Age." In News That Matters: AgendaSetting and Priming in a Television Age,.

Jamieson, Kathleen Hall. 1992. Dirty Politics: Deception, Distraction, and Democracy. Oxford University Press.

Jue, Arthur L., Jackie Alcalde Marr, and Mary Ellen Kassotakis. 2009. Social Media at Work: How Networking Tools Propel Organizational Performance. John Wiley \& Sons.

Kahneman, Daniel. 2011. Thinking, Fast and Slow. London: Macmillan. 
Kahneman, Daniel, Paul Slovic, and Amos Tversky, eds. 1982. Judgement under Uncertainty: Heuristics and Baises. Cambridge University Press.

Katz, Elihu. 1957. "The Two-Step Flow of Communication: An Up-To-Date Report on an Hypothesis." The Public Opinion Quarterly 21(1): 61-78.

Kim, Yonghwan. 2011. "The Contribution of Social Network Sites to Exposure to Political Difference: The Relationships among SNSs, Online Political Messaging, and Exposure to Cross-Cutting Perspectives." Computers in Human Behavior 27(2): 971-77.

Kirkpatrick, David. 2011. The Facebook Effect: The inside Stor of the Company That Is Connecting the World. Simon and Schuster.

Ksiazek, Thomas B., Edward C. Malthouse, and James G. Webster. 2010. "News-Seekers and Avoiders: Exploring Patterns of Total News Consumption across Media and the Relationship to Civic Participation." Journal of Broadcasting \& Electronic Media 5(4): 551-68.

Kuklinski, James H., and Paul J. Quirk. 2000. "Reconsidering the Rational Public: Cognition, Heuristics, and Mass Opinion." In Elements of Reason: Cognition, Choice, and the Bounds of Rationality, Cambridge: Cambridge University Press, 153-82.

Kushin, Matthew James, and Masahiro Yamamoto. 2010. "Did Social Media Really Matter? College Students' Use of Online Media and Political Decision Making in the 2008 Election." Mass Communication and Society 13(5): 608-30.

Lau, Richard R., and David P. Redlawsk. 2001. "Advantages and Disadvantages of Cognitive Heuristics in Political Decision Making." American Journal of Political Science 45(4): 951-71.

Lazer, David M.J. et al. 2018. "The Science of Fake News." Science 359(6380): 1094-96.

Leighly, Jan E., and Arnold Vedlitz. 1999. "Race, Ethnicity, and Political Participation: Competing Models and Contrasting Explanations." The Journal of Politics 61(4): 1092-1114.

Luskin, Robert C. 1990. "Explaining Political Sophistication." Political Behavior 12(4): 331-61.

Manin, Bernard, Adam Przeworski, and Susan Stokes. 1999. "Elections and Representation." In Democracy, Accountability, and Representation, Cambridge University Press, 29-54. 
Marichal, Jose'. 2012. Facebook Democracy: The Architecture of Disclosure and the Threat to Public Life. Farnham: Ashgate Publishing Limited.

Messing, Soloman, and Sean J. Westwood. 2012. "How Social Media Introduces Biases in Selecting and Processing News Content (PDF Download Available)." ResearchGate. https://www.researchgate.net/publication/265673993_How_Social_Media_ Introduces_Biases_in_Selecting_and_Processing_News_Content (February 25, 2017).

Mitchell, Amy, Jeffrey Gottfried, Michael Barthel, and Elisa Shearer. 2016. The Modern New Consumer: News Attitudes and Practices in the Digital Era. Pew Research Center. http://www.journalism.org/2016/07/07/the-modernnews-consumer/ (October 3, 2016).

Mitchell, Amy, Jeffrey Gottfried, Elisa Shearer, and Kristine Lu. 2017. How Americans Encounter, Recall and Act Upon Digital News. Pew Research Center. http://www.journalism.org/2017/02/09/how-americans-encounterrecall-and-act-upon-digital-news/.

Mitchell, Amy, Kiley Jocelyn, Jeffrey Gottfried, and Emily Guskin. 2013. The Role of News on Facebook: Common yet Incidental. Pew Journalism Project.

Mitchelstein, Eugenia, and Pablo J. Boczkowski. 2010. "Online News Consumption Research: An Assessment of Past Work and an Agenda for the Future." New Media \& Society 12(7): 1085-1102.

Murthy, Dhiraj. 2013. Twitter: Social Communication in the Twitter Age. John Wiley \& Sons.

Mutz, Diana C. 2011. Population-Based Survey Experiments. Princeton: Princeton University Press.

"Number of Monthly Active Instagram Users from January 2013 to September 2017 (in Million)." 2017. Statista. https://www.statista.com/statistics/253577/number-of-monthly-activeinstagram-users/ (April 6, 2018).

Pasek, Josh, eian more, and Daniel Romer. 2009. "Realizing the Social Internet? Online Social Networking Meets Offline Civic Engagement." Journal of Information Technology \& Politics 6(3-4): 197-215.

Petty, Richard E., and John T. Cacioppo. 1986. "The Elaboration Likelihood Model of Persuasion." In Communication and Persuasion, New York: Springer, 1-24. 
Pinkleton, Bruce E., and Erica Weintraub Austin. 2010. "Individual Motivations, Perceived Media Importance, and Political Disaffection." Political Communication. http://www-tandfonlinecom.proxy.lib.pdx.edu/doi/abs/10.1080/10584600152400365 (February 25, 2017).

Popkin, Samuel L. 1994. The Reasoning Voter: Communication and Persuasion in Presidential Campaigns. Chicago: University of Chicago Press.

Prior, Markus. 2005. "News vs. Entertainment: How Increasing Media Choice Widens Gaps in Political Knowledge and Turnout." American Journal of Political Science 49(3): 577-92.

- 2007. Post-Broadcast Democracy: How Media Choice Increases Inequality in Political Involvement and Polarizes Elections. Cambridge: Cambridge University Press.

Przeworski, Adam. 1999. "Minimalist Conception of Democracy: A Defense." In Democracy's Values, eds. Ian Shapiro and Hacker-Cordsn Casiano. Cambridge: Cambridge University Press, 23.

Przeworski, Adam, and Susan Stokes, eds. 1999. 2 Democracy, Accountability, and Representations. Cambridge: Cambridge University Press.

Purcell, Kristen, and Lee Rainie. 2014. Americans Feel Better Informed Thanks to the Internet. Pew Research Center. http://www.pewinternet.org/2014/12/08/better-informed/.

"Q4 and Fiscal Year 2017 Leter to Shareholders." 2018. http://files.shareholder.com/downloads/AMDA2F526X/6182965052x0x970882/AF653BFB-8C4D-4D91-8F128867CDA665DB/Q4_2017_Shareholder_Letter.pdf (April 6, 2018).

Rivlin, Gary. 2006. "Wallflower at the Web Party." New York Times. http://www.nytimes.com/2006/10/15/business/yourmoney/15friend.html (August 10, 2017).

Rubenson, Daniel, Andre Blais, Patrick Fournier, and Neil Nevitte. 2004. "Accounting for the Age Gap in Turnout." Acta Politica 39(4): 407-21.

Ruffini, Patrick. 2017. "Why Russia's Facebook Ad Campaign Wasn't Such a Success." https://www.washingtonpost.com/outlook/why-russiasfacebook-ad-campaign-wasnt-such-a-success/2017/11/03/b8efacca-bffa11e7-8444-a0d4f04b89eb_story.html?utm_term=.9258320995f0 (November 7, 2017). 
Shearer, Elisa, and Jeffrey Gottfried. 2017. News Use Across Social Media Platforms 2017. Pew Research Center.

http://www.journalism.org/2017/09/07/news-use-across-social-mediaplatforms-2017/ (September 10, 2017).

Smets, Kaat, and Carolien van Ham. 2013. "The Embarrassment of Riches? A Meta-Analysis of Individual-Level Research on Voter Turnout." Electoral Studies 32(2): 344-59.

Smidt, Corwin D. 2017. "Polarization and the Decline of the American Floating Voter." American Journal of Political Science 61(2): 365-81.

Snap Inc. 2017. Crunchbase.

https://www.crunchbase.com/organization/snapchat (September 15, 2017).

"Snap Inc. Reports Fourth Quarter and Full Year 2017 Results." 2018. https://investor.snap.com/ /media/Files/S/Snap-IR/press-release/q4-17earnings-release.pdf (April 6, 2018).

Sunstein, Cass R. 2009. Republic.Com 2.0. Princeton: Princeton University Press.

Tang, Gary, and Francis L. F. Lee. 2013. "Facebook Use and Political Participation: The Impact of Exposure to Shared Political Information, Connections With Public Political Actors, and Network Structural Heterogeneity." Social Science Computer Review 31(6): 763-73.

Teodorczuk, Tom. 2018. "Netflix Is Poised to Enter the TV News Business." MarketWatch. https://www.marketwatch.com/story/netflix-is-poised-toenter-the-tv-news-business-2018-03-13 (April 2, 2018).

Timberg, Craig, and Elizabeth Dwoskin. 2017. "Russian Content on Facebook, Google and Twitter Reached Far More Users than Companies First Disclosed, Congressional Testimony Says." The Washington Post. https://www.washingtonpost.com/business/technology/2017/10/30/450958 7e-bd84-11e7-97d9-bdab5a0ab381_story.html?utm_term=.5e63fac9339f (November 7, 2017).

Towner, Terri L. 2013. "All Political Participation Is Socially Networked?: New Media and the 2012 Election." Social Science Computer Review 31(5): 527-41.

Tversky, Amos, and Daniel Kahneman. 1975. "Judgement under Uncertainty: Heuristics and Biases." In Utility, Probability, and Human Decision Making, The Netherlands: Spring, 141-62. 
- 1981. "The Framing of Decisions and the Psychology of Choice." Science 211(4481): 453-58.

Vargo, Chris J., Lei Guo, Maxwell McCombs, and Donald L. Shaw. 2014. "Network Issue Agendas on Twitter During the 2012 U.S. Presidential Election." Journal of Communication 64(2): 296-316.

Verba, Sidney, Kay Lehman Schlozman, Henry Brady, and Norman H. Nie. 1993. "Race, Ethnicity and Political Resources: Participation in the United States." British Journal of Political Science 23(4): 453-97.

Vitak, Jessica et al. 2011. "It's Complicated: Facebook Users' Political Participation in the 2008 Election." CyberPsychology, Behavior \& Social Networking 14(3): 107-14.

Vogelstein, Fred. 2008. "The Untold Story: How the IPhone Blew Up the Wireless Industry." Wired. https://www.wired.com/2008/01/ff-iphone/ (August 25, 2017).

Warren, Anne Marrie, Ainin Sulaiman, and Noor Ismawati Jaafar. 2014. "Social Media Effects on Fostering Online Civic Engagement and Building Citizen Trust and Trust in Institutions." Government Information Quarterly 31(2014): 291-301.

Williams, Bruce A., and Michael X. Delli Carpini. 2011. After Broadcast News: Media Regimes, Democracy, and the New Information Environment. Cambridge: Cambridge University Press.

Williams-Hawkins, Maria. 2013. "Brigding the Great Divide: African and Asian American Use of Social Media." In The Social Media Industries, ed. Alan B. Albarran. New York: Routledge.

Wolfinger, Raymond E., and Steven J. Rosenstone. 1980. 22 Who Votes? New Haven: Yale University Press.

Xenos, Michael, Ariadne Vromen, and Brian D. Loader. 2014. "The Great Equalizer? Patterns of Social Media Use and Youth Political Engagement in Three Advanced Democracies." Information, Communication \& Society 17(2): 151-67.

Zaller, John. 1990. "Political Awareness, Elite Opinion Leadership, and the Mass Survey Response." Social Cognition 8(1): 125-53.

- 1992. The Nature and Origins of Mass Opinion. Cambridge: Cambridge University Press. 
Zhang, Weiwu, Trent Seltzer, and Shannon L. Bichard. 2013. "Two Sides of the Coin: Assessing the Influence of Social Network Site Use During the 2012 U.S. Presidential Campaign." Social Science Computer Review 31(5): 542-51. 


\section{Appendix}

Appendix A: Political Knowledge Questions
2016 American National Election Study
"For how many years is a United States Senator elected that is,
how many years are there in one full term of office for a U.S.
Senator?"
"On which of the following does the U.S. federal government
currently spend the least? Randomized response option order:
Foreign aid; Medicare; National defense; Social security
"Do you happen to know which party currently has the most
members in the U.S. House of Representatives in Washington?
"Do you happen to know which party currently has the most
members in the U.S. Senate?"
"Joe Biden. What job or political office does he now hold?" If
'don't know' probe with "Well, what's your best guess?"
"Paul Ryan. What job or political office does he now hold?" If
'don't know' probe with "Well, what's your best guess?"
"John Roberts. What job or political office does he now hold?" If
'don't know' probe with "Well, what's your best guess?"
Cronbach's alpha = .775, M = 3.84, SD = 1.71




\begin{tabular}{|c|}
\hline $\begin{array}{c}\text { Appendix B: Civic Engagement Questions } \\
\text { 2016 American National Election Study }\end{array}$ \\
"During the past 12 months, have you worked with other people \\
to deal with some issue facing your community?" \\
"During the past 12 months, did you attend a meeting about an \\
issue facing your local community or schools?" \\
"Most people say they have less time these days to do volunteer \\
work. What about you, were you able to devote any time to \\
volunteer work in the past 12 months or did you not do so?" \\
\hline Cronbach's alpha $=.725, \mathrm{M}=1.08, \mathrm{SD}=1.15$ \\
\hline
\end{tabular}


Appendix C: Questions for Additional Regression Variables 2016 American National Election Study

Internet Access at Home: "Do you or does anyone in this household connect to the Internet from home?"

Social Media Use: "During a typical week, how many days do you use social media such as Twitter or Facebook?:

Education Level: "What is the highest level of school you have completed or the highest degree you have received?" 